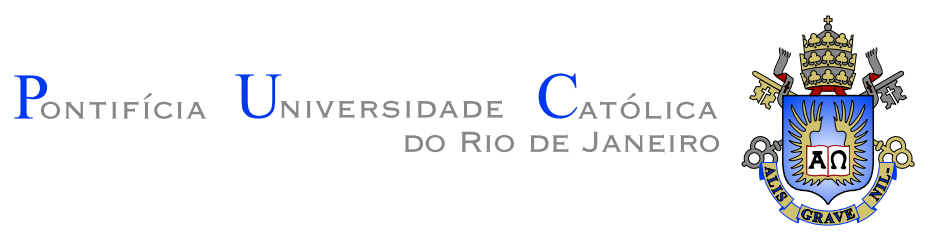

Pedro Henrique Fonseca da Silva Diniz

\title{
A Spatio-Temporal Model for Average Speed Prediction on Roads
}

\section{Dissertação de Mestrado}

Thesis presented to the Programa de Pós-Graduação em Informática of the Departamento de Informática from PUC-Rio as partial fulfilment of the requirements for the degree of Mestre em Informática

Advisor: Prof. Hélio Côrtes Vieira Lopes

Rio de Janeiro

August of 2015 


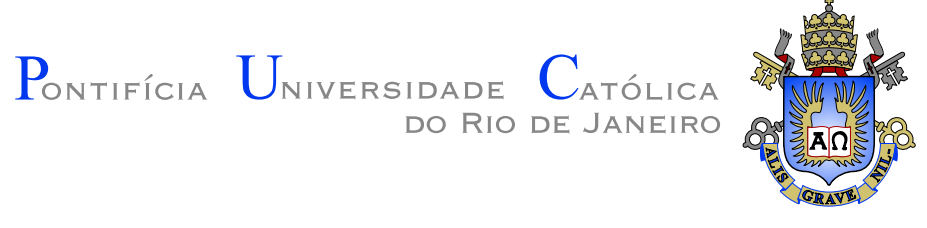

\section{Pedro Henrique Fonseca da Silva Diniz}

\section{A Spatio-Temporal Model for Average Speed Prediction on Roads}

Thesis presented to the Programa de Pós-Graduação em Informática of the Departamento de Informática from PUC-Rio as partial fulfilment of the requirements for the degree of Mestre em Informática.

Prof. Hélio Côrtes Vieira Lopes

Advisor

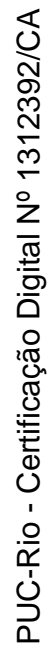

Departamento de Informática - PUC-Rio

Prof. Marco Antonio Casanova

Departamento de Informática - PUC-Rio

Prof. Ruy Luiz Milidiú

Departamento de Informática — PUC-Rio

Prof. Marcelo Tílio

Instituto Tecgraf — PUC-Rio

Prof. José Eugênio Leal

Coordinator of the Centro Técnico Científico - PUC-Rio

Rio de Janeiro, August 21, 2015 
All rights reserved

\section{Pedro Henrique Fonseca da Silva Diniz}

Pedro Henrique Fonseca da Silva Diniz holds a Bachelor's Degree in Computer Science from the Pontifical Catholic University of Rio de Janeiro (PUC-Rio). Currently, Pedro is a senior developer at the Tecgraf Institute of PUC-Rio, working with Big Data GIS applications specialized on GPS signal processing to monitor and identify moving object events through movement workflows. His main research interests include Algorithmic Optimizations, Distributed Systems, and Machine Learning

Bibliographic data

Diniz, Pedro Henrique Fonseca da Silva

A Spatio-Temporal Model for Average Speed Prediction on Roads / Pedro Henrique Fonseca da Silva Diniz; advisor: Hélio Côrtes Vieira Lopes. $-2015$.

75 f. : il. (color); $30 \mathrm{~cm}$

1. Tese (mestrado) - Pontifícia Universidade Católica do Rio de Janeiro, Departamento de Informática, 2015.

Bibliography included.

1. Informática - Teses. 2. Spatiotemporal Modeling. 3. Statistical Learning. 4. GPS data. I. Lopes, Hélio Côrtes Vieira. II. Pontifícia Universidade Católica do Rio de Janeiro. Departamento de Informática. III. Título. 


\section{Acknowledgments}

To my parents, Carlos Alberto and Jussara Oliveira, who not only supported me and my dreams, but also always encouraged me to do better. Even if all fails, if I can make you happy, than it is sure worth it. To my wife Anna Carolina, who patiently listened my ideas, gave me strength in my weakest moments, and gave me love when I needed most. To my brother, whose wisdom always inspired me in my life and career, and all of my family, you guys are one of the reasons why I smile every day when I wake up. To my advisor Hélio Côrtes Vieira Lopes for guiding and supporting me throughout this work, I am really lucky to have been given an opportunity to learn from you. To the Tecgraf Institute for sponsoring my studies and being one of the best places a developer/researcher can work in Rio de Janeiro, without this support the results would not have been the same. You can be certain that you have changed a person's life, the world is a better place with organizations like you. 


\section{Abstract}

Diniz, Pedro Henrique Fonseca da Silva; Lopes, Hélio Côrtes Vieira(Advisor) . A Spatio-Temporal Model for Average Speed Prediction on Roads. Rio de Janeiro, 2015. 75p. MSc. Thesis - Departamento de Informática, Pontifícia Universidade Católica do Rio de Janeiro.

Many factors may influence a vehicle speed in a road, but two of them are usually observed by many drivers: its location and the time of the day. To obtain a model that returns the average speed as a function of position and time is still a challenging task. The application of such models can be in different scenarios, such as: estimated time of arrival, shortest route paths, traffic prediction, and accident detection, just to cite a few. This study proposes a prediction model based on a spatio-temporal partition and mean/instantaneous speeds collected from historic GPS data. The main advantage of the proposed model is that it is very simple to compute. Moreover, experimental results obtained from fuel delivery trucks, along the whole year of 2013 in Brazil, indicate that most of the observations can be predicted using this model within an acceptable error tolerance.

\section{Keywords}

Spatiotemporal Modeling; Statistical Learning; GPS data. 


\section{Resumo}

Diniz, Pedro Henrique Fonseca da Silva; Lopes, Hélio Côrtes Vieira. Um Modelo Espaço-Temporal para a Previsão de Velocidade Média em Estradas. Rio de Janeiro, 2015. 75p. Dissertação de Mestrado - Departamento de Informática, Pontifícia Universidade Católica do Rio de Janeiro.

Muitos fatores podem influenciar a velocidade de um veículo numa rodovia ou estrada, mas dois deles são observados diariamente pelos motoristas: sua localização e o momento do dia. Obter modelos que retornem a velocidade média como uma função do espaço e do tempo é ainda uma tarefa desafiadora. São muitas as aplicações para esses tipos de modelos, como por exemplo: tempo estimado de chegada, caminho mais curto e previsão de tráfico, detecção de acidente, entre outros. Este estudo propõe um modelo de previsão baseado em uma média espaço-temporal da velocidade média/instantânea coletada de dados históricos de GPS. A grande vantagem do modelo proposto é a sua simplicidade. Além disso, os resultados experimentais obtidos de caminhões de entrega de combustíveis, por todo o ano de 2013 no Brasil, indicaram que a maioria das observações podem ser preditas usando esse modelo dentro de uma tolerância de erro aceitável.

\section{Palavras-chave}

Modelagem Espaço-Temporal; Aprendizado Estatístico. 


\section{Contents}

$\begin{array}{lll}1 & \text { Introduction } & 10\end{array}$

2 Related Work 12

3 Preliminaries $\quad 14$

3.1 Motivating Data 14

3.2 Data Preparation 17

$\begin{array}{ll}3.3 \text { Map Matching } & 17\end{array}$

4 Data Analysis $\quad 18$

4.1 Temporal Analysis 18

$\begin{array}{lll}4.2 & \text { Spatial Analysis } & 25\end{array}$

5 Spatio-Temporal Partitioning $\quad 30$

5.1 Spatial Partitioning 30

5.2 Temporal Partitioning 40

5.3 Proposed Solution 45

6 Experiments $\quad 48$

6.1 Experimental Setup 48

6.2 Evaluation Measures 48

6.3 Implemented Methods 49

6.4 Experimental Results 49

$\begin{array}{lll}7 & \text { Conclusions and Future Works } & 70\end{array}$

8 Bibliography $\quad 72$ 


\section{List of figures}

3.1 Piecewise linear view of the 4 routes used in this study, on a map 16

4.1 GPS signal density plot on Av. Brasil, differentiating weekends from week days

4.2 GPS signals observations from the data as a function of space, time, and speed

4.3 Travel plot obtained from the data as a function of space, speed and time

5.1 Spatial partition quartils $\quad 35$

5.2 Spatial segment quartil comparison $\quad 39$

5.3 Temporal analysis of a road segment speed varying over time. $\quad 44$

5.4 Spatio-temporal model based on instantaneous and mean speed observations

6.1 Contour comparison of methods 4 and 5 on direction 1

6.2 Contour comparison of methods 4 and 5 on direction 2

6.3 Method 5 prediction error distribution analysis on direction $1 \quad 65$

6.4 Method 5 prediction error distribution analysis on direction $2 \quad 69$ 


\section{List of tables}

6.1 Mean Absolute Error $(\mathrm{km} / \mathrm{h})$

6.2 Root Mean Squared Error $(\mathrm{km} / \mathrm{h}) \quad 52$

6.3 Median Absolute Deviation $(\mathrm{km} / \mathrm{h})$

6.4 Running Times (seconds) 53

6.5 Mean Absolute Percentage Error (ETA) 53 


\section{1}

\section{Introduction}

With GPS devices becoming more accessible each year, the search for a good prediction model derived from such data is becoming a common task (Hofmann-Wellenhof et al., 2013). However, raw GPS data comes with its own set of problems that can also be a challenge to work with. Travel direction is generally unknown, signal precision is, in many circumstances, unreliable, and each device has its own transmission interval that contains no relation with its current location, leading to irregular time and space properties.

Being a subject of general interest, a reliable model for road speed prediction could be used to solve many of our day-to-day problems, including traffic prediction (Fabritiis et al., 2008), estimated time of arrival (Vanajakshi et al., 2009), shortest route paths (Derekenaris et al., 2001), and accident detection (Kamran and Haas, 2007). Solving such problems constitutes part of the challenges that must be overcome to implement a Smart City (Hollands, 2008), and it is a challenging task involving the correlation study of many factors including time, space, accidents, rain condition, vehicle type, and many others. It remains an open question that doesn't have a unique answer, since each scenario generally requires a specific prediction model (a good model for cars may not be a good model for motorcycles or buses, for example).

While there are many models (SVR, ARIMA, ANN, and others) that can be used to tackle this problem, most of them are focused on Travel Time applications and are also highly dependent on real-time data, a limitation that improves prediction accuracy, but makes them unsuitable for a future logistic planning. A reliable model that learns from historical data and can be used to predict speed in few months ahead is still needed. 
By acknowledging this need, the objective of this study is to build a reliable average speed prediction model for highways or speedways. Such model is a function of space and time, and its input set is a collection of GPS data. Its main idea is to build a piece-wise speed prediction model based on segment partition of a road.

This work is organized as follows; Chapter 2 presents some of the existing speed prediction models and attempts to classify them. The motivational data and initial preparations are discussed in Chapter 3. Chapter 4 visually analyses the influence of each studied dimension over the motivating data, while Chapter 5 proposes a spatial-temporal partition strategy for modeling the average speed at each point of a road at a given time of the day. Chapter 5.3 presents the model and Chapter 6 shows the results in some Brazilian highways and speedways from the GPS data collected from fuel delivery trucks. Chapter 7 concludes the work and suggests future works. 


\section{2}

\section{Related Work}

It has been recognized in the literature that to build an universally accepted prediction model for traffic state prediction is a very hard task (Kirby et al., 1997; Zhang et al., 1998). Different results have been achieved so far, with each model usually exceeding in a specific scenario.

chotravel proposed a spatially segmented model based on Linear Regression that differentiates days of week to predict travel times. (Georgescu et al., 2012) proposed an Hierarchical Linear Regression model to predict vehicle speeds. (Mark et al., 2004), (Yasdi, 1999), and (Chien et al., 2002) used Artificial Neural Networks based models. These works indicate that non-linear models are more suitable for traffic data. (Bin et al., 2006) and (Wu et al., 2004) improved results over historical means using Support Vector Regression. (Gopi et al., 2013) proposed an Bayesian SVR model to provide error bars and (Yusuf, 2013) presented an additional Wavelet Packet Decomposition (WDSVR) of inputs to improve SVR predictions even further. (Yang, 2005), (Nanthawichit et al., 2003), and (Shalaby and Farhan, 2003) also proposed models based on Kalman Filtering, a model that achieved a good performance, but mainly on short-time predictions (usually less than 10 minutes). Using Additive Models, (Kormaksson et al., 2014) proposed a flexible prediction model, capable of handling features, such as time and space to forecast travel times using raw GPS data.

Some other relevant studies on this topic are: real-time travel time predictions on a route by summing up link travel times with intersections delay (Lee et al., 2009); adaptive travel time predictions based on pattern matching (Bajwa et al., 2004); usage of bus data to predict travel time on urban corridors (Chakroborty and Kikuchi, 2004); travel time predictions 
using both historic and real-time data (Steven et al., 2003); improved results using heuristics for long horizon and constant models for short horizon travel time predictions (Chrobok et al., 2004); and (Thomas et al., 2010) introduced a prediction scheme that can be used in both short and long horizon travel time prediction improvement, using the correlation between and the noise levels within traffic-flow volume patterns. 


\section{3}

\section{Preliminaries}

This chapter describes the motivating data and how it was prepared for analysis.

\section{1}

\section{Motivating Data}

The motivating data is a collection of signals collected from fuel delivery trucks in Brazil. Running all over the country, each truck was equipped with a GPS device informing its position (GPS signal) at a constant time interval, which varied from truck to truck. Every signal contained 5 informations: the device id, date/time it was collected, latitude position, longitude position, and instantaneous speed. The average interval between signals of the same device was of 1 minute. Every truck was assigned to 1 or more fuel deliveries, in which the total travel time could span to one or more days. Delivery routes could be shared between fuel trucks while respecting the speed limit of $80 \mathrm{~km} / \mathrm{h}$ to avoid accidents, a limit that in practice was often disrespected.

From this collection, four roads ( 3 highways and 1 freeway) were selected for this study, as demonstrated in Figure 3.1. These roads were selected based on the number of samples and the State they belong to, with the aim to maximize learning examples and minimize geographic similarities. 


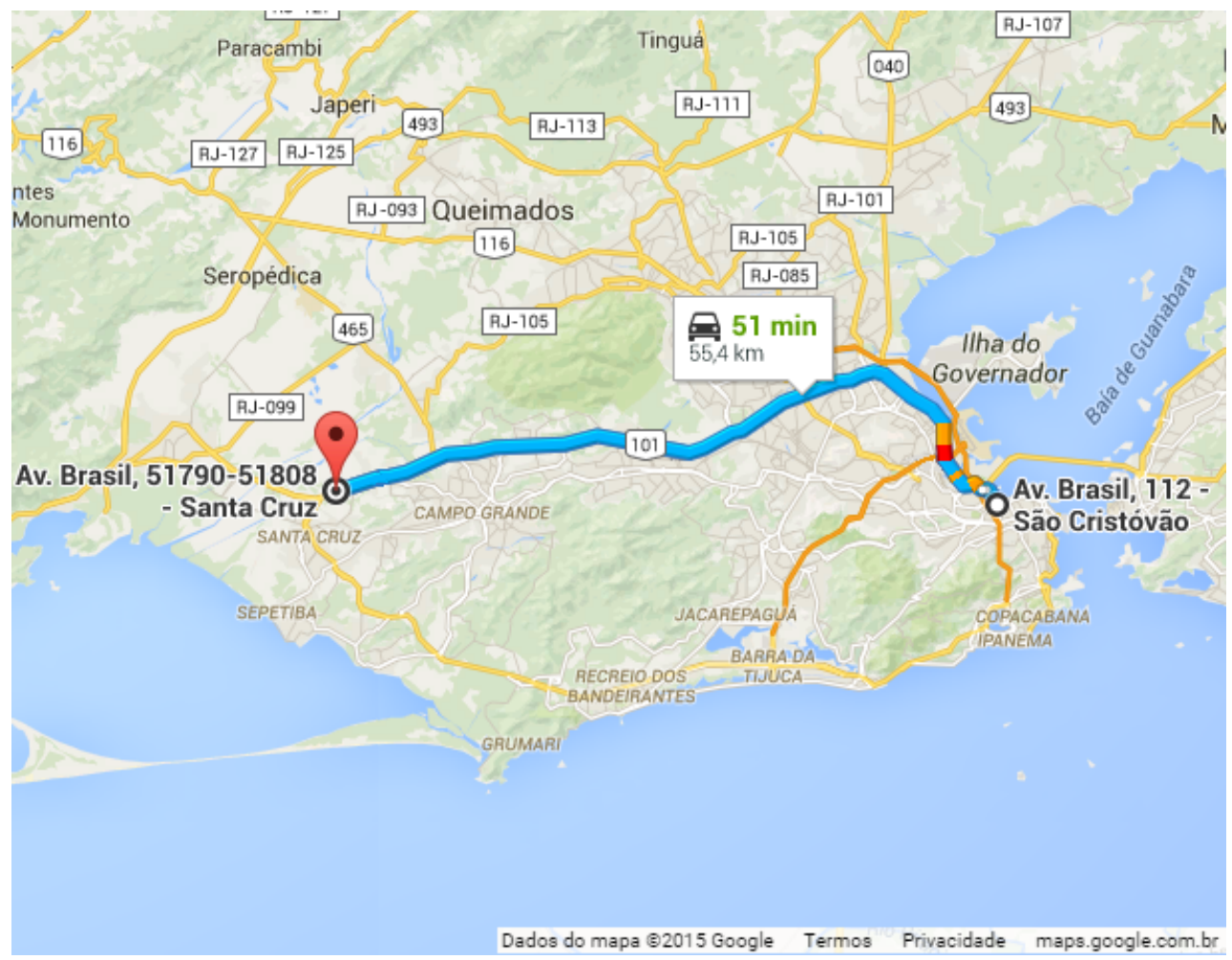

3.1(a): Avenida Brasil, RJ, Brazil

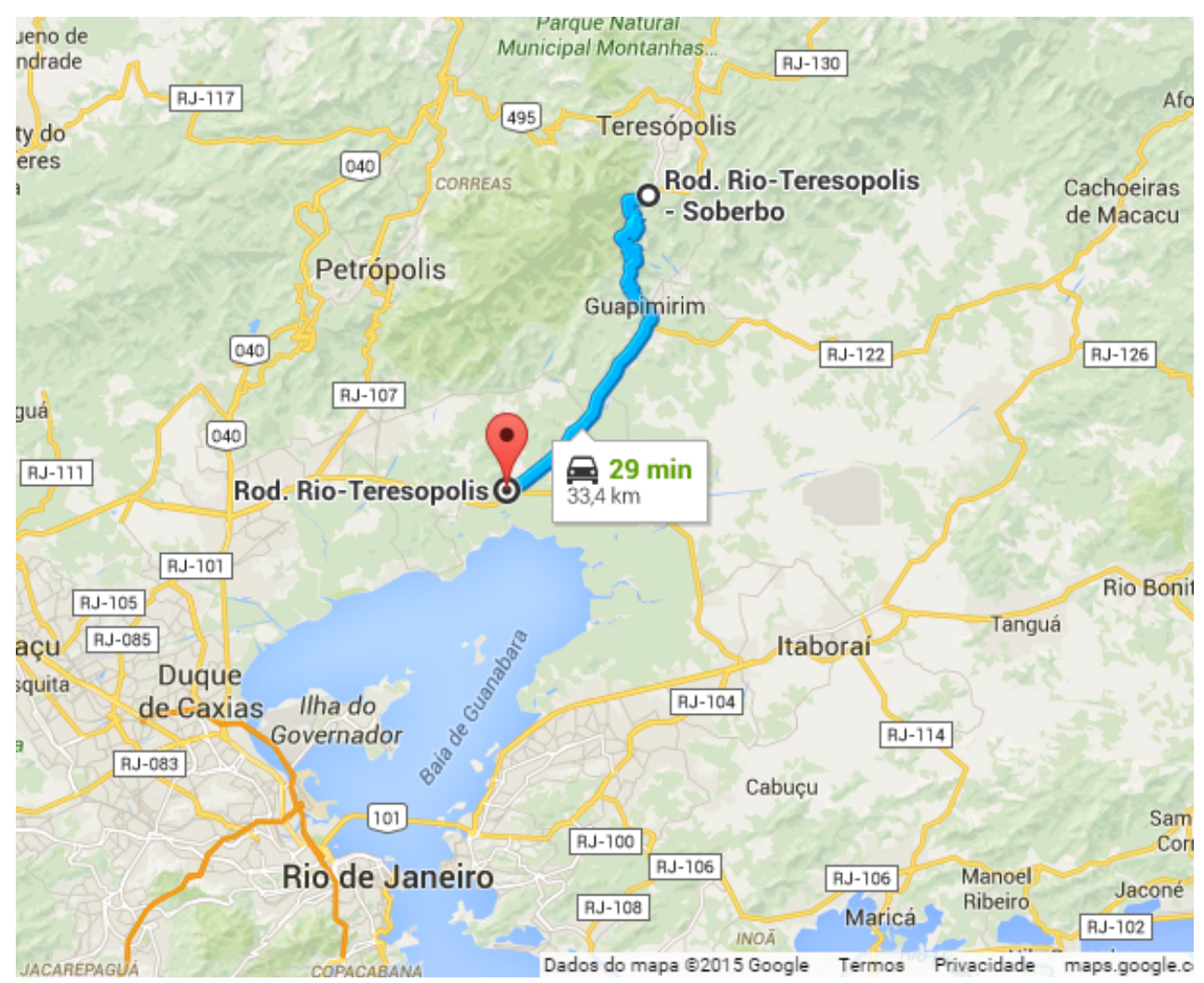

3.1(b): Rodovia Rio Teresópolis, RJ, Brazil 


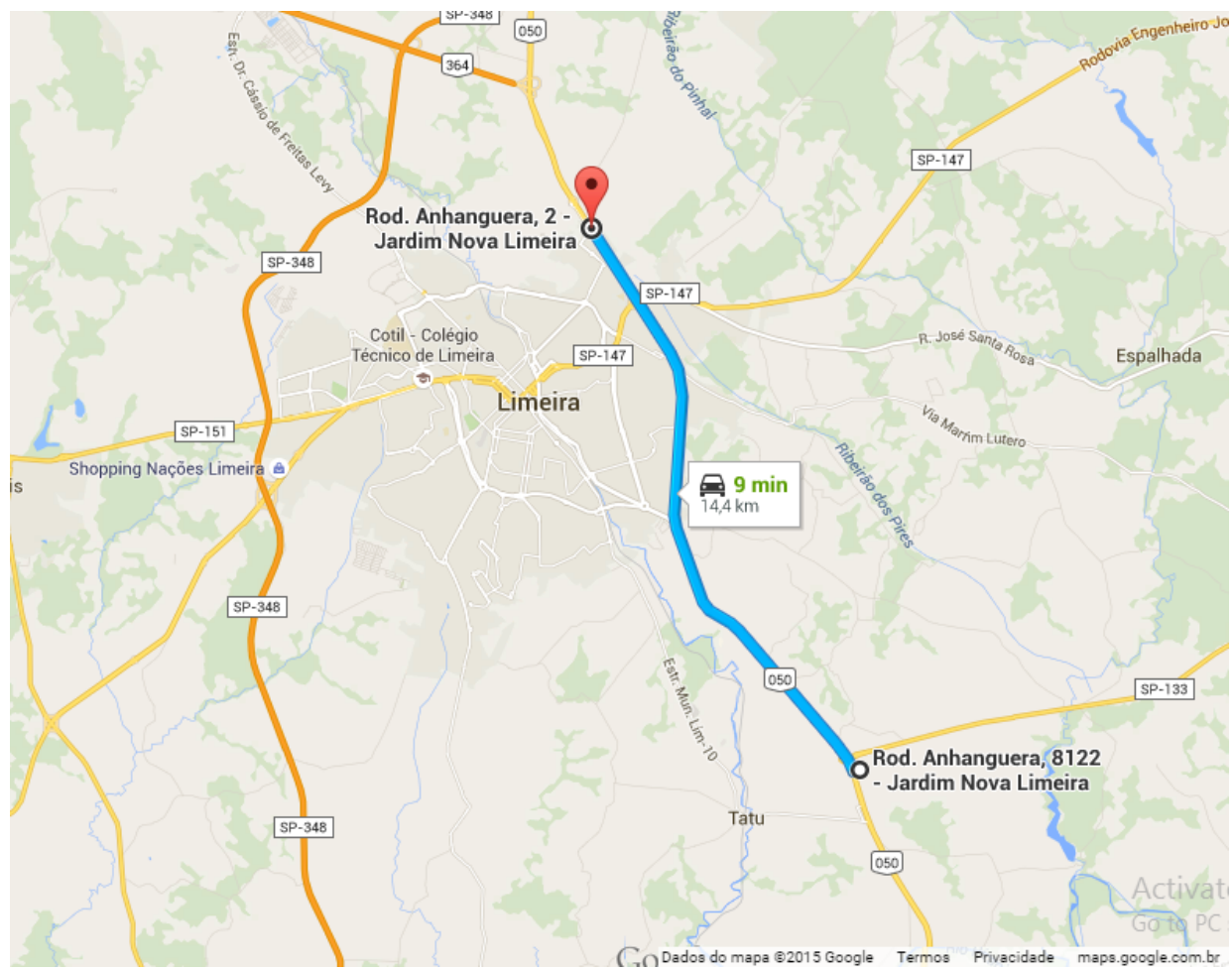

3.1(c): Rodovia Anhanguera, SP, Brazil

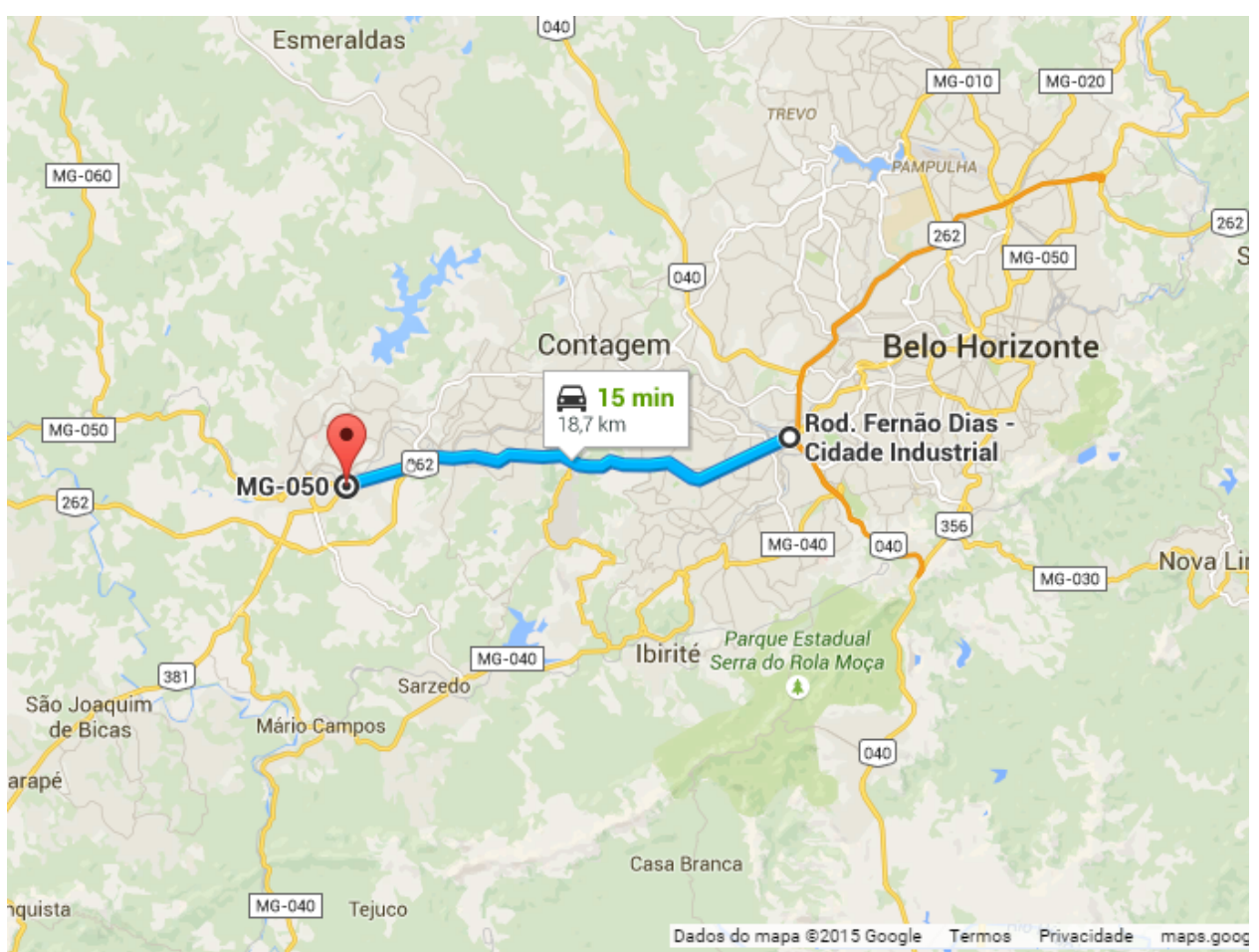

3.1(d): Rododiva Fernão Dias, MG, Brazil

Figure 3.1: Piecewise linear view of the 4 routes used in this study, on a map 


\section{2}

\section{Data Preparation}

Since the delivery schedule for each truck was unknown, all observations generated from pair of signals that indicated a speed equal to $0 \mathrm{~km} / \mathrm{h}$ were ignored. This step was executed because delivery trucks will stop at clients to deliver its load, and without the truck schedule there is no reliable method to identify which signal was generated while inside a client, and which signal was generated while inside a congested road.

\section{3}

\section{Map Matching}

In order to identify in which road a given latitude/longitude position may be, a Map Matching (Brakatsoulas et al., 2005) algorithm should be used. While many accurate methods (Zheng, 2015) are known to solve this problem, a simple one was implemented in this study.

Iterating through each road, Map Matching was done in 2 steps: the first step consisted in projecting the closest point of the current observation to the current road on the iteration, if closer than a predefined value (ex. 10 meters), it was accepted for that road. The second step was to identify the direction of each observation by pairing it with the next observation of the same device. If both occurred inside the signal interval of that device, they were considered consecutive, and the direction could be determined by verifying the difference in each signal position.

Prediction accuracy demonstrated to be strongly affected by signal direction, when direction was not being considered, it dropped to a half or less than expected. 


\section{4}

\section{Data Analysis}

This chapter analyzes the GPS data of each selected road regarding time and space. Even though mean speed can be related to many factors, these two properties alone may define accurate patterns for prediction models.

\section{1}

\section{Temporal Analysis}

For temporal analysis two visualization types were adopted.

The first visualization type adopted was a heat map of GPS signal density as a function of hour of day $\times$ speed. This visualization type focuses on assisting temporal pattern identification by evidencing the most predominant speed value at each hour, and while it may have smaller data fidelity (when compared to the next visualization type) as a consequence of smoothing, it certainly makes temporal patterns even more obvious to spot. Plots generated using this visualization type to compare week days, as demonstrated in Figure 4.1, indicated that speed behavior on weekends was different from week days, and that each subset of days must be learned separately.

The second visualization type, as demonstrated in Figure 4.2, is a scatter plot of speed as a function of travel distance $\times$ hour of the day, with an alpha transparency over speed occurrences, using the GPS signal. This visualization type is focused on data fidelity (no smoothing), while also trying to assist temporal speed pattern identification. Over the generated plots, a strong influence of time over speed can be identified quite clearly on Avenida Brasil and Rodovia Fernão Dias images, while on Rodovia Anhanguera and Rodovia Rio Teresópolis images the influence of time was much smaller. 
On Avenida Brasil, the first kilometers seem to decrease in speed as time approaches between 18:00 and 20:00, while on Rodovia Fernão Dias some kilometers had slower speed concentration at 8:00 to 10:00 and 18:00 to 19:00. It may be seen as a coincidence, but in Brazil these periods are popularly known as rush hours, a period of the day in which most workers are going to and leaving their work place. Figure 4.3 may be used for this purpose also, but it makes the visual search for this kind of hour pattern less evident.

Overall, these analyses confirmed the existence of sufficient variances to justify prediction of speed as a function of time, in which time can be used as a continuous value or a discrete value. In the next section, this study proposes the use of time as discrete value, with each value representing a partition of time as hours of a day. 


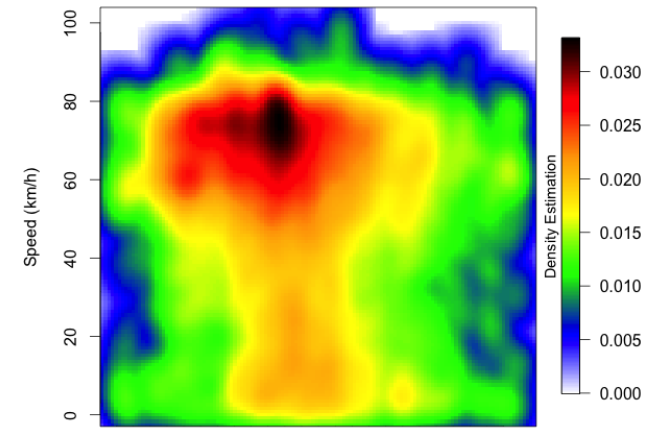

Hour of day (24h)

4.1(a): Saturday

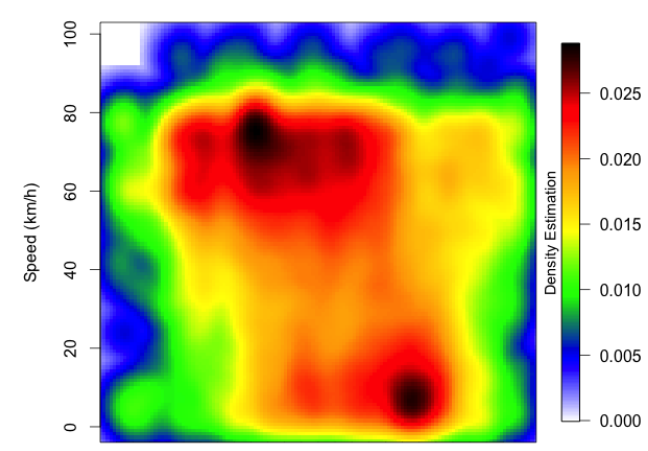

4.1(c): Monday

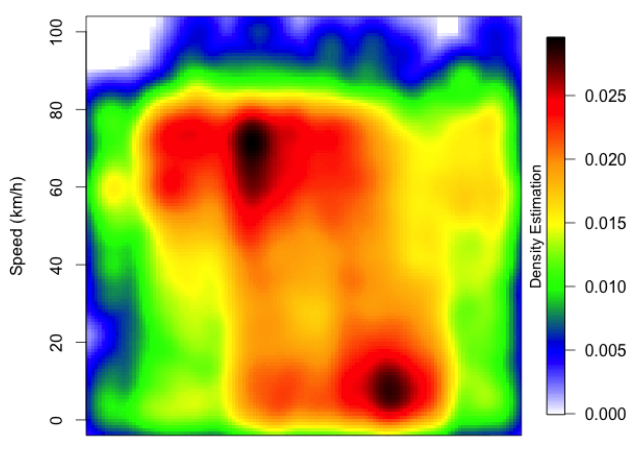

Hour of day (24h)

4.1(e): Wednesday

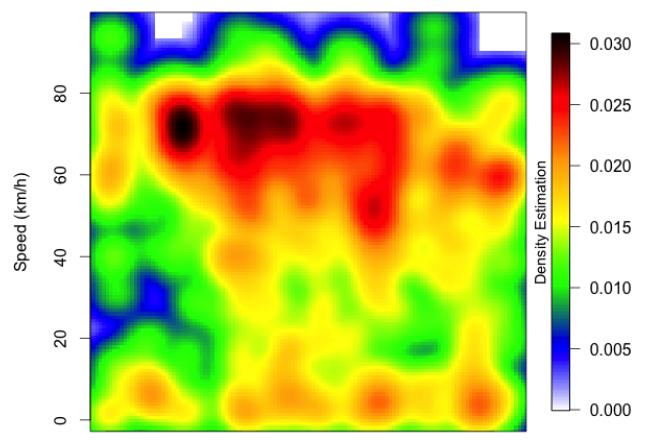

Hour of day (24h)

4.1(b): Sunday

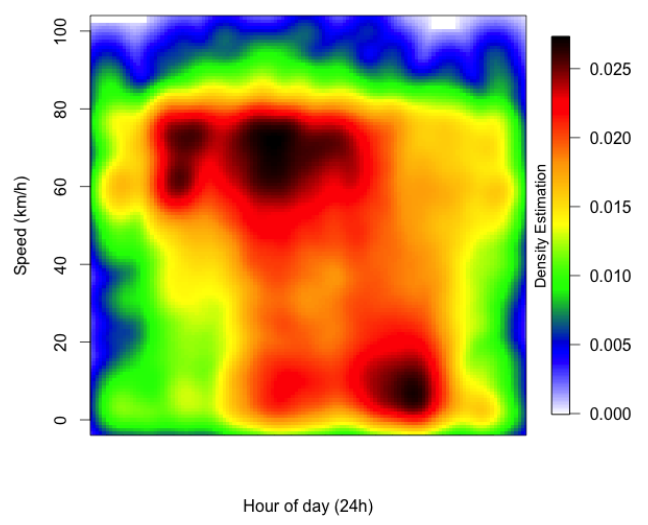

4.1(d): Thursday

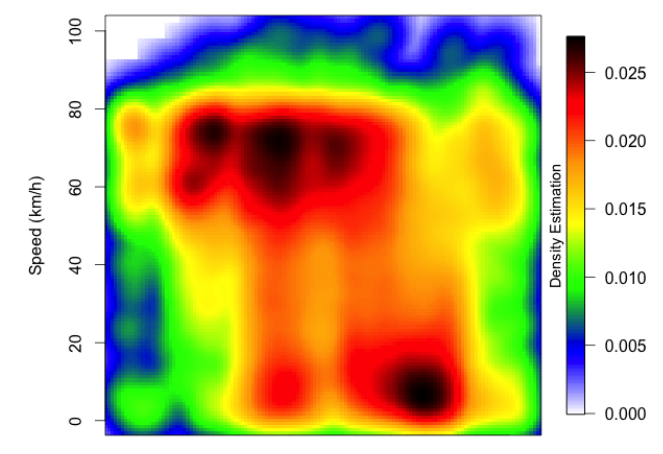

Hour of day (24h)

4.1(f): Tuesday

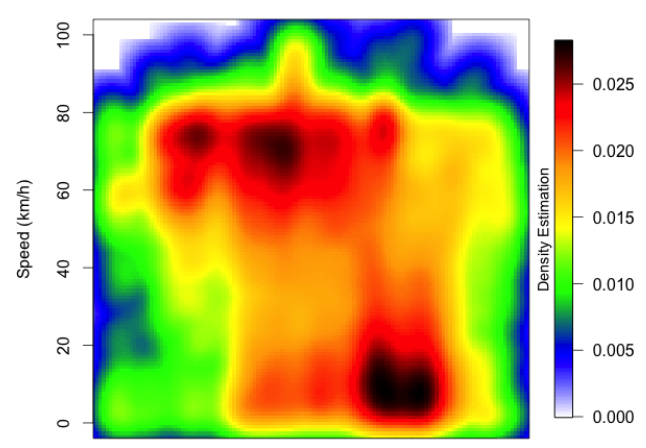

Hour of day (24h)

4.1(g): Friday

Figure 4.1: GPS signal density plot on Av. Brasil, differentiating weekends from week days 


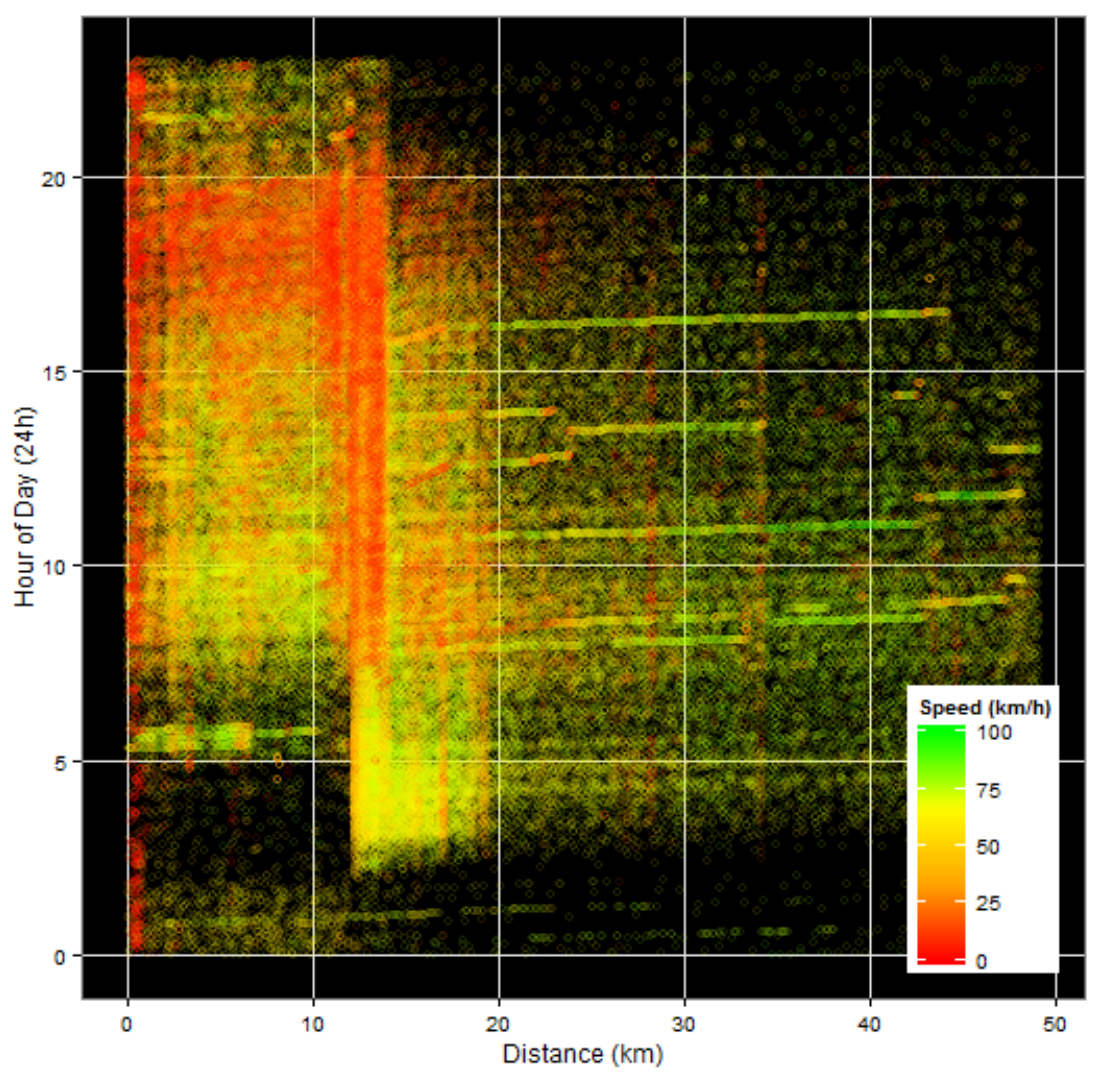

4.2(a): Av. Brasil, directed to Santa Cruz

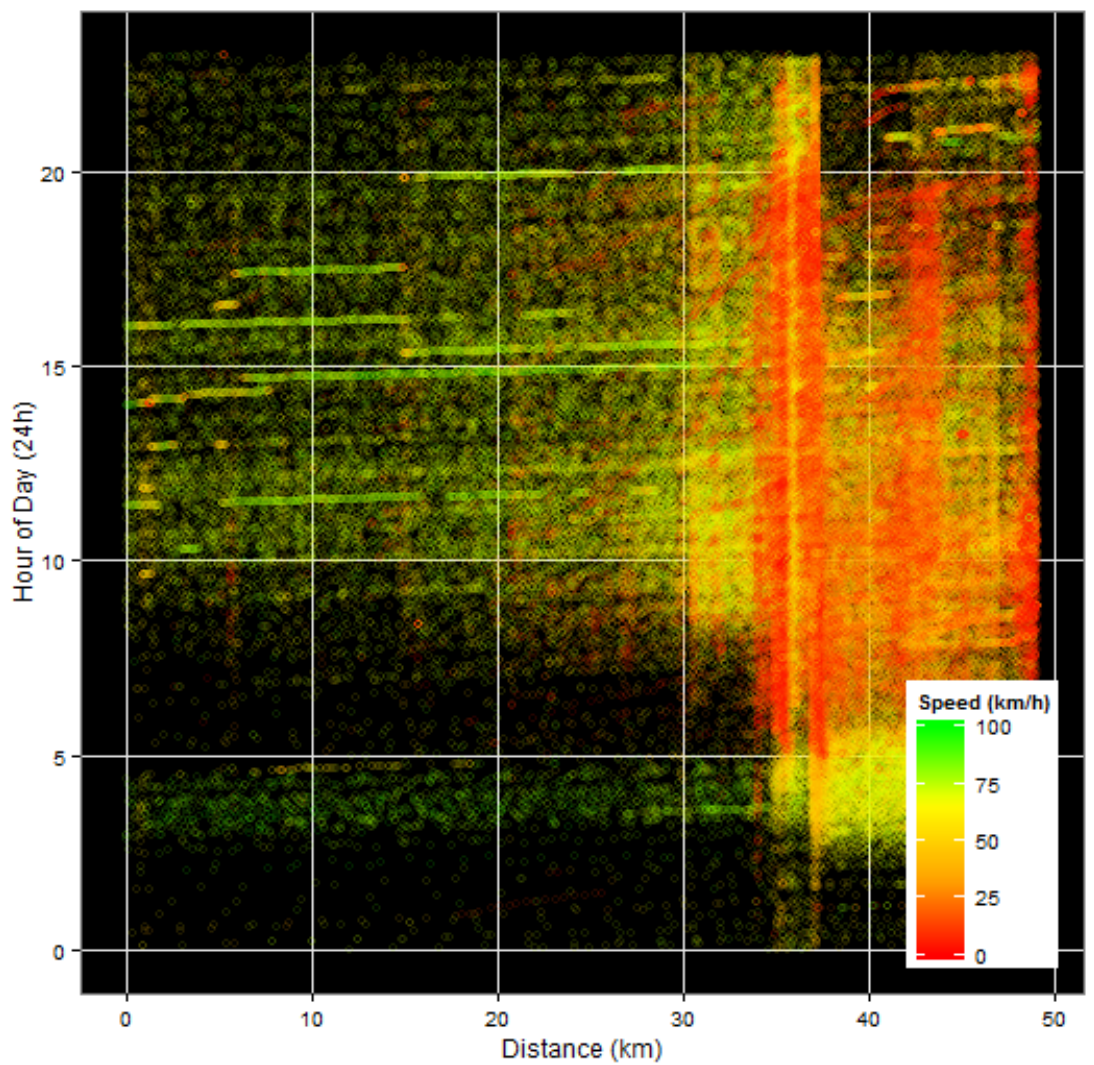

4.2(b): Av. Brasil, directed to Centro 


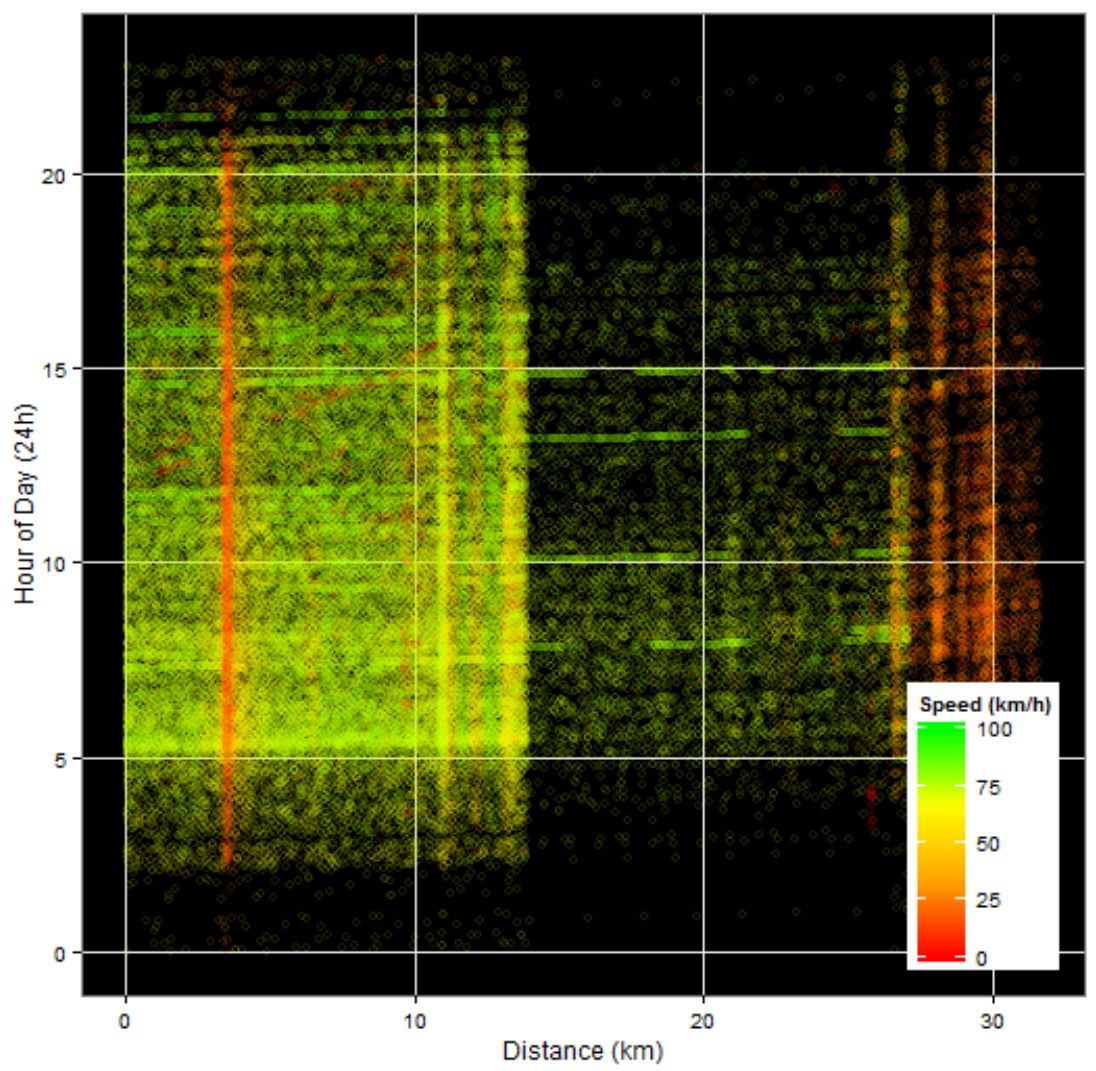

4.2(c): Rod. Rio Teresópolis, directed to Rio

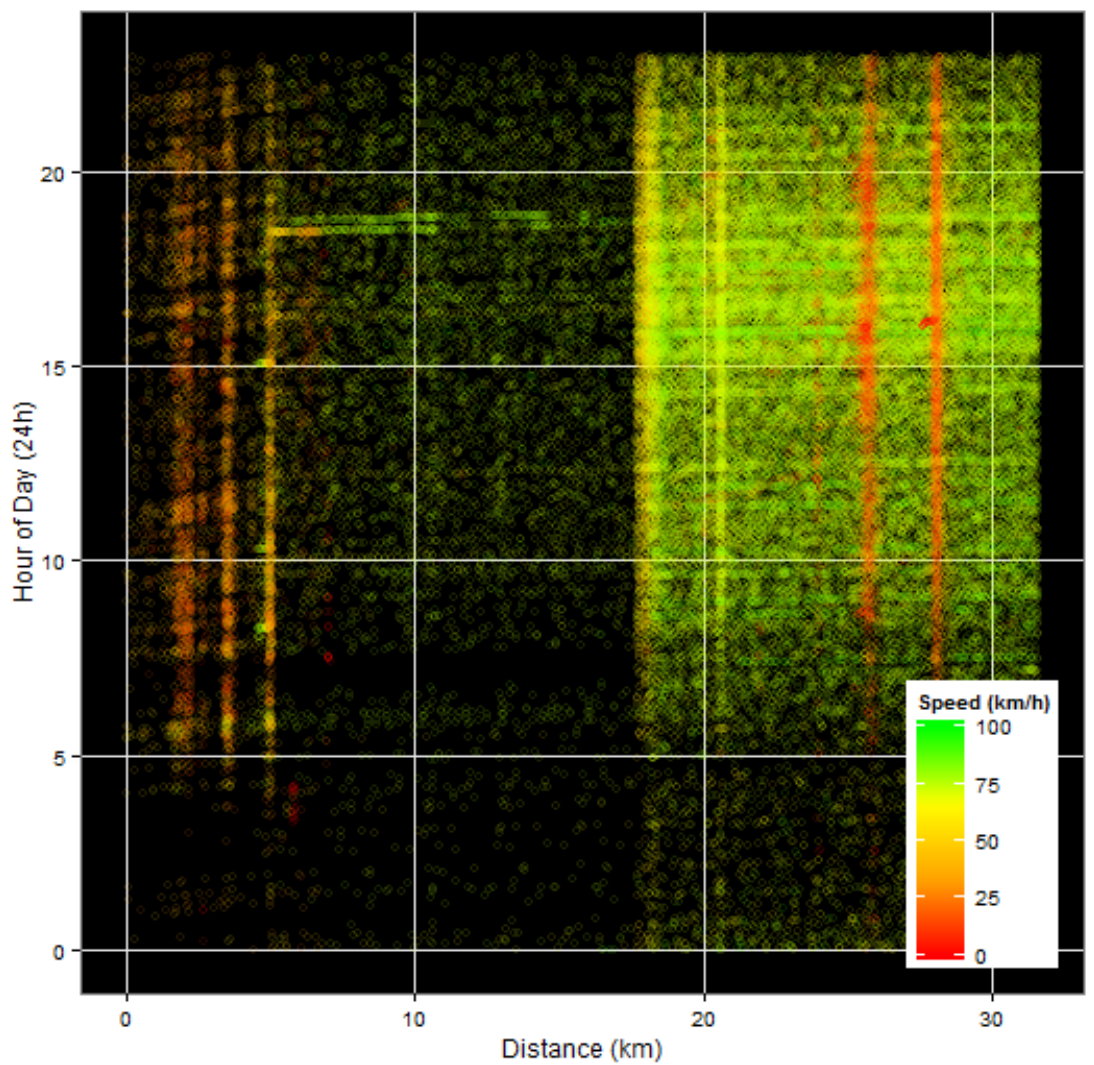

4.2(d): Rod. Rio Teresópolis, directed to Teresópolis 


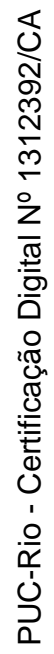

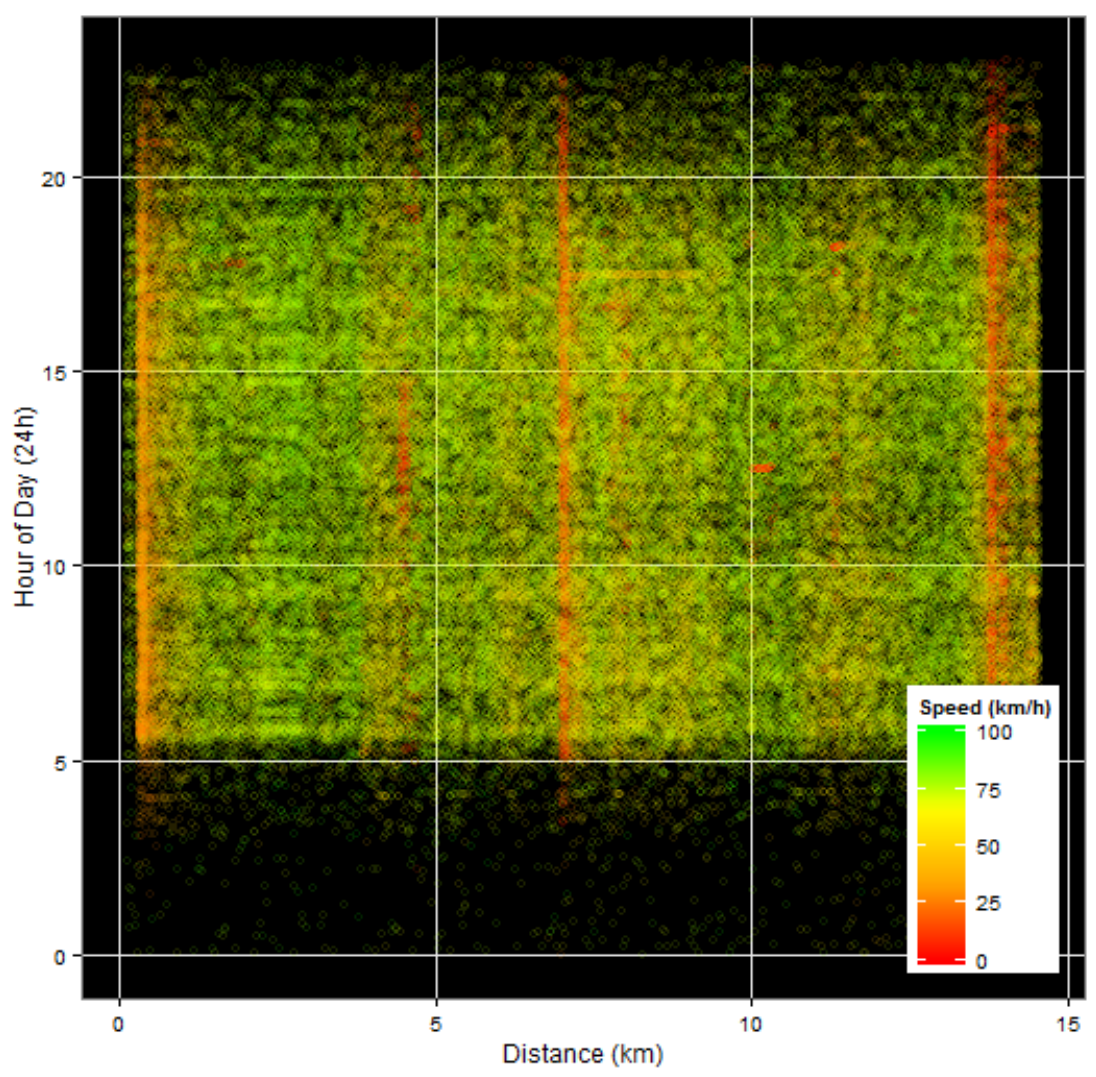

4.2(e): Rod. Anhanguera, directed to Limeira

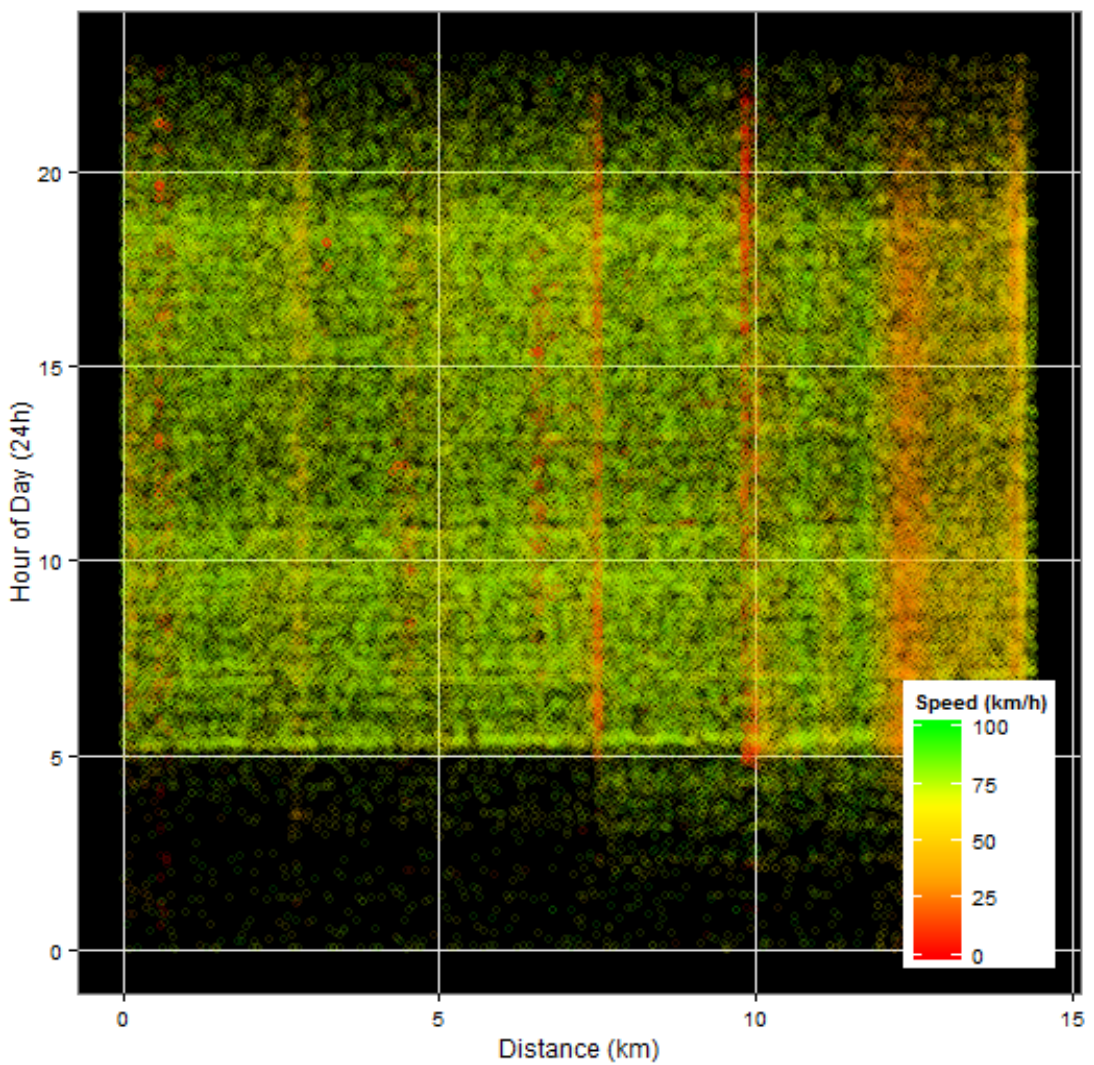

4.2(f): Rod. Anhanguera, directed to Americana 


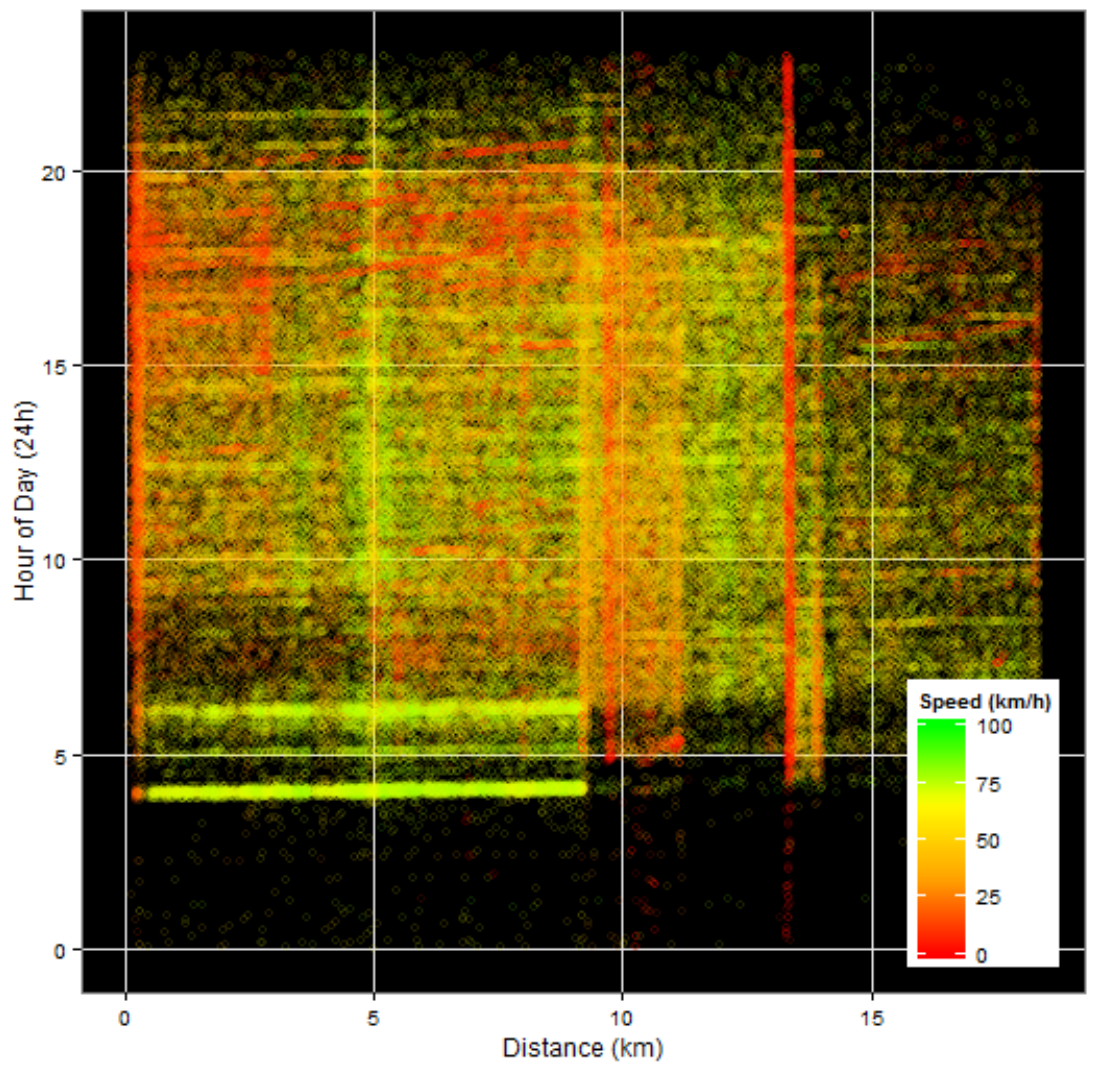

4.2(g): Rod. Fernão Dias, directed to Betim

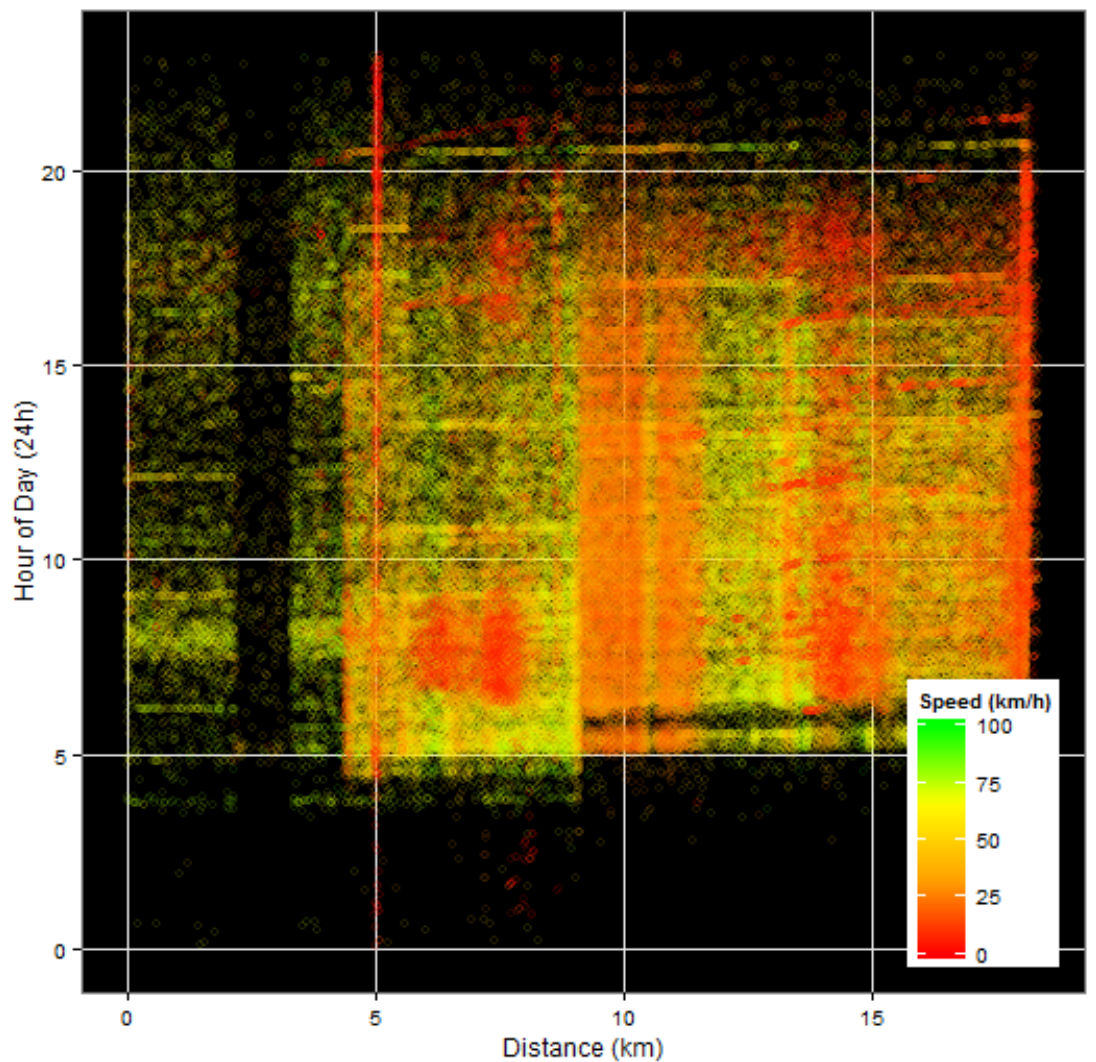

4.2(h): Rod. Fernão Dias, directed to Belo Horizonte

Figure 4.2: GPS signals observations from the data as a function of space, time, and speed 


\section{2}

\section{Spatial Analysis}

Figure 4.3 shows all truck travels, from Monday to Friday, plotted in a travel distance $\times$ speed graph model (Amaral, 2015) to aid spatial pattern identification. Each line in the image represents a truck traveling through the road. This visualization type (with distance, speed, and hour of day as $\mathrm{x}, \mathrm{y}$, and $\mathrm{t}$, respectively) allows an easy understanding on how speed behaves as road travel distance increases, indicating that speed may be subject to non-linear variances. Note that every road had one or more points with major speed decrease or increase, including Rodovia Anhanguera and Rodovia Rio Teresópolis, which had a more uniform mean speed.

Some road points containing major speed drops were marked with the letters $\mathrm{T}, \mathrm{R}, \mathrm{A}, \mathrm{M}, \mathrm{C}$, and $\mathrm{S}$ to explain what is happening at that travel point. $\mathrm{T}$ indicates road tolls, $\mathrm{R}$ indicates returns to reverse road direction, $\mathrm{A}$ is an access to another road (on Rio-Teresópolis it is an access using Rodovia Raphael de Almeida Magalhães going to Magé), M indicates a rise (e.g., going up on a mountain), $\mathrm{C}$ is carrier base (most trucks from a carrier will start and end its travel at its carrier base), and $\mathrm{S}$ is a gas station. Gas stations may represent a client where fuel is being delivered, or a mandatory rest point, since the company imposes that every truck driver must rest at every $\mathrm{x}$ hours. On Rodovia Anhanguera $\mathrm{S}$ denotes a famous gas station entitled "Graal".

Based on this analysis, there were sufficient variances to justify prediction of speed as being a function of distance, where distance can be used as a continuous value (the current distance) or a discrete value. In the next section, this study proposes the use of distance as discrete value, with each value representing a partition of the road extension, namely a road segment. 


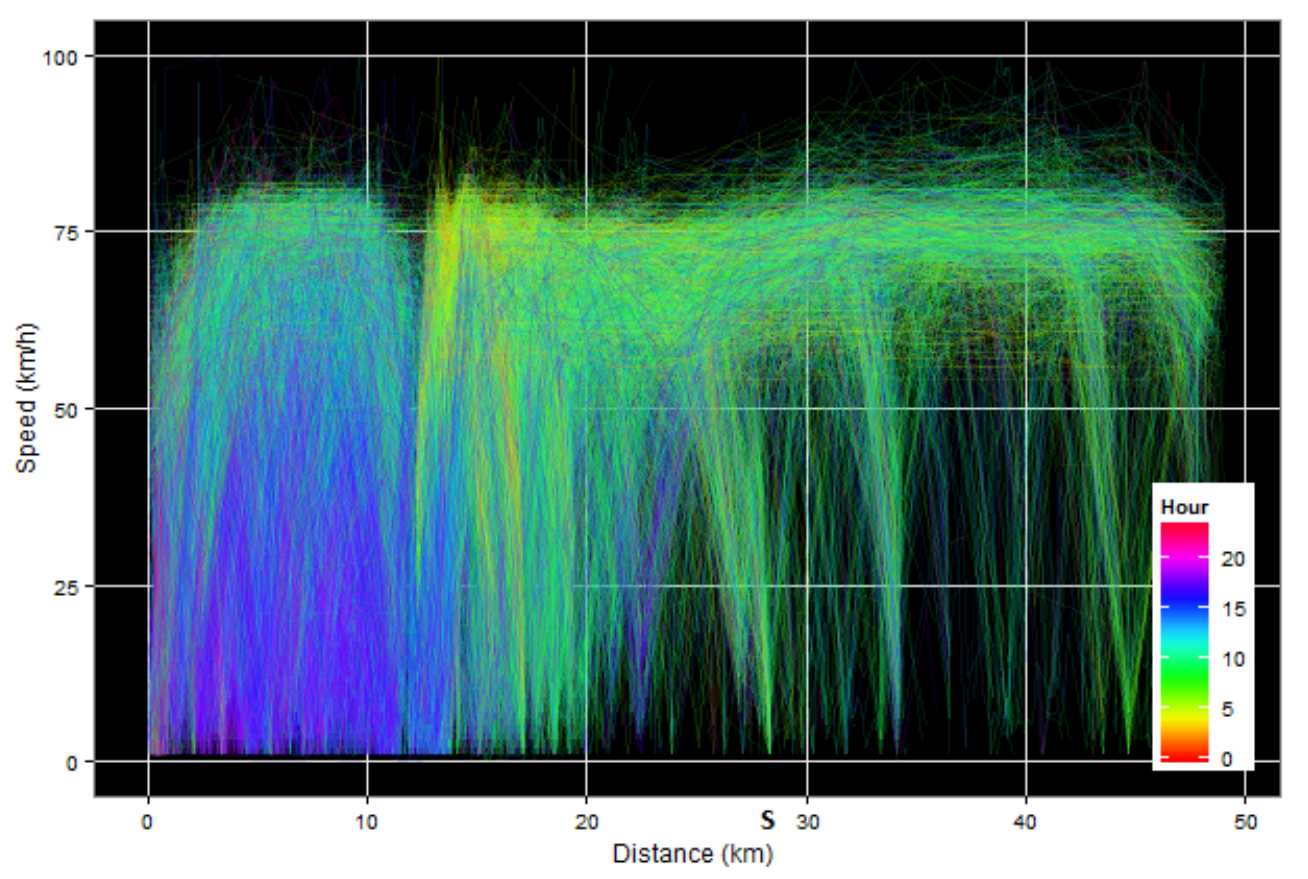

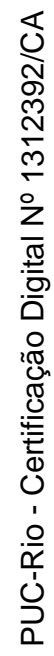

4.3(a): Av. Brasil, directed to Santa Cruz

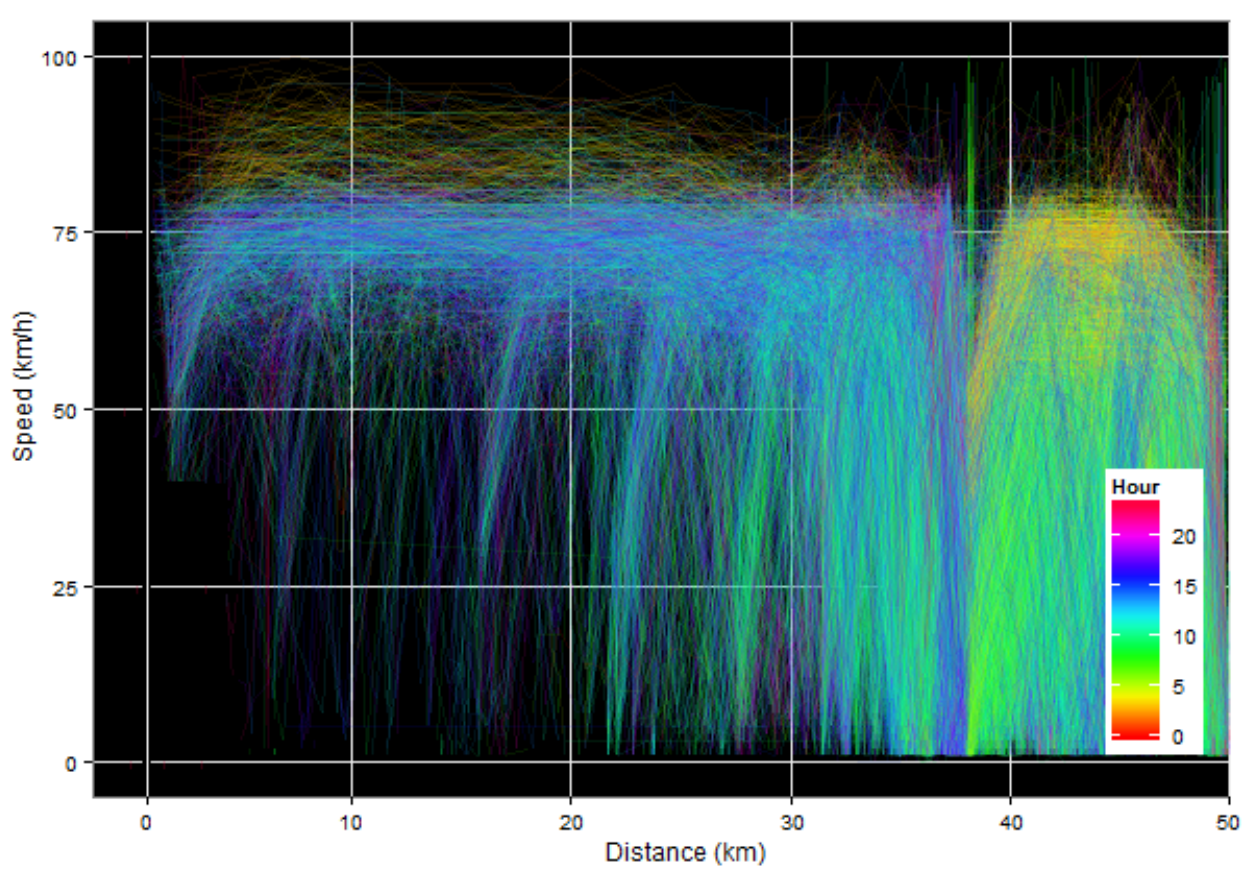

4.3(b): Av. Brasil, directed to Centro 


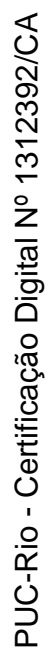

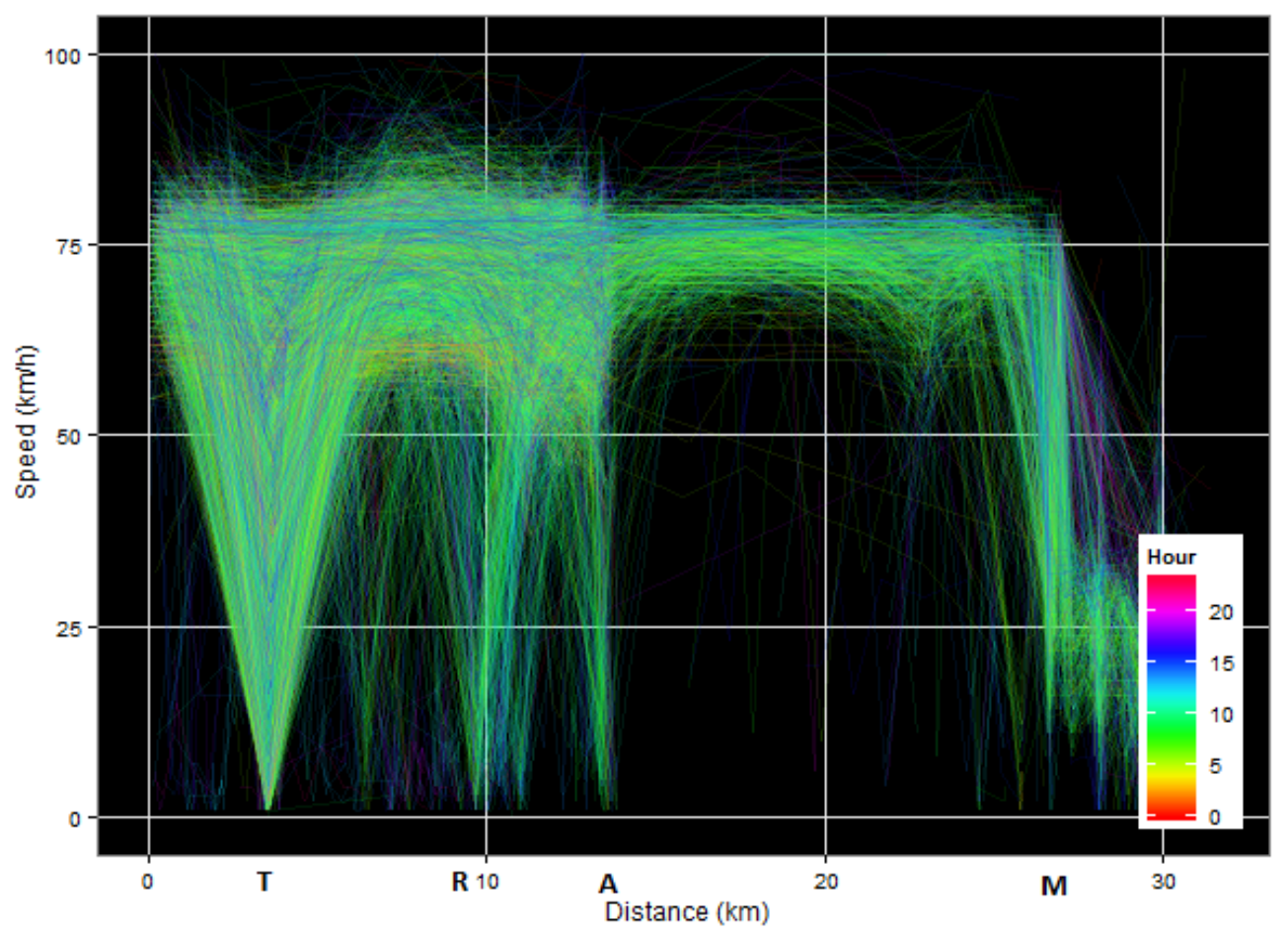

4.3(c): Rod. Rio Teresópolis, directed to Rio

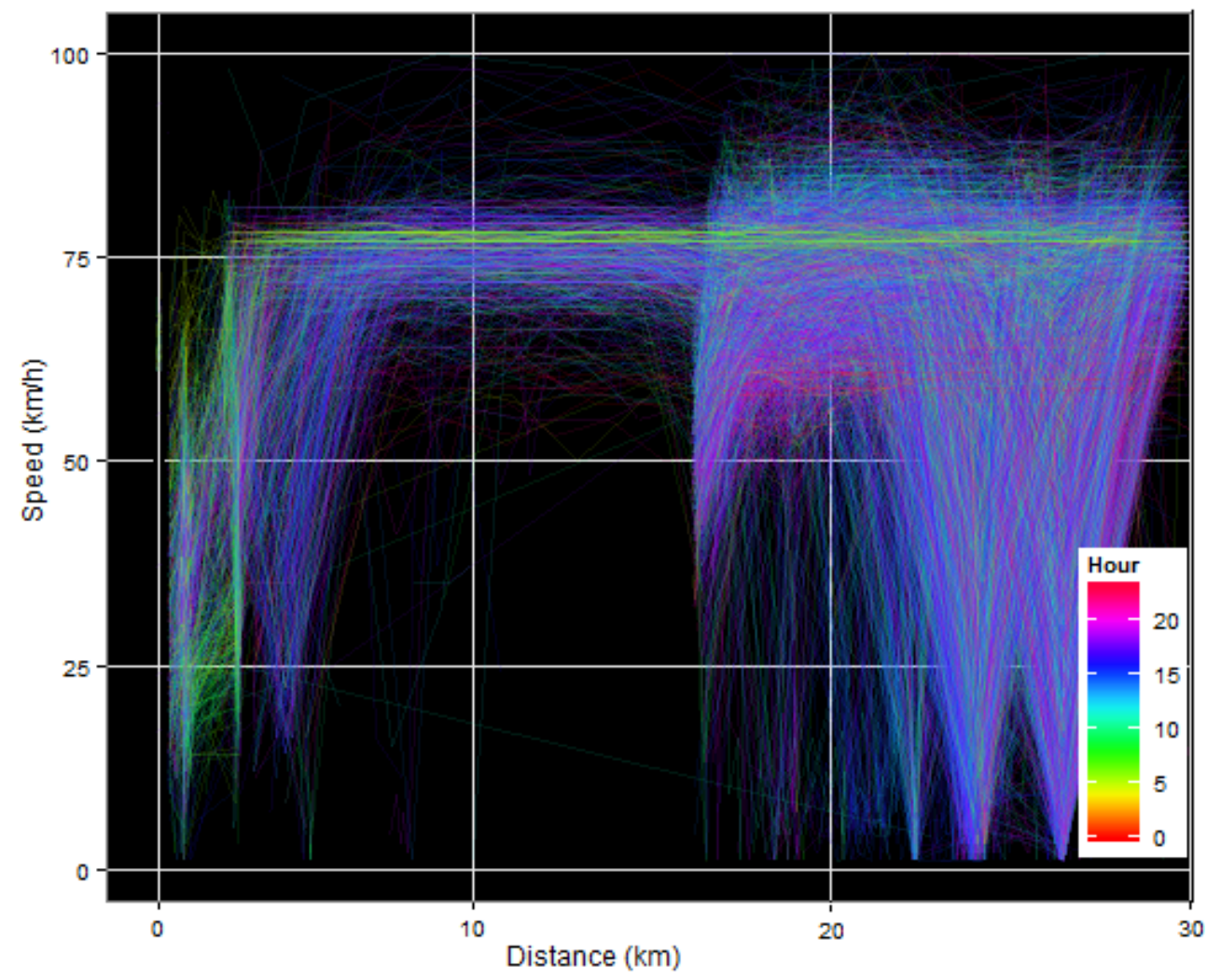

4.3(d): Rod. Rio Teresópolis, directed to Teresópolis 


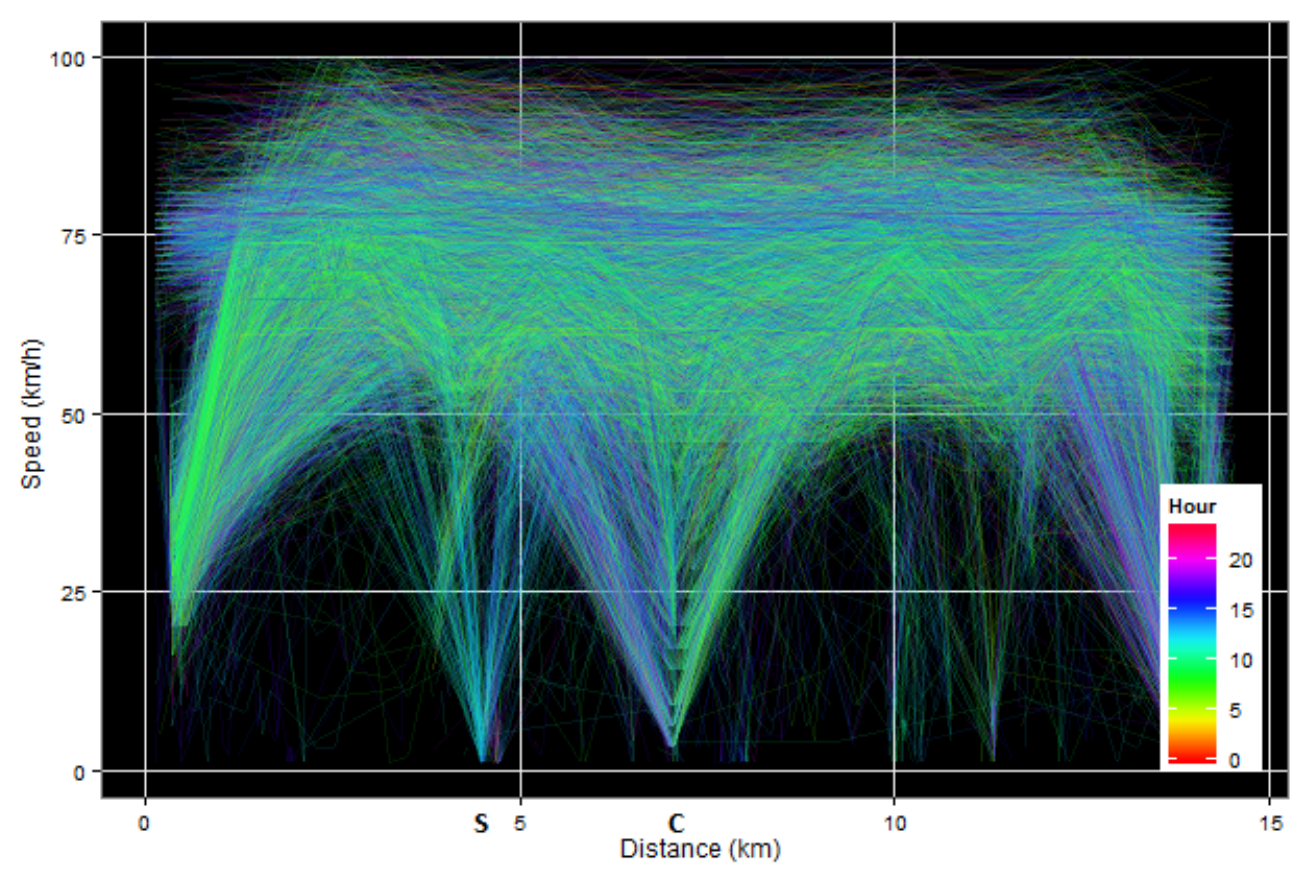

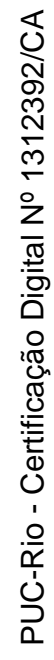

4.3(e): Rod. Anhanguera, directed to Limeira

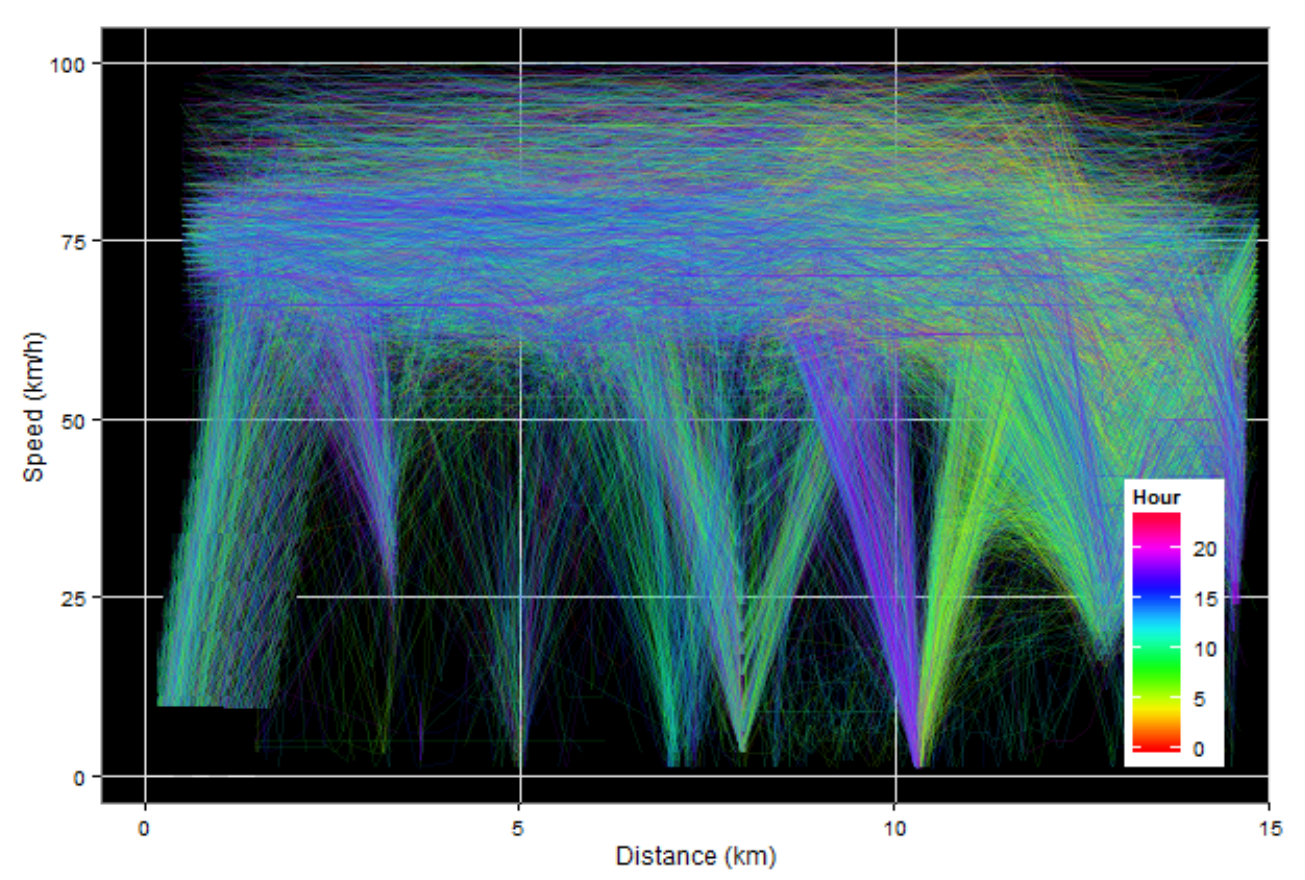

4.3(f): Rod. Anhanguera, directed to Americana 


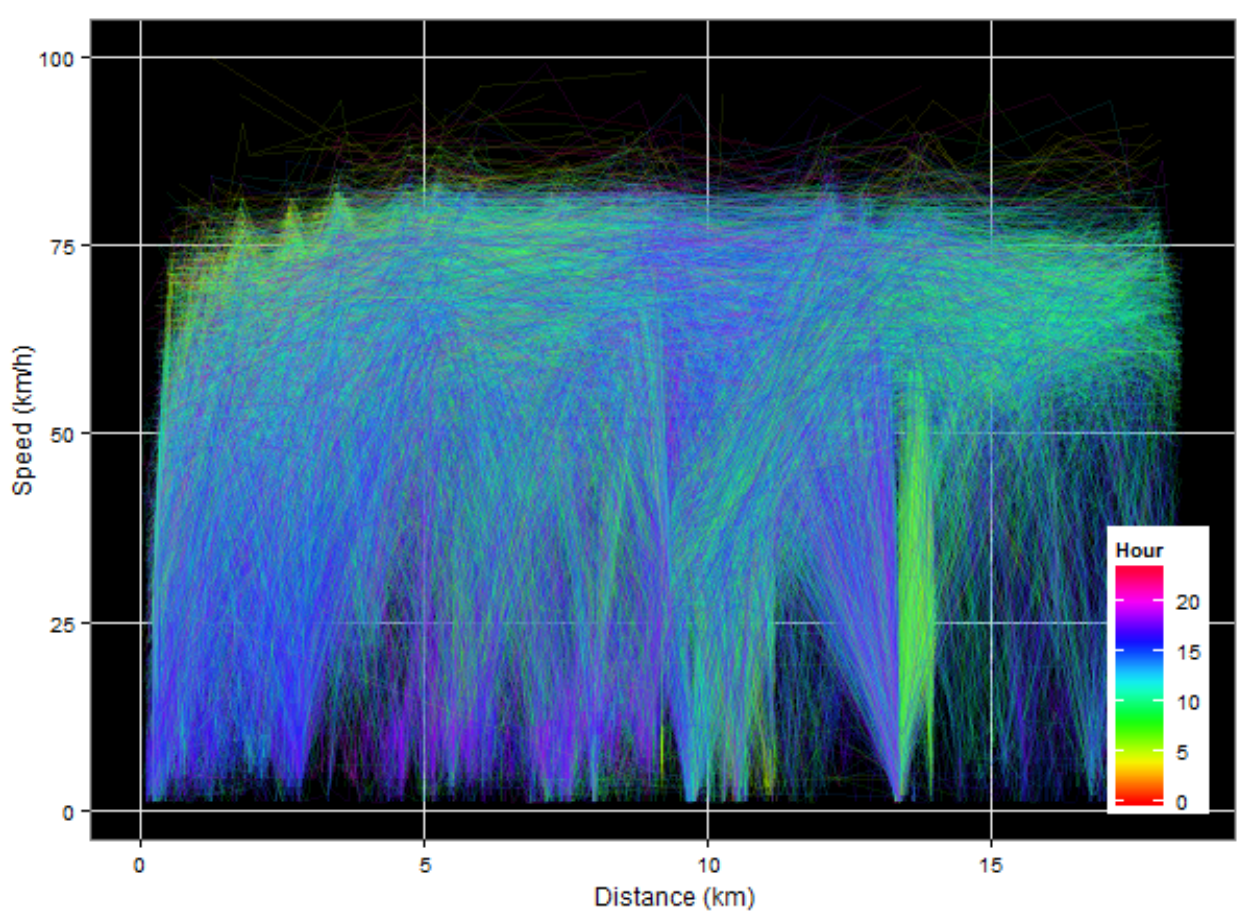

4.3(g): Rod. Fernão Dias, directed to Betim

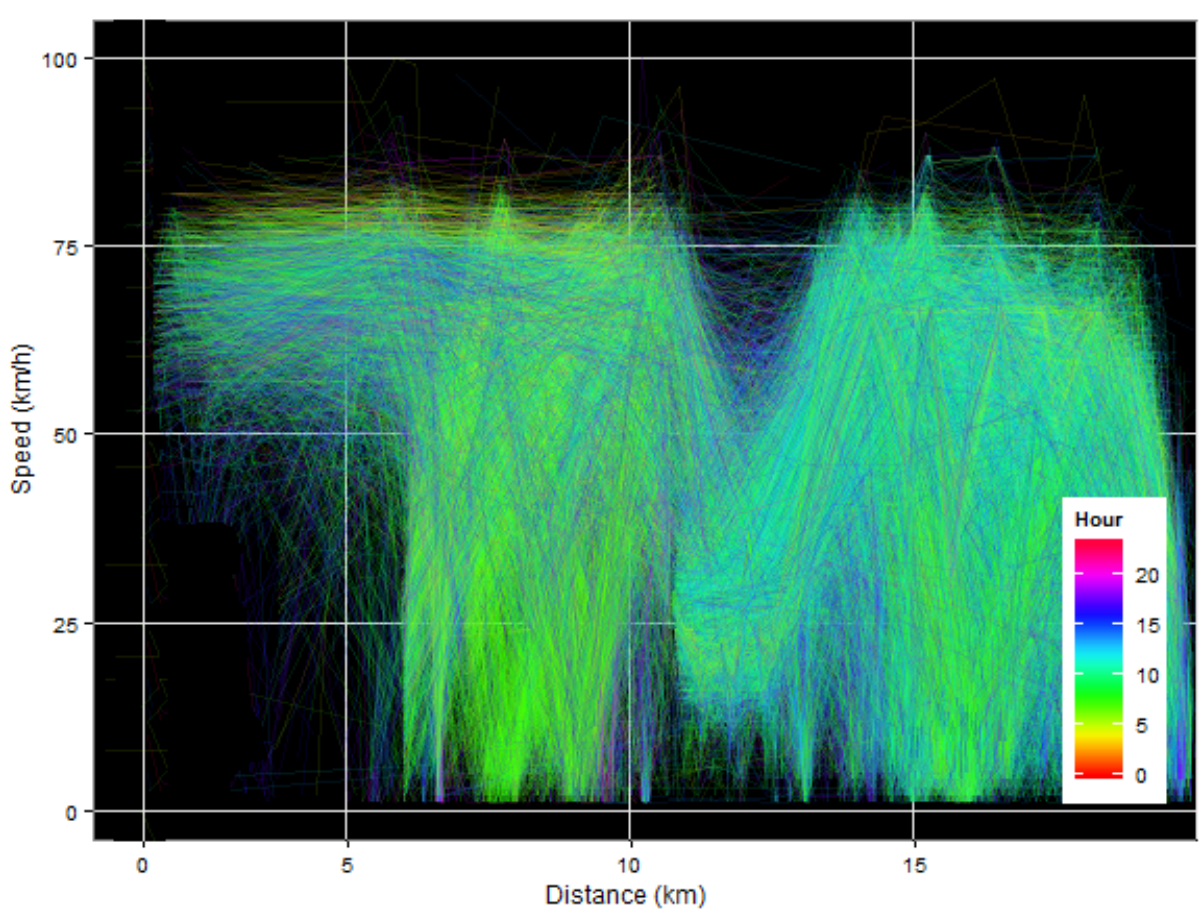

4.3(h): Rod. Fernão Dias, directed to Belo Horizonte

Figure 4.3: Travel plot obtained from the data as a function of space, speed and time 


\section{5}

\section{Spatio-Temporal Partitioning}

This chapter proposes a spatial-temporal partition strategy based on the previously discussed spatio-temporal analysis. Although there are many different ways to proceed, this work selected an heuristic based on the statistics of the historic GPS data.

\section{1}

\section{Spatial Partitioning}

Supported by the previous spatial analysis, this study proposes partitioning a road extension into segments, where the segment size is selected based on the average distance traveled between each pair of consecutive signals of the same vehicle. The objective is to find the segment size that best learns from the given gps road observations.

In order to visualize the distance distribution over these pairs, a histogram was generated, as illustrated in Figure 5.1, indicating that each road should have its own segment size. The proposal is to use the median value as the segment size, since it is simple to calculate and should perform reasonably in most cases, but it is important to note that, although it is a good choice, the median is not necessarily optimum. Quartile analysis of these same distances, as shown in Figure 5.2, demonstrated that smaller segment sizes should give even more information about the average speed, while large sizes will tend to over generalize it. Mean speed was over generalized as the segment was over sized (3rd and 4th quartiles), and although the 1st quartile appeared to be an even better choice than the 2nd quartile, in some cases, the "shorter is better" approach won't always give the best prediction if the selected size is too small. If a 1 meter sized is used, there may be no 
improvement in prediction accuracy, and if the data doesn't provide a good amount of observations for every 1 meter on the road, it will add unnecessary complexity to the model, making the learning process slower. 


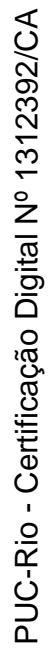

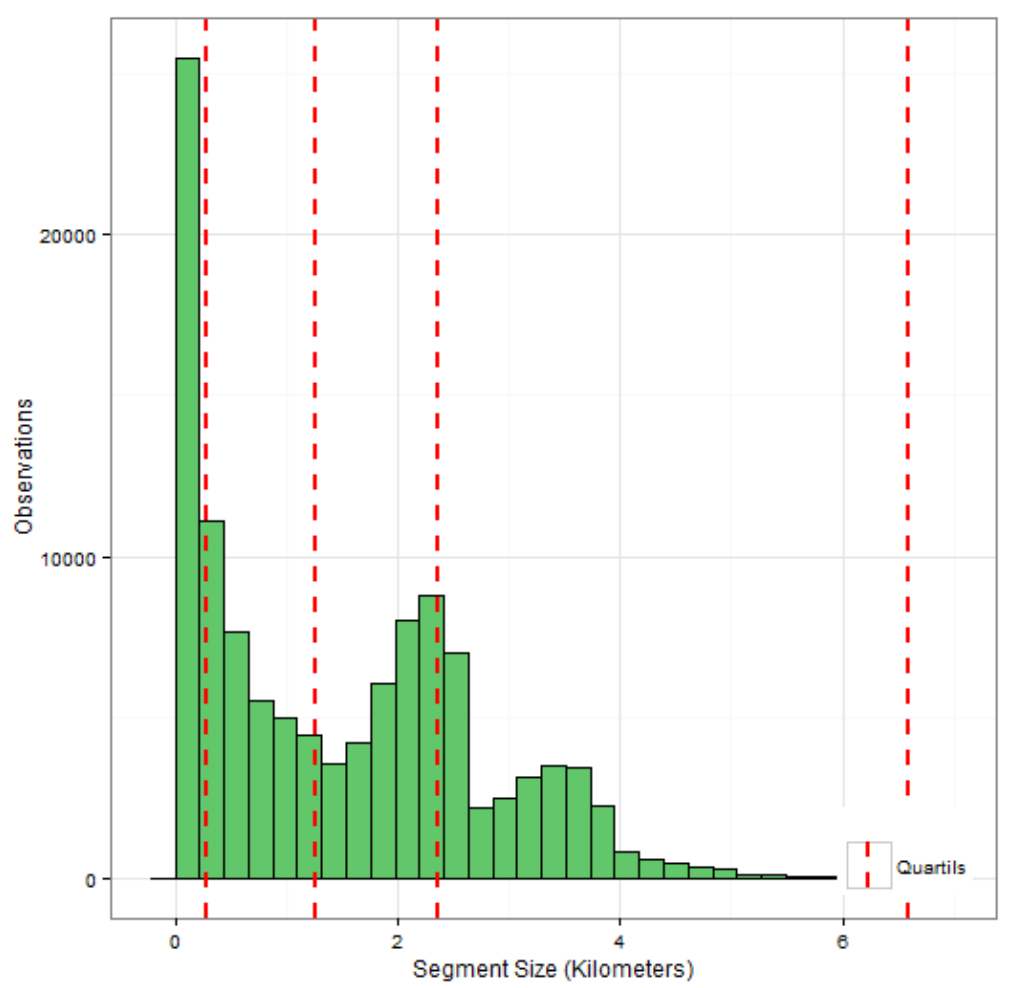

5.1(a): Av. Brasil, directed to Santa Cruz

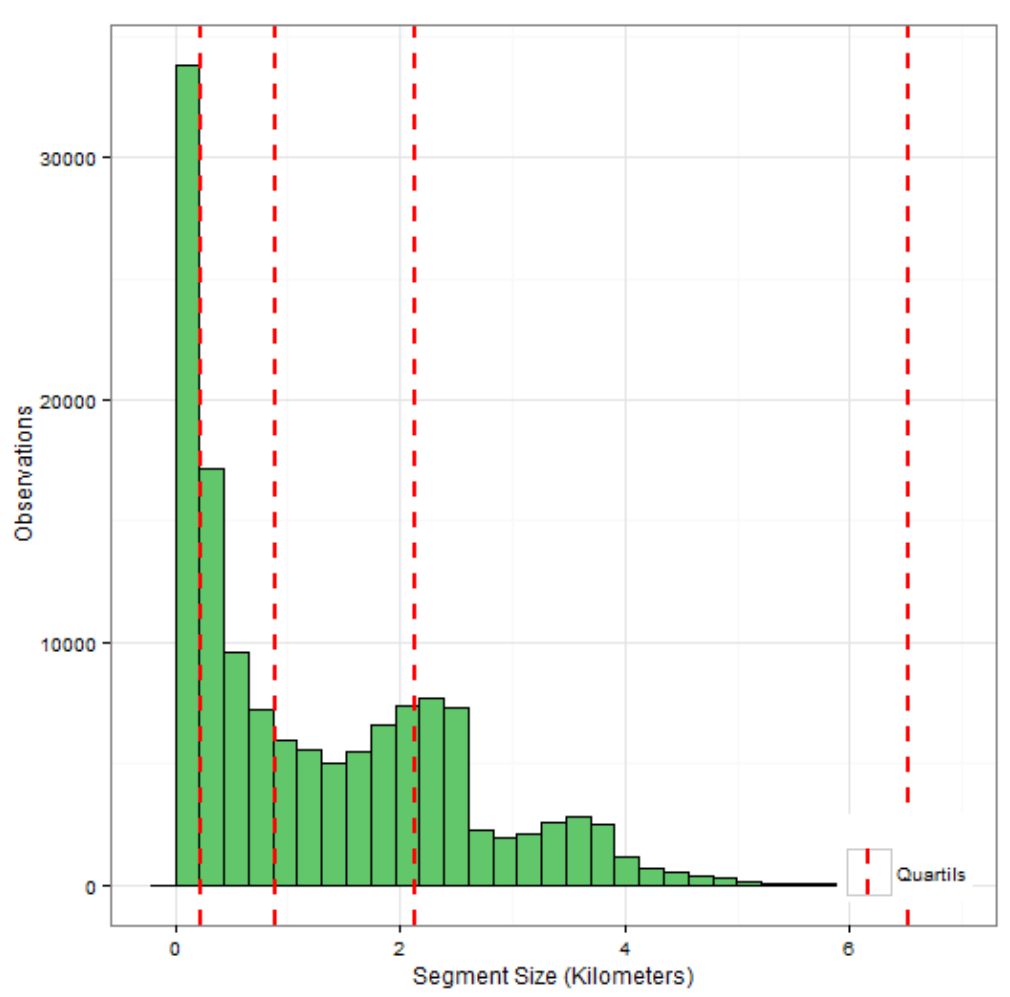

5.1(b): Av. Brasil, directed to Centro 


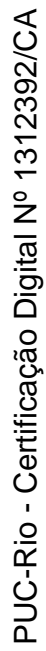

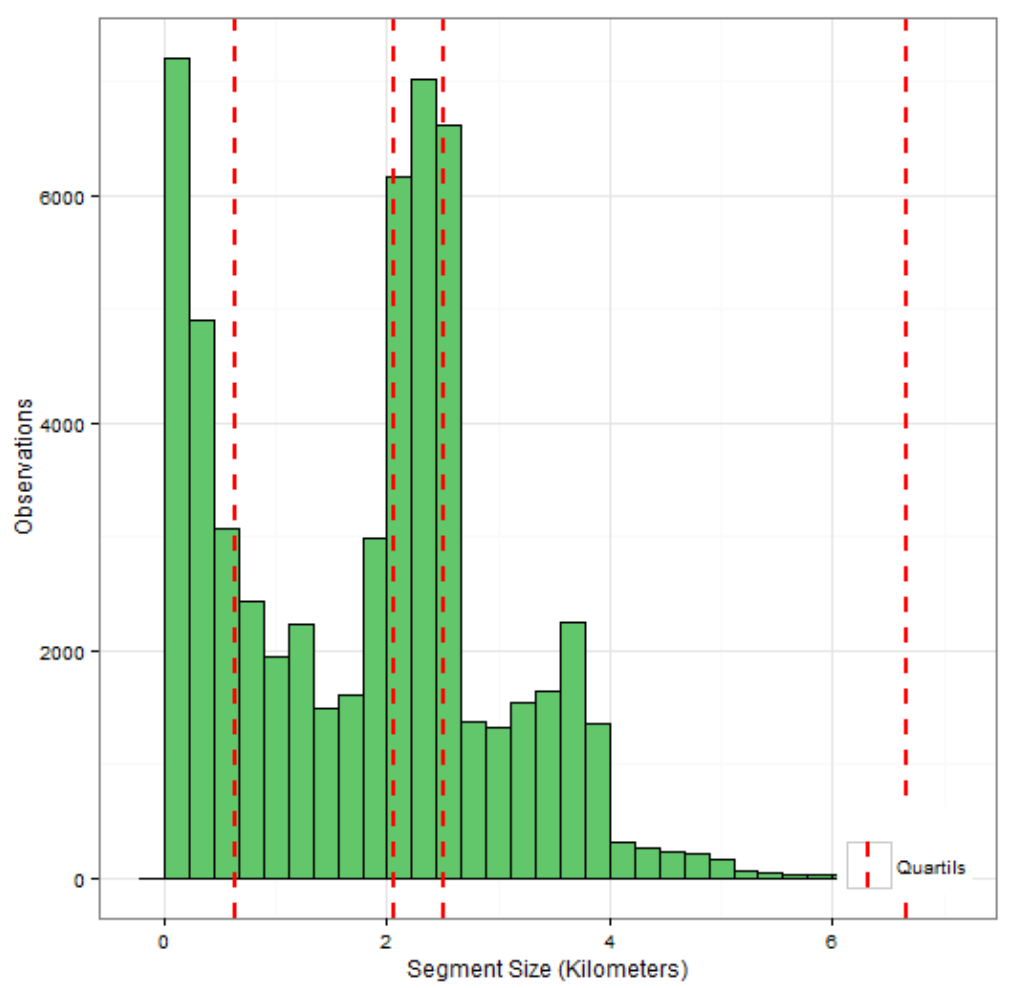

5.1(c): Rod. Rio Teresópolis, directed to Rio

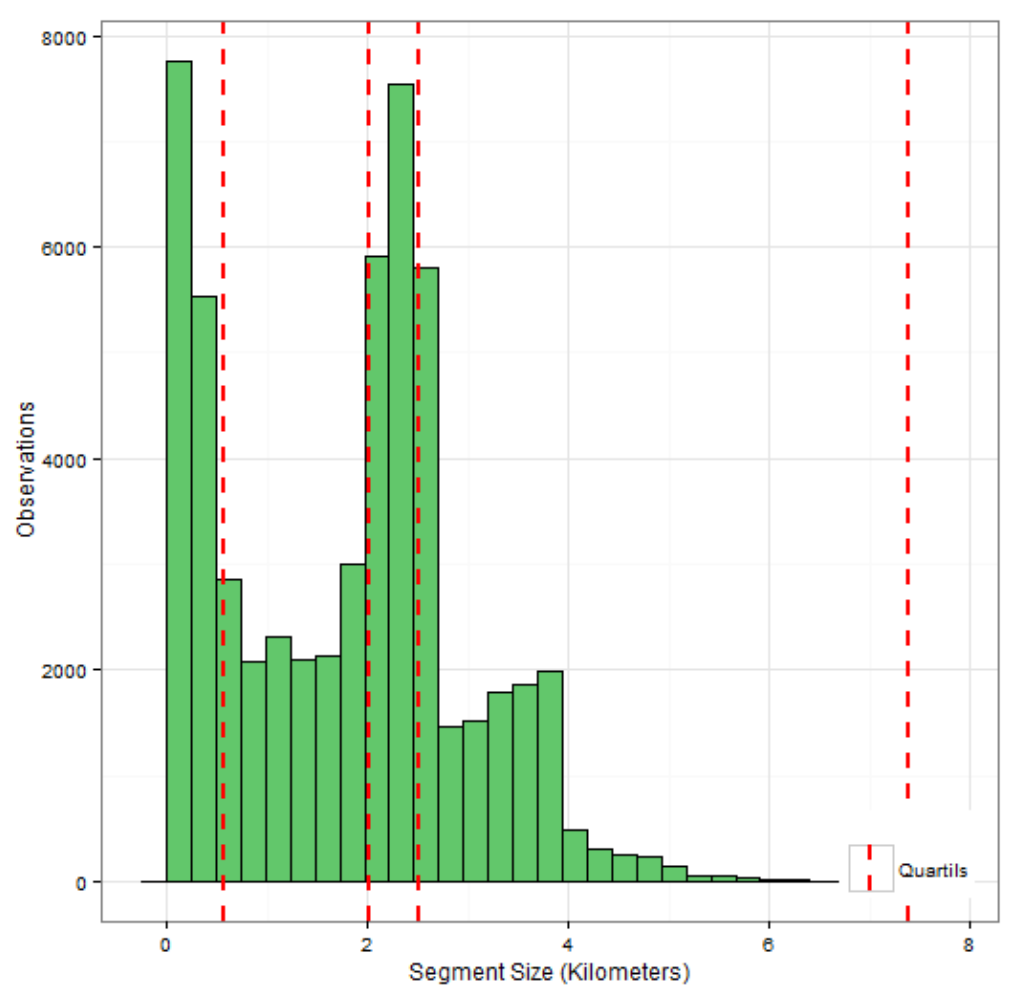

5.1(d): Rod. Rio Teresópolis, directed to Teresópolis 


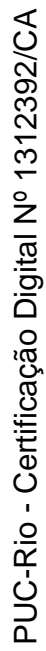

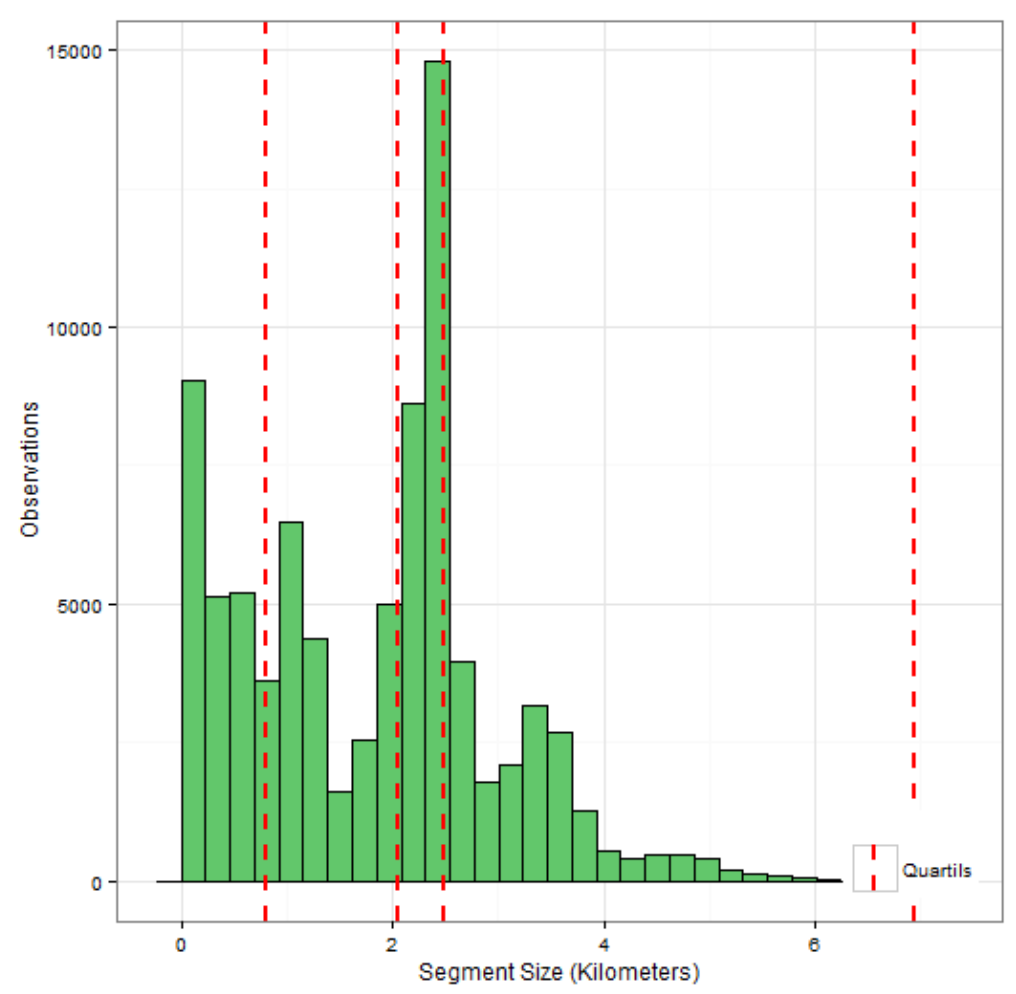

5.1(e): Rod. Anhanguera, directed to Limeira

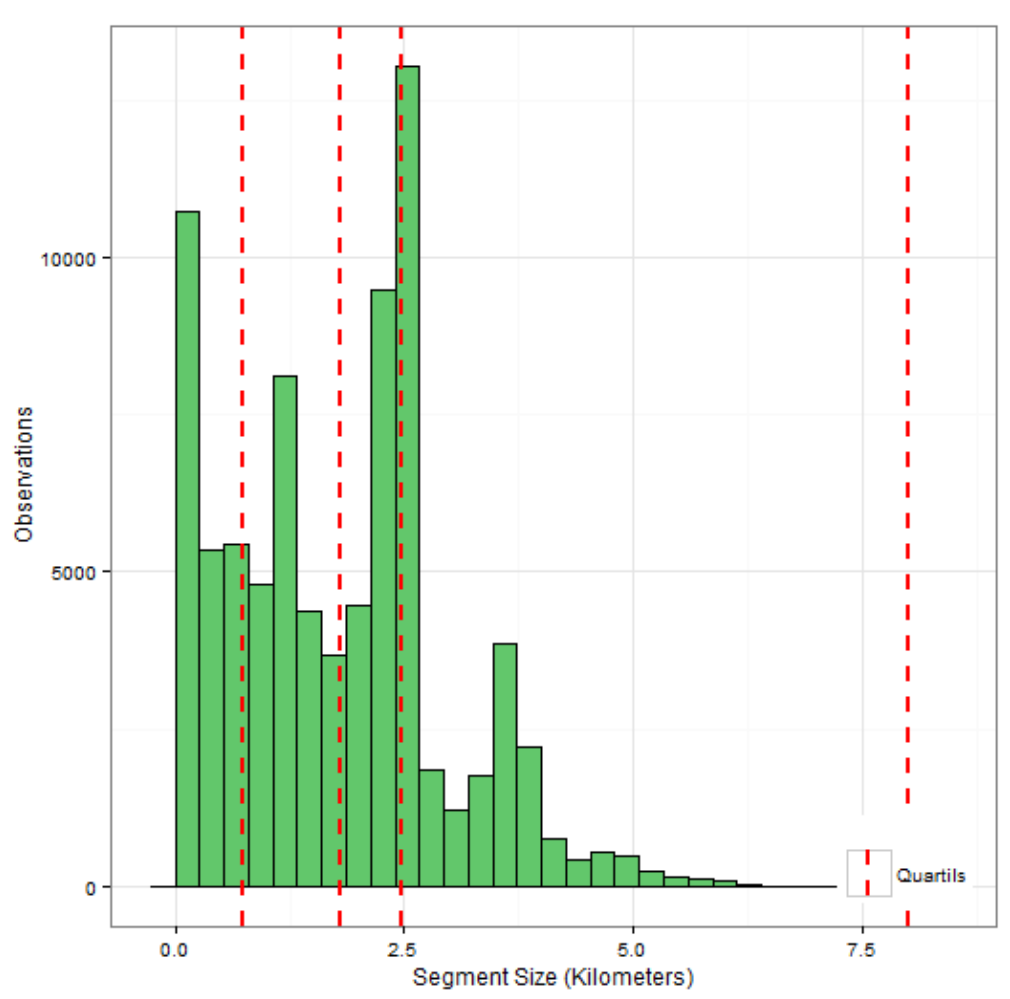

5.1(f): Rod. Anhanguera, directed to Americana 


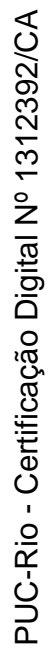

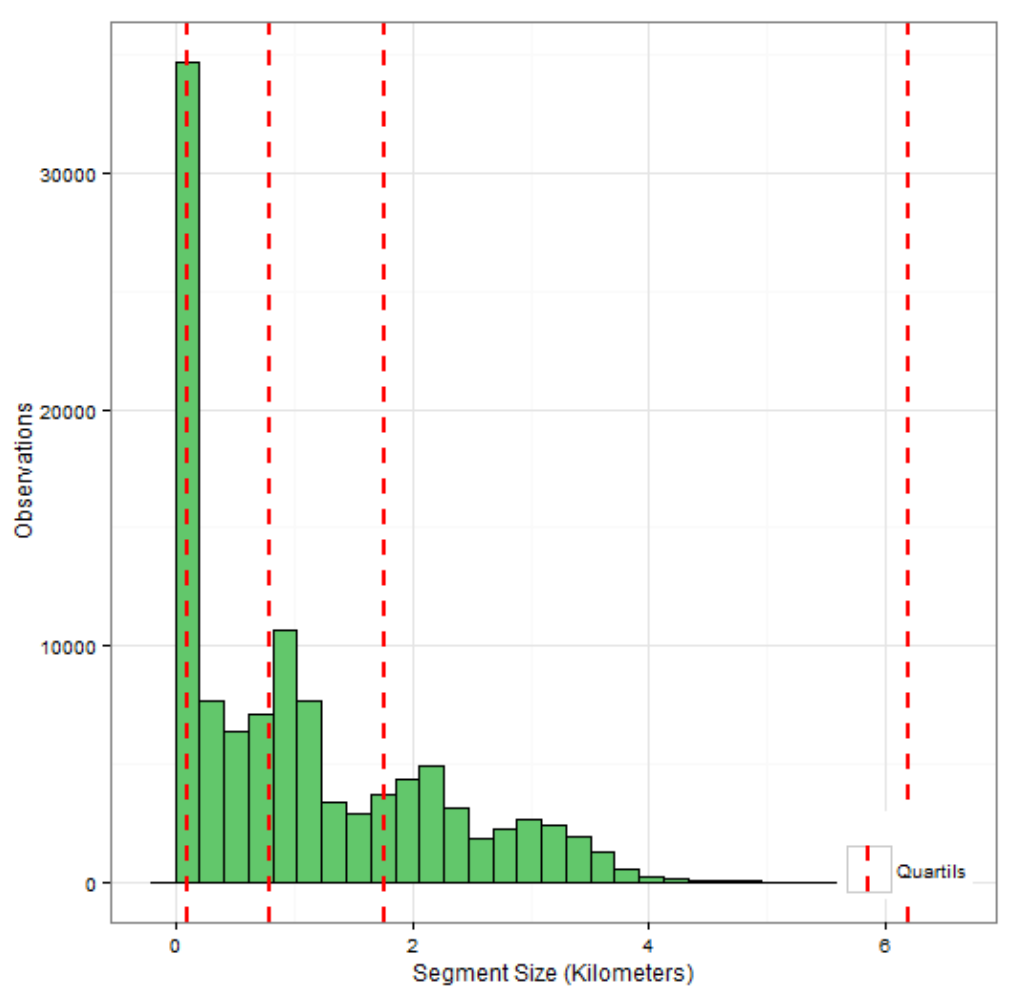

5.1(g): Rod. Fernão Dias, directed to Betim

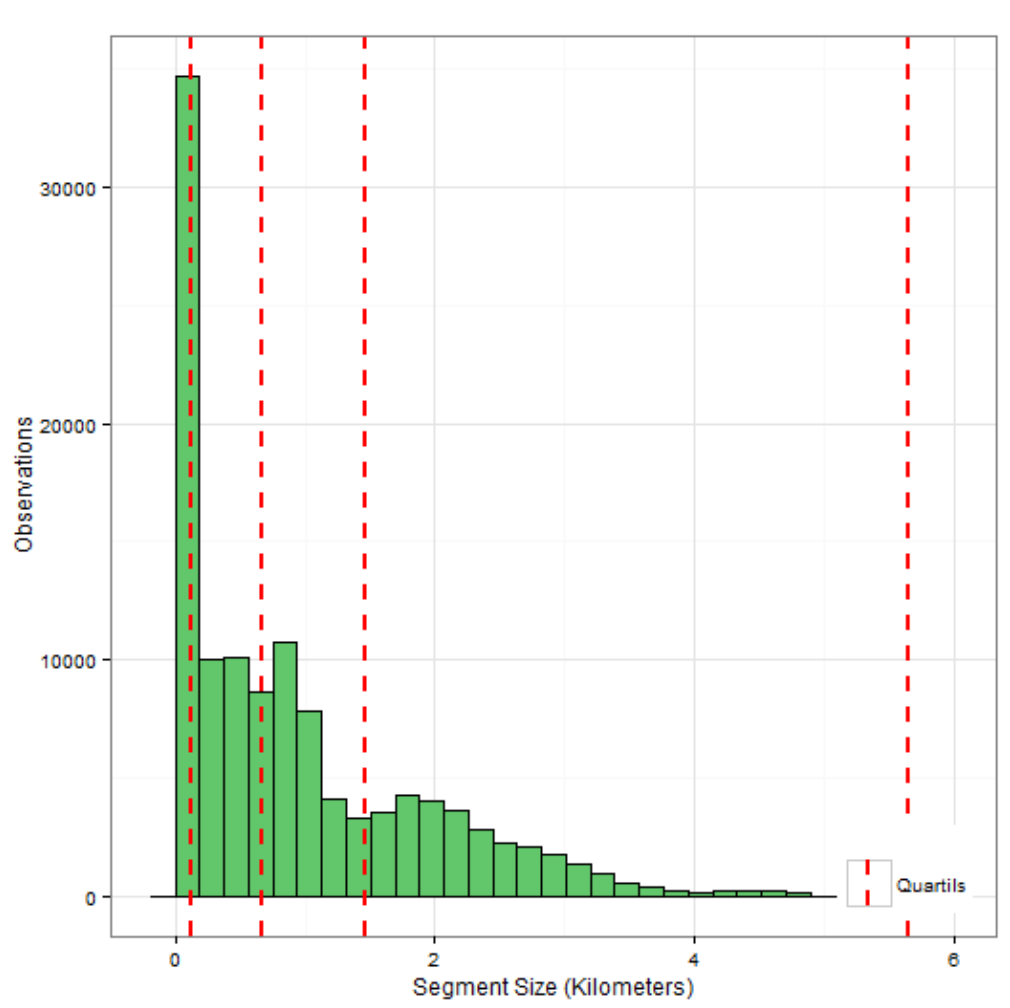

5.1(h): Rod. Fernão Dias, directed to Belo Horizonte

Figure 5.1: Spatial partition quartils 


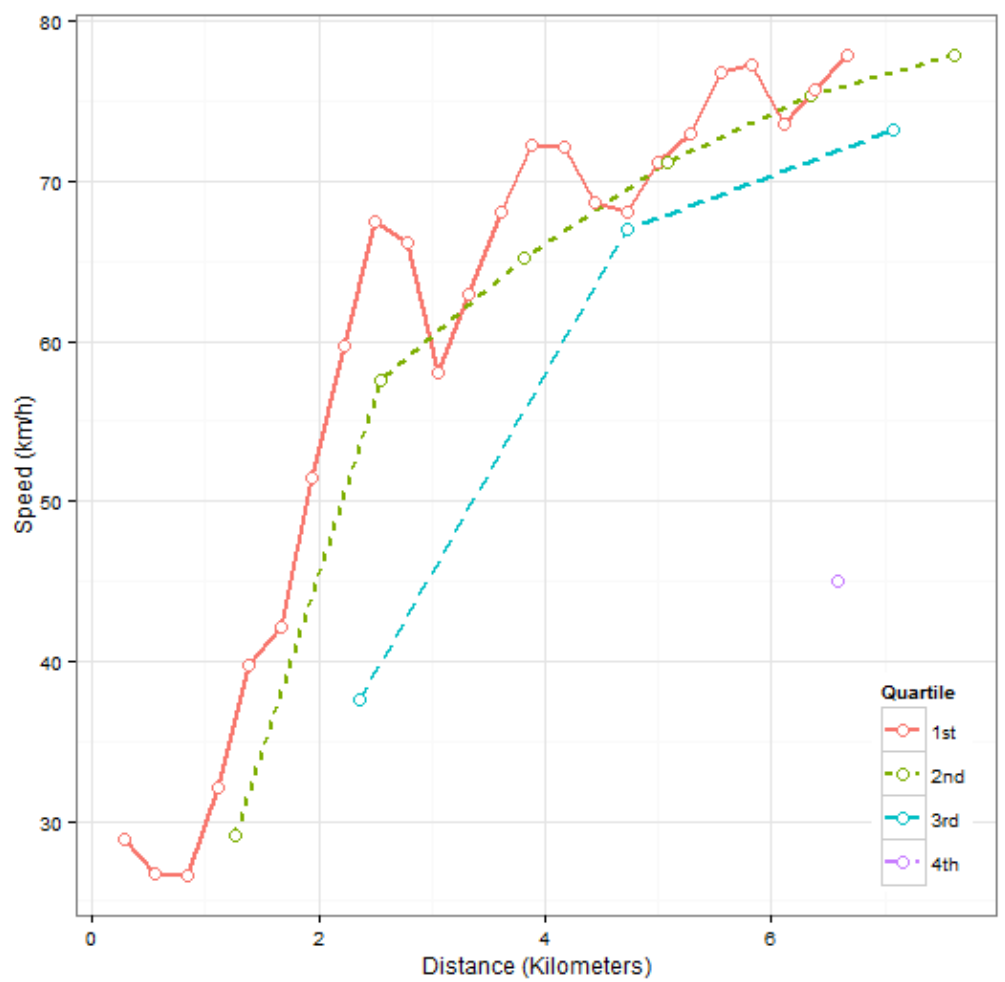

5.2(a): Av. Brasil, directed to Santa Cruz

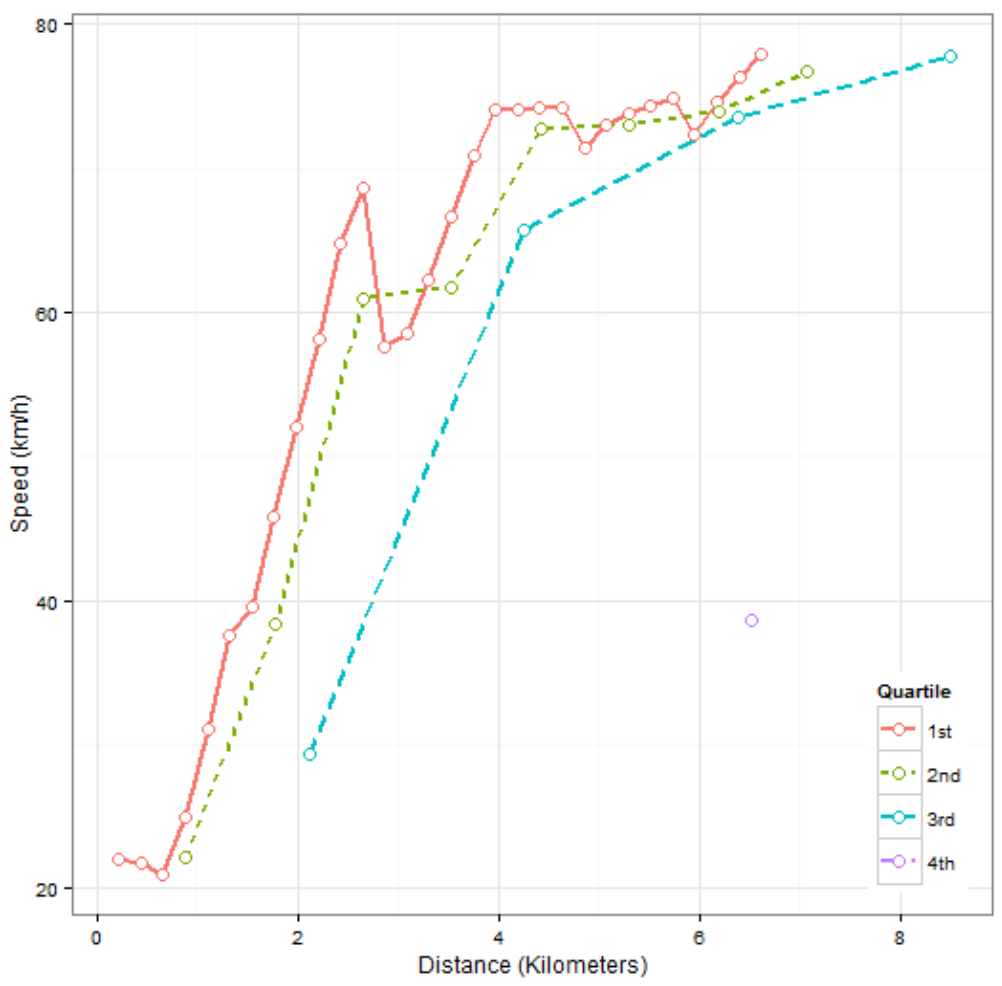

5.2(b): Av. Brasil, directed to Centro 


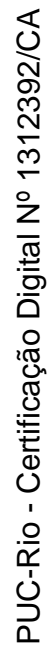

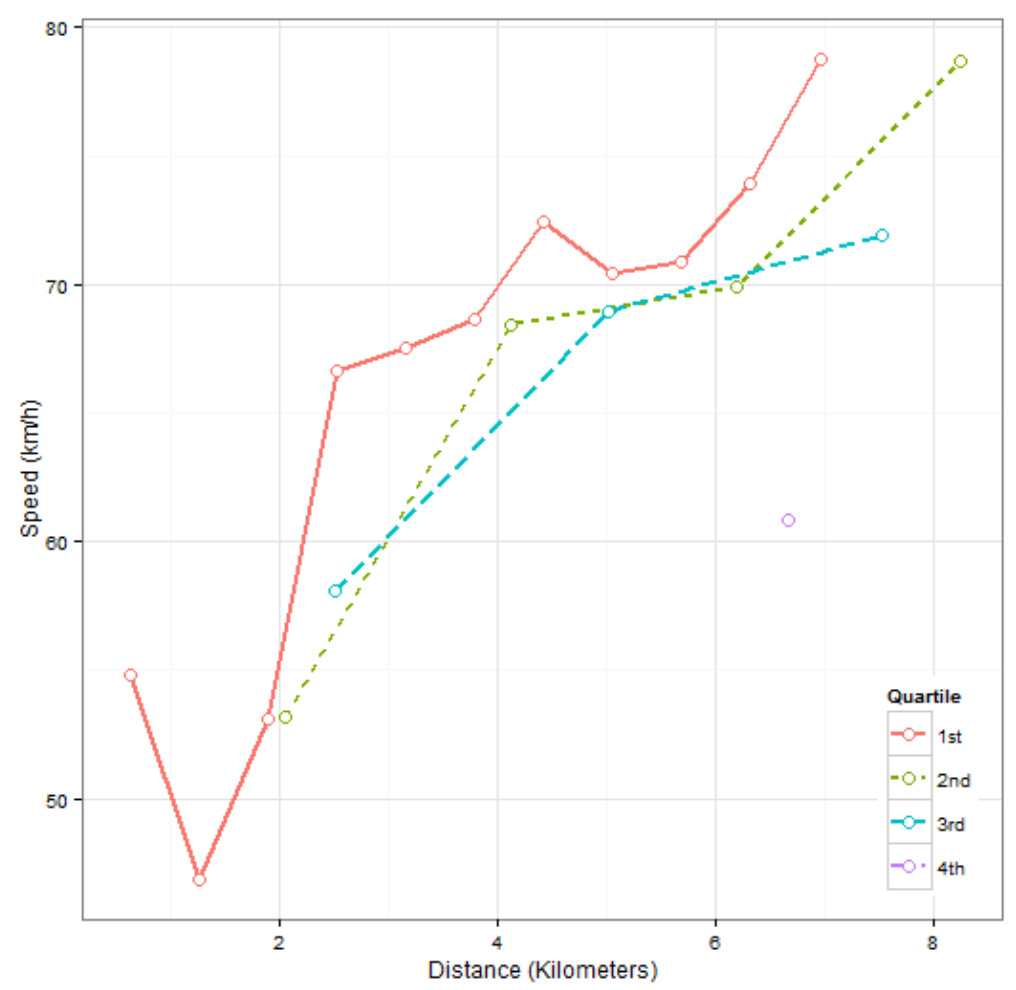

5.2(c): Rod. Rio Teresópolis, directed to Rio

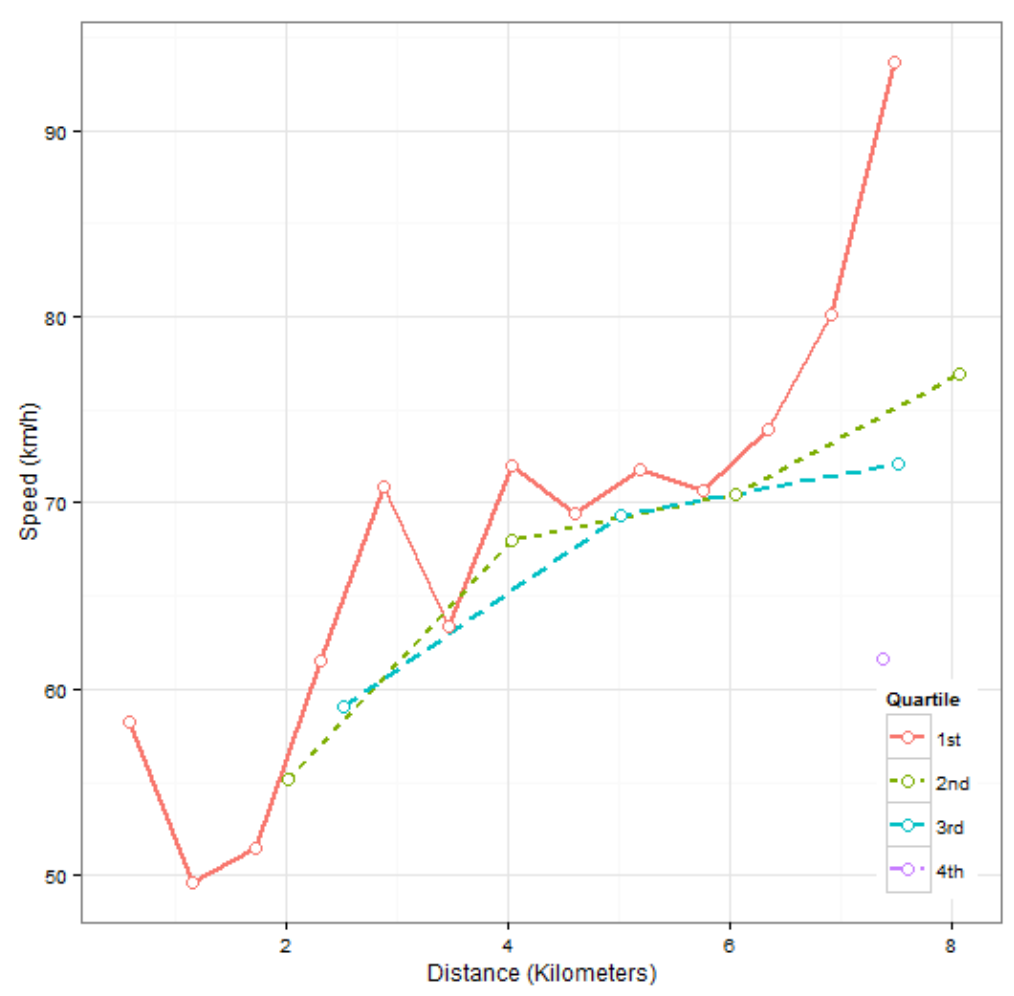

5.2(d): Rod. Rio Teresópolis, directed to Teresópolis 


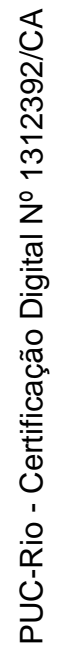

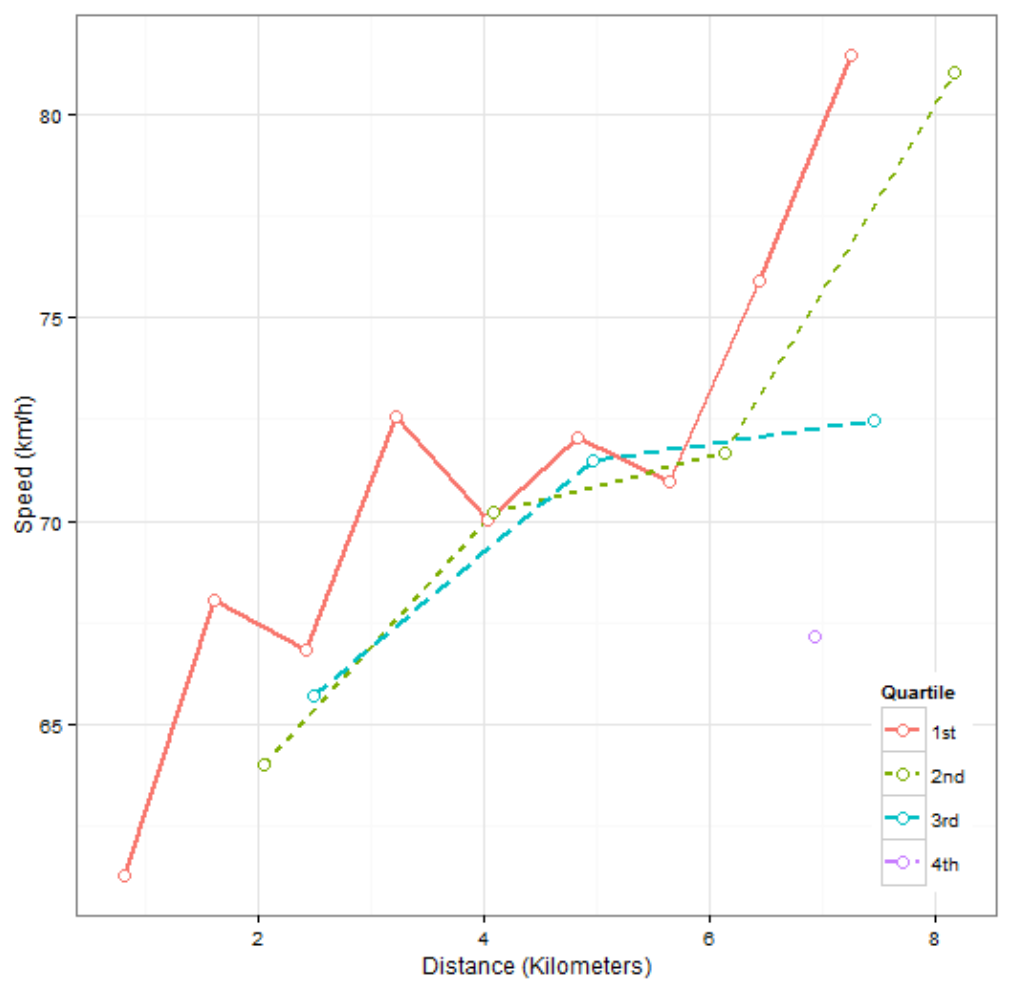

5.2(e): Rod. Anhanguera, directed to Limeira

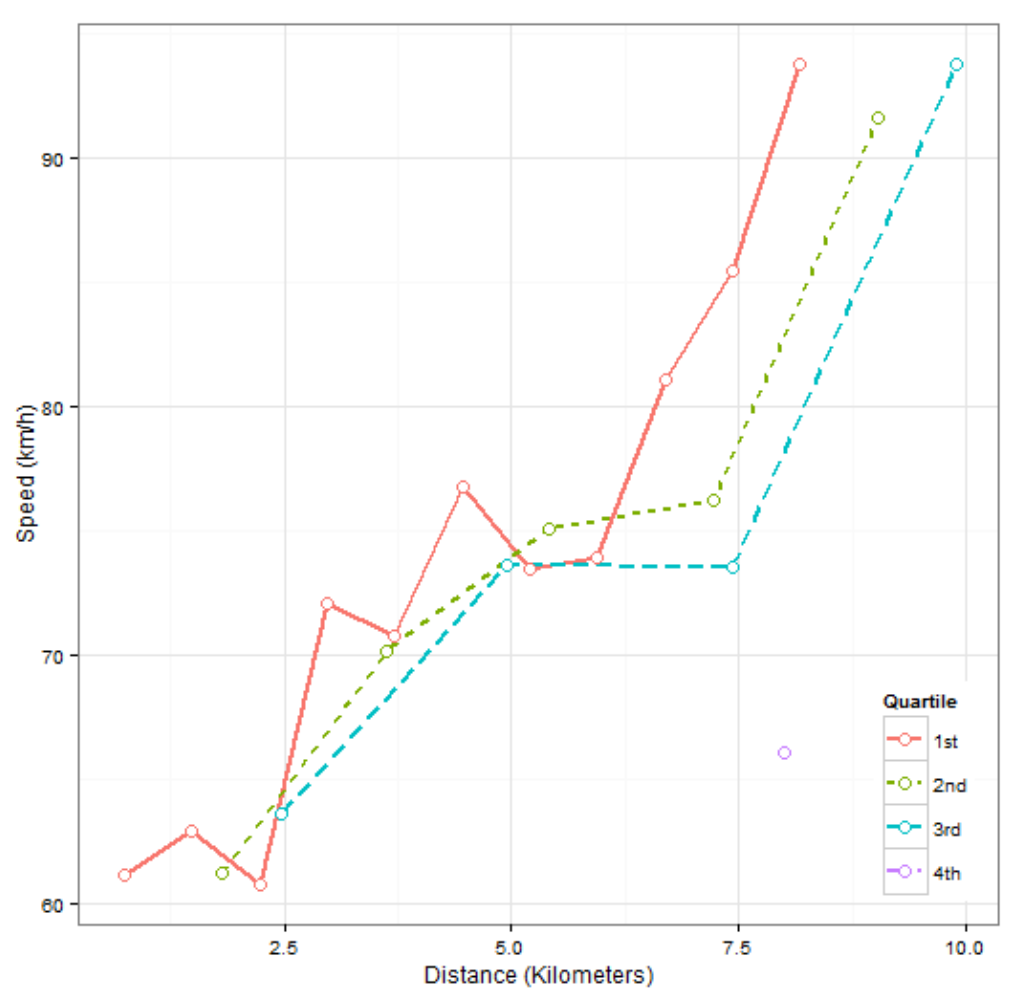

5.2(f): Rod. Anhanguera, directed to Americana 


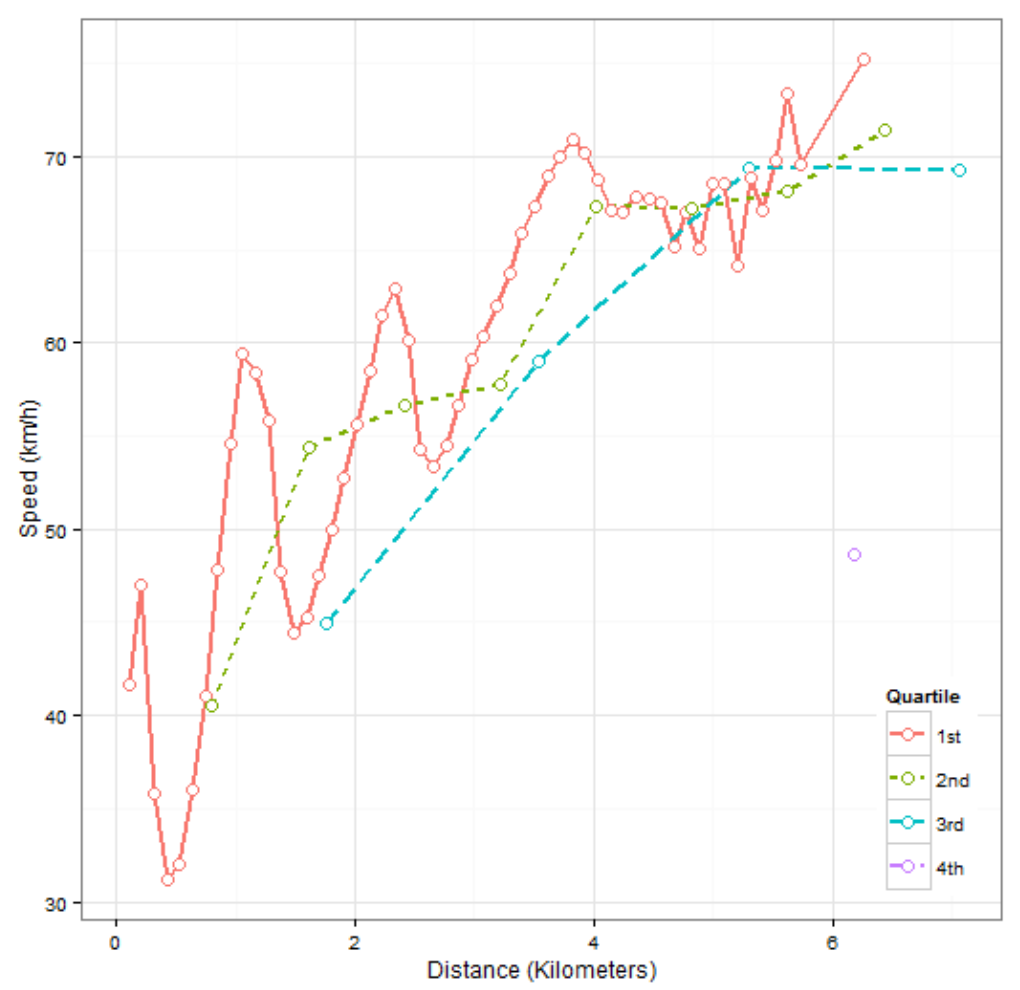

5.2(g): Rod. Fernão Dias, directed to Betim

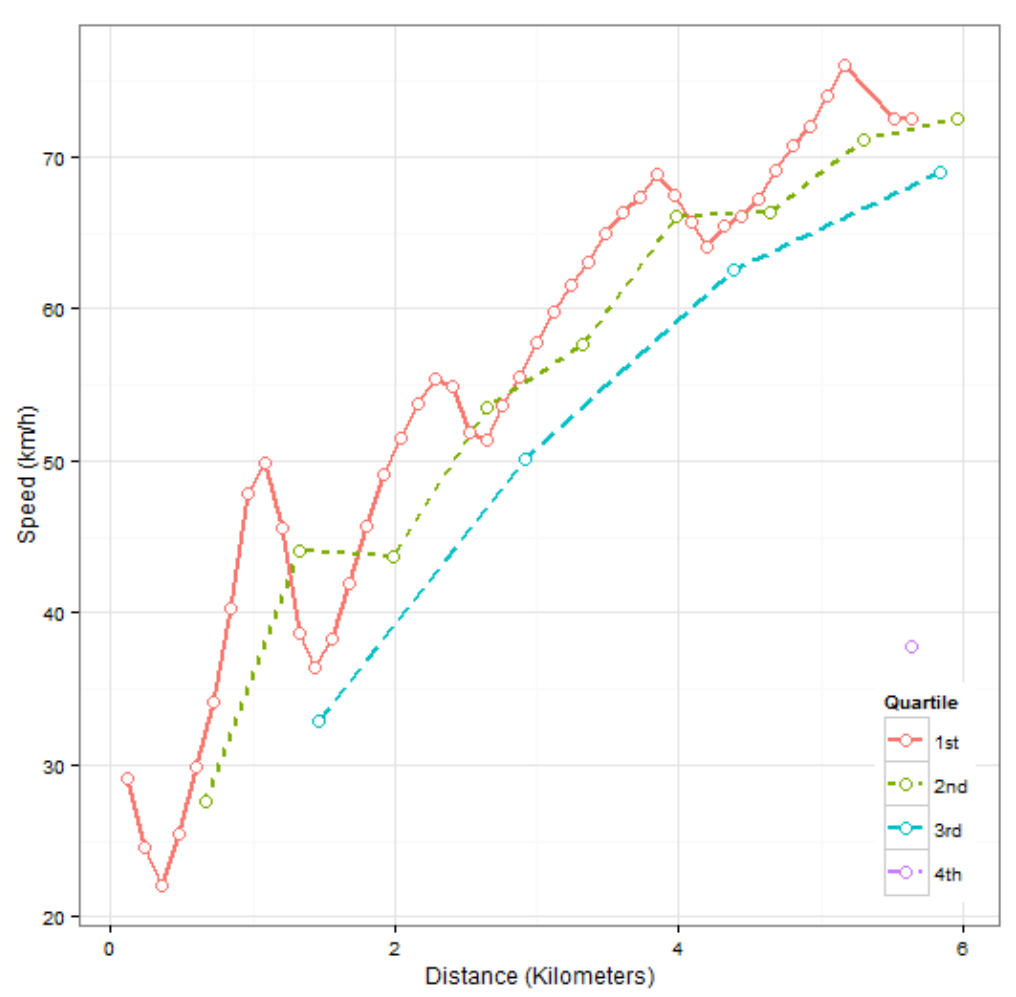

5.2(h): Rod. Fernão Dias, directed to Belo Horizonte

Figure 5.2: Spatial segment quartil comparison 


\section{2}

\section{Temporal Partitioning}

For temporal partition, this study proposes a time segmentation into hours. This choice was based mostly on the number of observations and prediction relevance.

Since a spatial partitioning was applied as well, a segment from each road was selected and studied in both directions with an hourly partition. Using a density plot with speed as a function of time, as shown in Figure 5.3, speed patterns could be identified at each road. While different speeds can be observed at the same hour, it is clear that each hour has a higher density at a determined speed value, and that each hour has its own average speed. These behaviors were especially evident on Avenida Brasil and Rodovia Fernão Dias.

A curious pattern on Avenida Brasil was that, when directed to Rio, speed decreases from 8:00 to 11:00. On the other hand, it increases in the afternoon and decreases again from 17:00 to 20:00, when directed to Santa Cruz. It may be seen as a coincidence again, but there is high traffic going to Rio in the morning followed by high traffic leaving Rio at night, very similar to a Rush Hour in Brazil. 


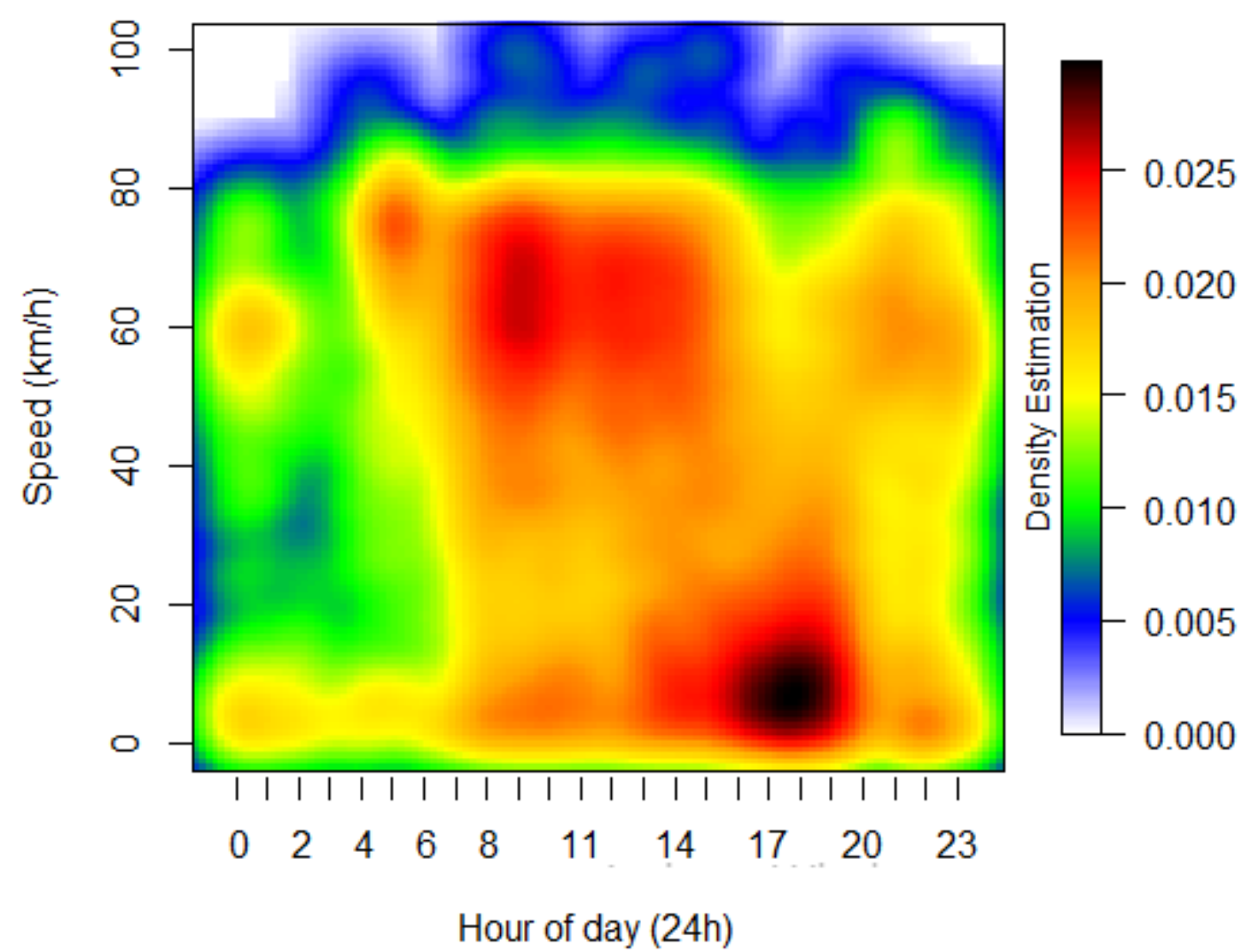

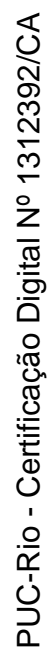

5.3(a): Av. Brasil, segment 5, directed to Santa Cruz

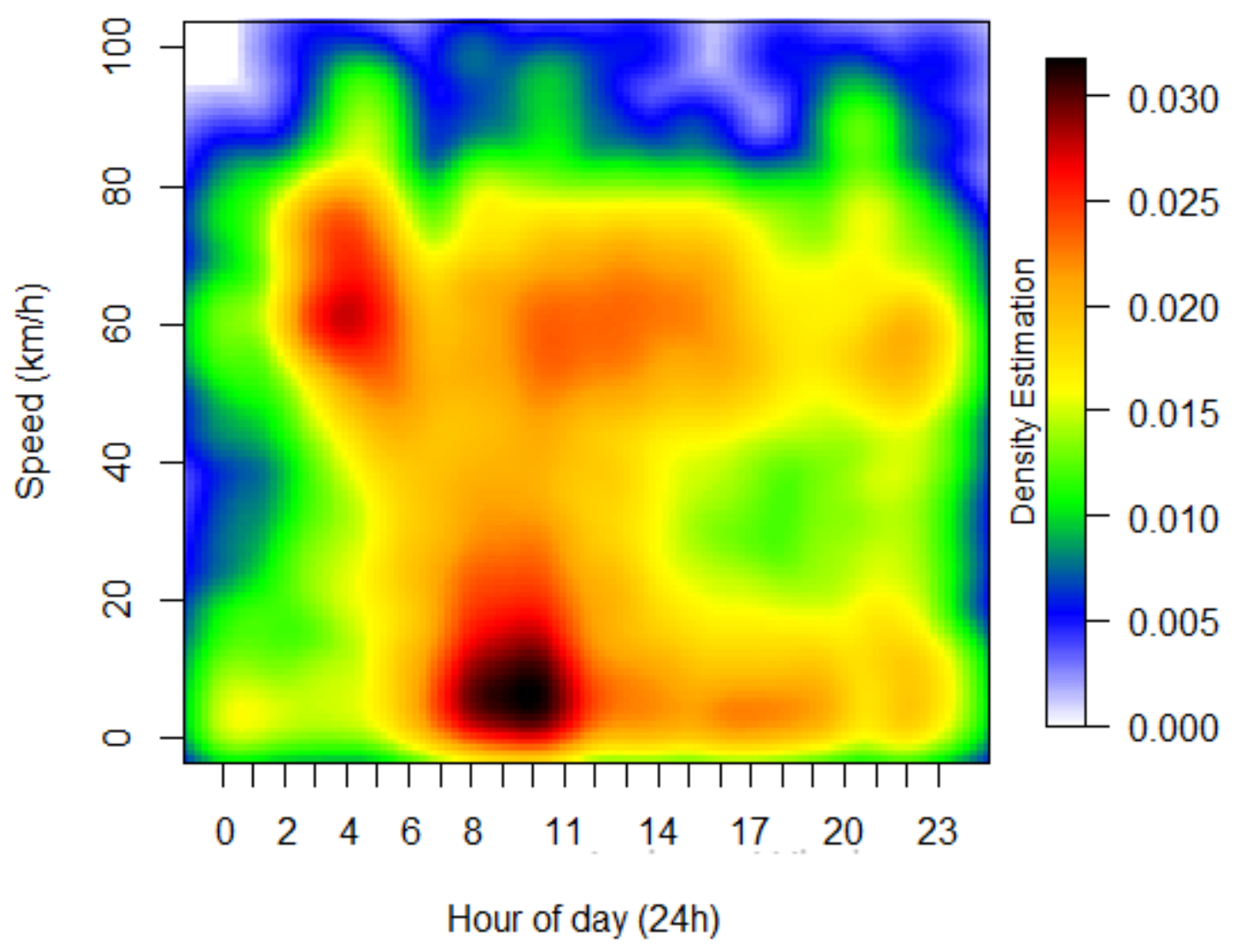

5.3(b): Av. Brasil, segment 45, directed to Centro 


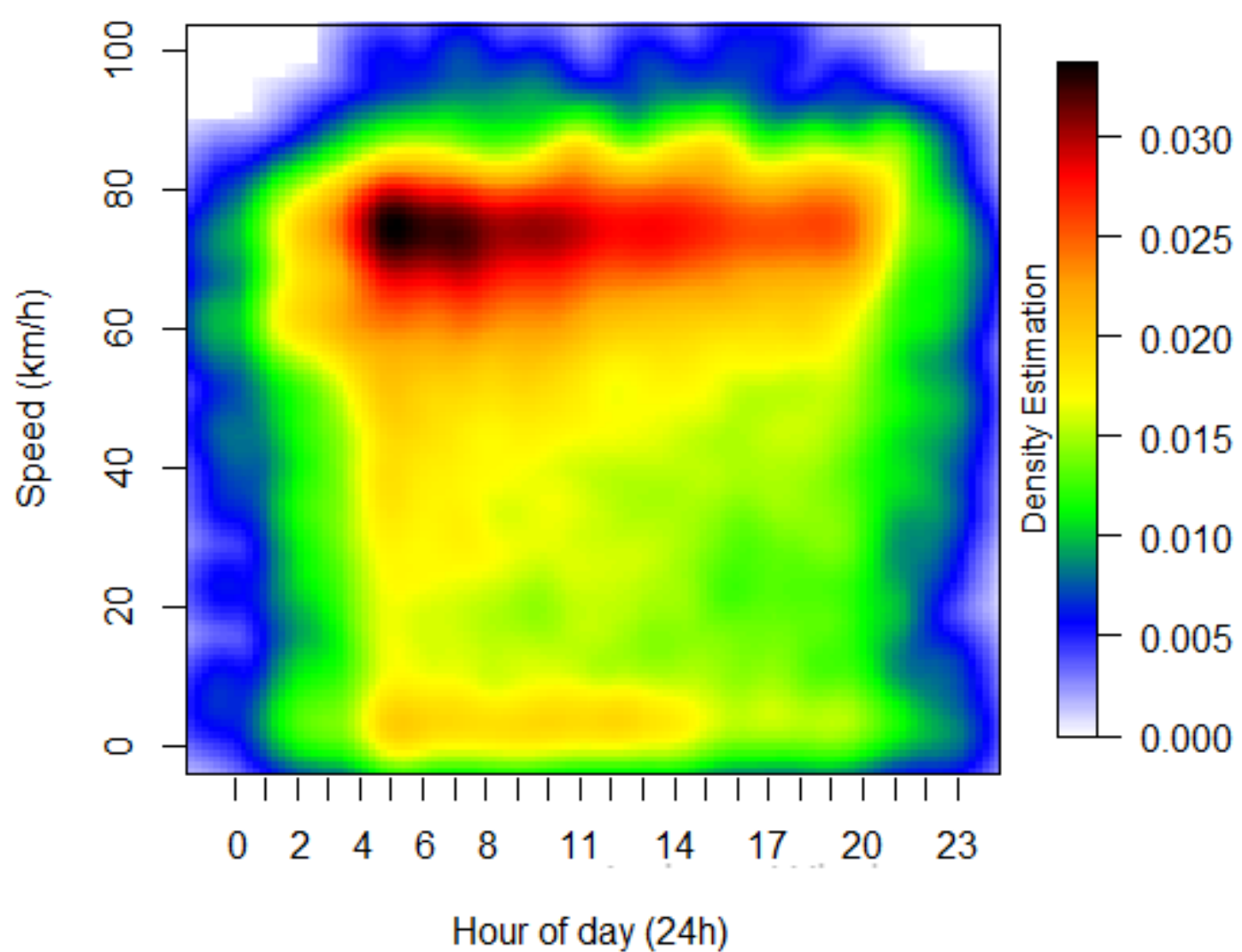

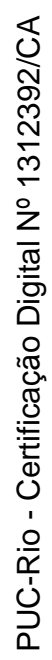

5.3(c): Rod. Rio Teresópolis, segment 5, directed to Rio

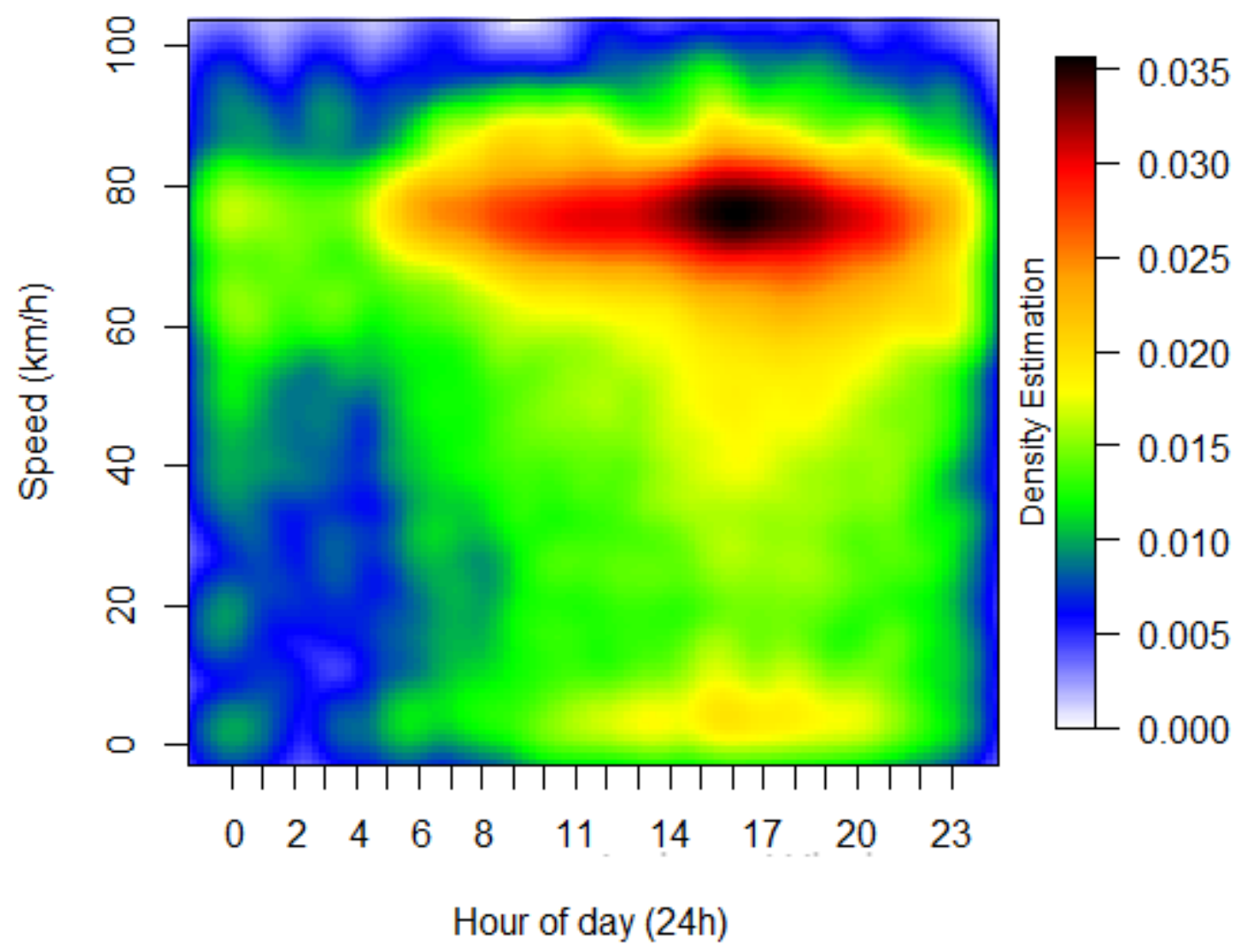

5.3(d): Rod. Rio Teresópolis, segment 25, directed to Teresópolis 


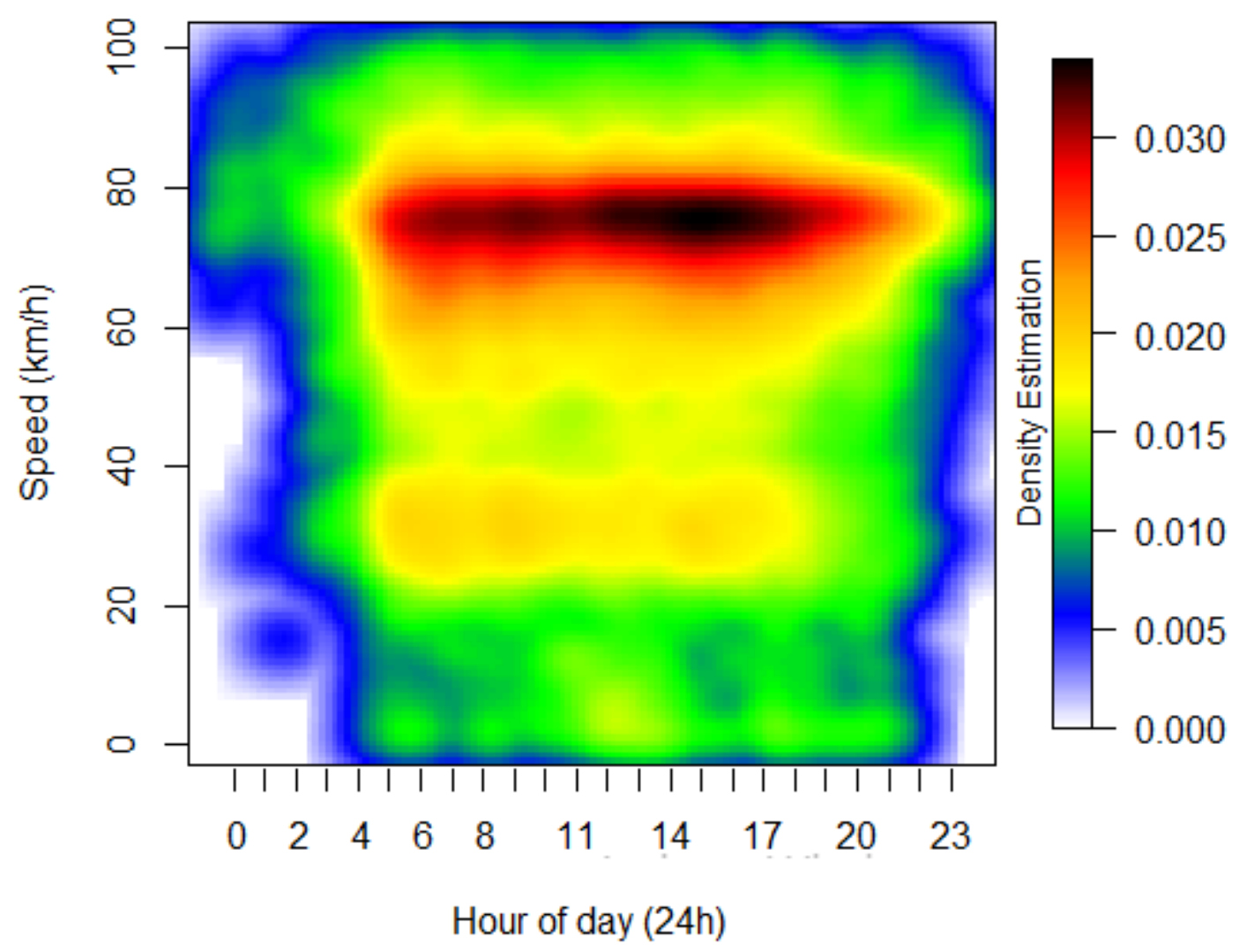

5.3(e): Rod. Anhanguera, segment 5, directed to Limeira

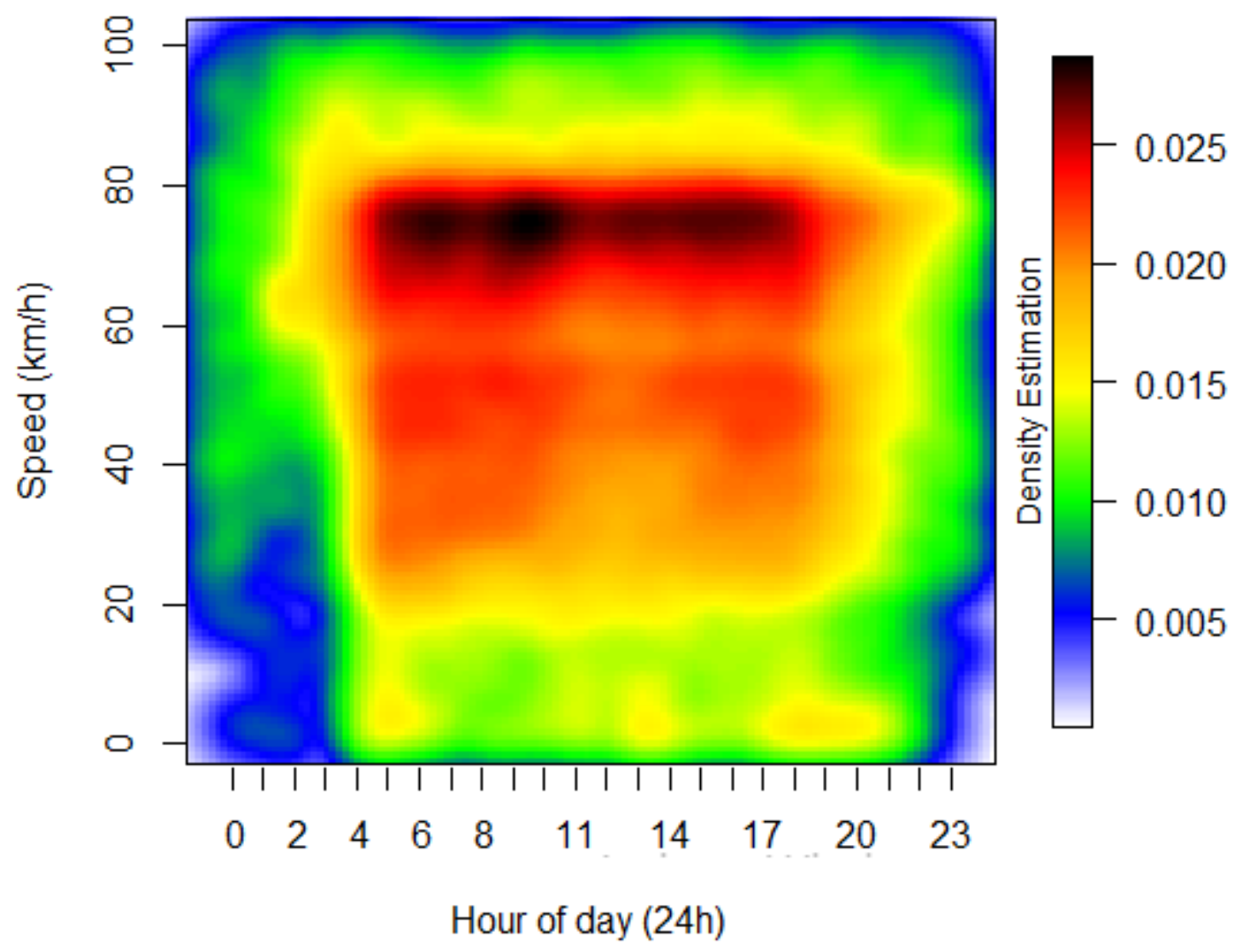

5.3(f): Rod. Anhanguera, segment 10, directed to Americana 


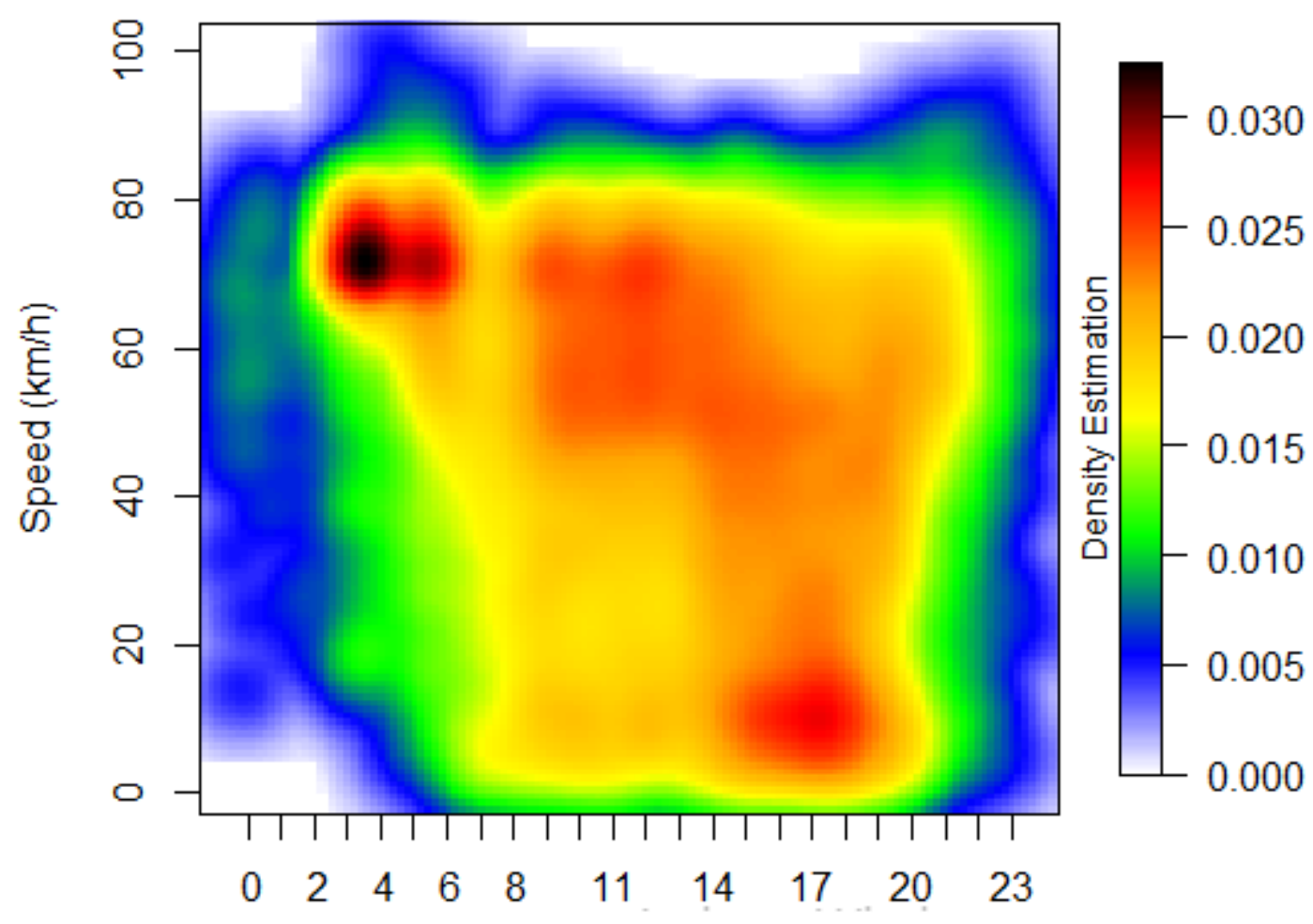

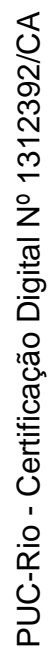

Hour of day (24h)

5.3(g): Rod. Fernão Dias, segment 5, directed to Betim

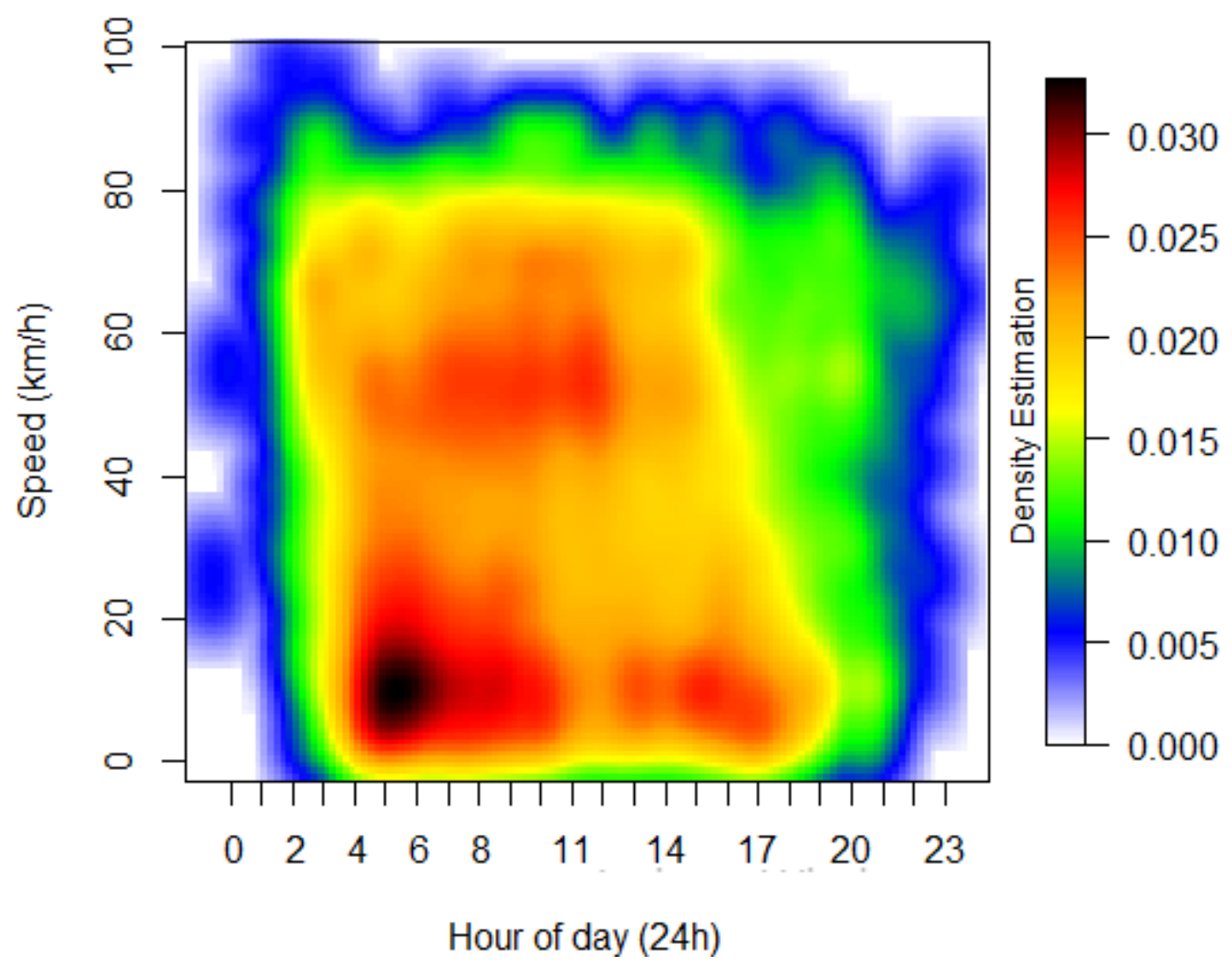

5.3(h): Rod. Fernão Dias, segment 15, directed to Belo Horizonte

Figure 5.3: Temporal analysis of a road segment speed varying over time. 


\section{3}

\section{Proposed Solution}

The proposed solution is a model based on the described spatio-temporal partitions to obtain mean speed predictions of a road. This model will predict the mean speed for a given road segment at a given hour of the day. The main idea is to group speed observations by two factors: the segment where it occurred, and the hour of the day when it was observed. To distinguish it from other models the word "STM" (Spatio-Temporal Model) will be used to reference it.

\subsection{1}

\section{Concept}

STM construction can be divided in 3 steps. The first step consists in calculating the mean speed observed from each pair of consecutive signals of the same vehicle, in order to use them as speed observations on each road segment the underlying pair travelled through. The second step is to add the instantaneous speed provided with the GPS signal in the exact road segment it was collected. Figure 5.4 visually illustrates procedures for both steps 1 and 2. The third and final step is to group speeds at each segment by the hour of the day that they were observed, meaning that each segment will be divided into 24 subgroups ( 24 hours), in which each subgroup will contain the average of all speed observations occurred in that segment at that hour.

Accurate Instantaneous GPS Speeds are usually calculated using Doppler Shifts (Townshend et al., 2008) and will only be available if the GPS device supports this functionality. When unavailable, the second step of the building procedure can be ignored in favour of a model variation using only the calculated mean speeds from each consecutive pair of the same vehicle. Prediction performance from both STM variations, using only instantaneous speeds and using only calculated mean speeds, were compared with STM (which uses both instantaneous and mean speeds) indicating that, while STM was superior in overall, MAE results varied at a maximum of $10 \%$ from its variations. 


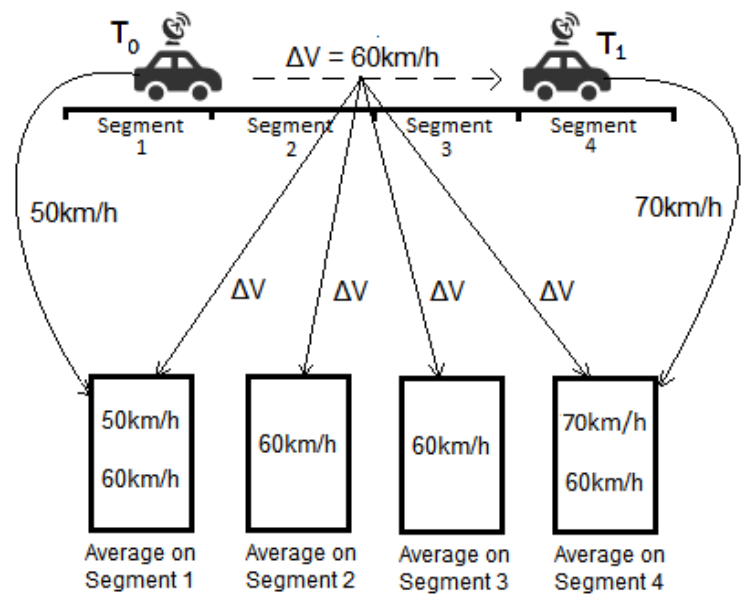

Figure 5.4: Spatio-temporal model based on instantaneous and mean speed observations

\subsection{2}

\section{Implementation}

Once Road Match was properly addressed, time complexity for STM can be analysed based on the pseudo-code described in Algorithm 5.1. The overall running time is $O(m n)$, where $m$ is the number of segments of the road and $n$ is the number of observations. Most of the complexity is defined at training phase, since prediction can be executed in constant time. Memory complexity is $O(m)$, since it must contain the accumulated speed and count (segment[0] and segment[1], respectively) for each hour of every segment. 


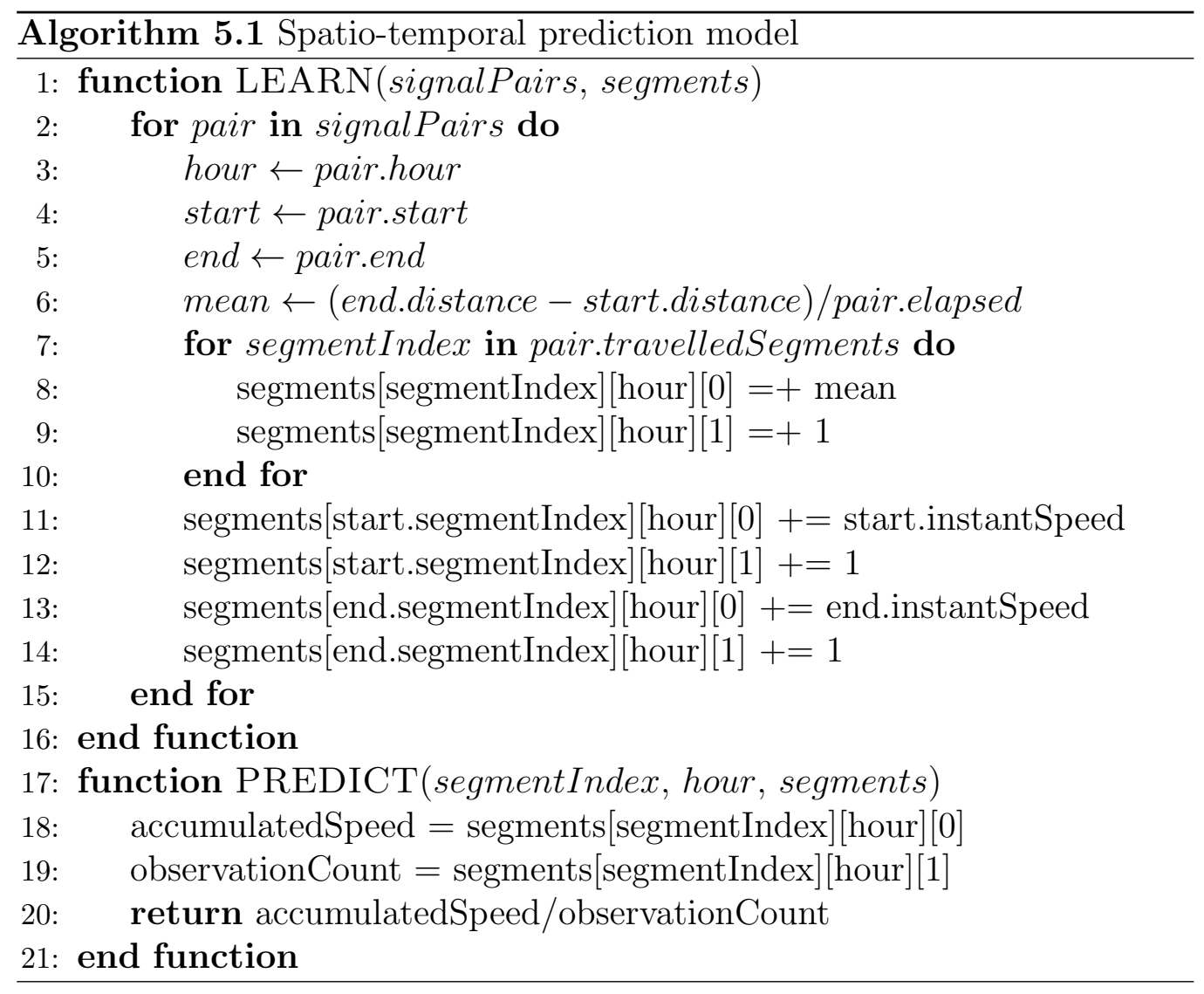




\section{6}

\section{Experiments}

Prediction experiments were carried out using 10 million signals from 10 thousand distinct fuel trucks in raw GPS format. This data contains all signals generated during the year of 2013, along with signals from the first two months of 2014, in four different roads: Avenida Brasil, Rodovia Anhanguera, Rodovia Rio Teresópolis and Rodovia Fernão Dias, as previously mentioned.

\section{1}

\section{Experimental Setup}

Data was sorted by date in ascending order and then divided into 3 different subsets: training, validation and test. The date sort is important in order to assure that prediction is based only on historic observations, excluding current and future ones while the subsets training, validation, and test sets, with sizes $64 \%, 16 \%, 20 \%$, respectively, are a commonly used learning strategy to avoid over-fitting. Using this methodology, subsets training and validation contained only data from 2013, while the test subset contained only data from 2014.

\section{2}

\section{Evaluation Measures}

Four measures were used to compare the results of the methods: RMSE, MAE, MAD, and MAPE.

Root Mean Squared Error (RMSE) is one of the most commonly used metrics for regression models, it represents the prediction error standard deviation and is defined as: $\sqrt{\frac{1}{n} \sum_{i=1}^{n}\left(\hat{Y}_{i}-Y_{i}\right)^{2}}$. 
Mean Absolute Error (MAE) is also a commonly used metric for regression and is being adopted as the reference metric in this study in favor of RMSE. It is less influenced by outliers and thus closer to what this study tries to measure. MAE is defined as follows: $\frac{1}{n} \sum_{i=1}^{n}\left|\hat{Y}_{i}-Y_{i}\right|$.

Median Absolute Deviation (MAD) is a statistically robust measure of the prediction error variability and is defined as: median $\left(\mid \hat{Y}_{i}-\operatorname{median}\left(\mid \hat{Y}_{j}-\right.\right.$ $\left.\left.Y_{j} \mid\right) \mid\right)$.

Mean Absolute Percentage Error (MAPE) is another commonly used metric for regression models. It measures prediction accuracy as a percentage value indicating how much of an observation can be predicted, in average, using the specified model. MAPE is defined as follows: $\frac{1}{n} \sum_{i=1}^{n}\left|\frac{Y_{i}-\hat{Y}_{i}}{Y_{i}}\right|$.

\section{3}

\section{Implemented Methods}

To understand the performance of STM an instantaneous speed prediction experiment was proposed using five methods. Method 1 uses the road mean speed as the predicted speed. Method 2 calculates a mean speed for each road segment and uses the mean speed at the segment where the sample was collected as the predicted speed. Method 3 calculates a mean speed for each hour of the day and uses the mean speed at the hour that sample was collected as the predicted speed. Method 4 represents the baseline, using Support Vector Regression on 2 features: distance (from road start) and hour of the day to predict the speed. Method 5 uses the STM model proposed in this study, which predicts speed based on a road segment and hour of the day.

\section{4}

\section{Experimental Results}

Using the implemented methods, an instantaneous speed prediction experiment was then conducted. Tables 6.1, 6.2, and 6.3 demonstrate prediction results using the metrics MAE, RMSE, and MAD, respectively. Comparing results from MAE, Method 1 was expected to have the worst performance between the implemented methods, but method 4 scored worse 
on Rodovia Fernão Dias. Method 2 consistently outperformed methods 1, 3 , and 4 on every road, indicating that spatial partitions are relevant for prediction, even more relevant than temporal partitions (using hours). It improved prediction error up to $40 \%$ when compared to method 4 , and up to $50 \%$ when compared to method 1 , while also being the best method in one direction of Rodovia Rio Teresópolis. While not as relevant as method 2, method 3 performed, most of the time, better than or near Method 1, indicating that in some roads time partitions will also improve prediction up $10 \%$ when compared to method 1 . Method 4, the baseline, performed better on the roads Rodovia Anhanguera and Rodovia Rio Teresópolis, where speed was more uniform along the road extension, on the other roads, however, it failed to improve prediction, even when compared to method 1 that applied a naive mean. Method 5 (STM) outperformed all of the other implemented methods, with the exception of a direction on Rodovia Rio Teresópolis, and close to the best result on the worst case, indicating that the union of space and time can improve prediction even further than using each dimension separately. STM improved prediction up to $55 \%$ when compared to method $1,40 \%$ when compared to method $2,55 \%$ when compared to method 3 , and $50 \%$ when compared to method 4.

Running times for both methods 4 and 5 are presented in Table 6.4, method 5 was up to seven times faster than method 4, using LIBLINEAR (Fan et al., 2008), the fastest SVR implementation available at the time of writing.

Comparing STM with its baseline, Figures 6.1 and 6.2 show a heat map representing the estimated velocity from methods 4 and 5 , for each road in each direction. Contour lines were added to delimite speed regions relative to both time and space dimensions. The number of regions identified using method 5 were considerably greater than the ones identified with method 4 (SVR). Visually, method 4 demonstrated difficulty at identifying suddenly decreases or increases in speed when compared to method 5 (STM), a deficiency that may render it inferior at identifying either spatial or temporal patterns, possibly justifying why method 5 achieved superior prediction results. While method 5 had middle regions shifting speed, method 4 appears 
to choose a direction to always increase or decrease it in a generalized smooth behaviour, as if speed could not change drastically in the middle of the road, or the day, and get back to the average speed again in later observations.

Performance from method 5 can be further analyzed in Figures 6.3 and 6.4. For each road, two plots were generated: one to demonstrate the absolute error growth over the observation population, and another to demonstrate the absolute error distribution. The first plot was used to visualize the curve slope as the absolute error grows, and results indicated that $60 \%$ to $70 \%$ of the observations had an error lesser than or equal to the MAE. The second plot was important to give another view of the results, having higher concentrations on lower values, and smaller concentration on higher values is an indication that STM is performing accordingly.

A last experiment was conducted to predict ETA. While instantaneous speed prediction refers to a single moment of a vehicle during its travel on a road, ETA refers to its whole passage, which constitutes a set of moments where a faulty prediction at a single segment may not influence travel prediction as a whole. ETA can be predicted for a pair of consecutive signals of the same device by dividing the distance it travelled through on each segment by the predicted mean speed of that segment at that same hour. As defined by the equation:

$$
\left(\hat{Y_{1, j}} \times D_{1}\right)+\left(\sum_{i=2}^{n-1} \frac{s}{\hat{Y_{i, j}}}\right)+\left(\hat{Y_{n, j}} \times D_{n-1}\right)
$$

Where $n$ is the number of segments the pair travelled through, $s$ is the size of a segment in kilometres, $\hat{Y}_{i, j}$ is the predicted mean speed of travelled segments set on index $i$ at hour $j$, and $\hat{D}_{i}$ is the distance travelled on travelled segments set at index $i .6 .5$ presents results of the ETA experiment. Near state of the art results were achieved in Rodovia Rio teresópolis (14\% and 16\% of error) and Rodovia Anhanguera (16\% and 17\% of error), while Avenida Brasil and Fernão Dias proved to be challenger. These results are impressive considering that no real time data was used, and that predictions ranged from 1 to 2 months ahead of the training data, contrary to the current state of the art models, which require real time data and are focused on short-time 
predictions.

Table 6.1: Mean Absolute Error $(\mathrm{km} / \mathrm{h})$

\begin{tabular}{ccccccc}
\hline \hline \multirow{2}{*}{ Road } & \multirow{2}{*}{ Direction } & \multicolumn{5}{c}{ Method } \\
& & 1 & 2 & 3 & 4 & 5 \\
\hline Av. Brasil & 1 & 25.52 & 20.26 & 23.78 & 24.03 & $\mathbf{1 1 . 9 6}$ \\
Av. Brasil & 2 & 25.78 & 19.98 & 25.19 & 22.59 & $\mathbf{1 3 . 9 2}$ \\
Rod. Anhanguera & 1 & 12.48 & 10.40 & 12.46 & 11.02 & $\mathbf{8 . 3 3}$ \\
Rod. Anhanguera & 2 & 13.45 & 9.97 & 13.47 & 11.95 & $\mathbf{8 . 1 5}$ \\
Rod. Rio Teresópolis & 1 & 15.14 & 7.99 & 15.09 & 9.85 & $\mathbf{6 . 9 6}$ \\
Rod. Rio Teresópolis & 2 & 14.64 & $\mathbf{9 . 2 3}$ & 14.57 & 12.84 & 9.42 \\
Rod. Fernão Dias & 1 & 22.65 & 20.97 & 20.48 & 28.69 & $\mathbf{1 5 . 6 1}$ \\
Rod. Fernão Dias & 2 & 20.61 & 17.19 & 19.99 & 28.28 & $\mathbf{1 5 . 8 3}$ \\
\hline
\end{tabular}

Table 6.2: Root Mean Squared Error $(\mathrm{km} / \mathrm{h})$

\begin{tabular}{ccccccc}
\hline \hline \multirow{2}{*}{ Road } & Direction & \multicolumn{5}{c}{ Method } \\
& & 1 & 2 & 3 & 4 & 5 \\
\hline Av. Brasil & 1 & 28.45 & 23.30 & 28.00 & 33.32 & $\mathbf{1 6 . 1 7}$ \\
Av. Brasil & 2 & 27.98 & 23.09 & 28.37 & 32.47 & $\mathbf{1 7 . 8 9}$ \\
Rod. Anhanguera & 1 & 17.89 & 15.91 & 17.89 & 20.18 & $\mathbf{1 4 . 1 5}$ \\
Rod. Anhanguera & 2 & 18.50 & 15.65 & 18.51 & 20.68 & $\mathbf{1 3 . 8 5}$ \\
Rod. Rio Teresópolis & 1 & 19.21 & 12.42 & 19.14 & 17.45 & $\mathbf{1 0 . 8 8}$ \\
Rod. Rio Teresópolis & 2 & 18.82 & $\mathbf{1 3 . 0 4}$ & 18.76 & 20.67 & 13.44 \\
Rod. Fernão Dias & 1 & 25.84 & 25.52 & 24.05 & 37.18 & $\mathbf{1 9 . 6 2}$ \\
Rod. Fernão Dias & 2 & 23.29 & 21.21 & 22.81 & 35.48 & $\mathbf{1 9 . 4 8}$ \\
\hline
\end{tabular}

Table 6.3: Median Absolute Deviation $(\mathrm{km} / \mathrm{h})$

\begin{tabular}{ccccccc}
\hline \hline Road & \multirow{2}{*}{ Direction } & 1 & 2 & 3 & 4 & 5 \\
\hline Av. Brasil & 1 & 10.00 & 8.32 & 11.39 & 13.00 & $\mathbf{5 . 7 2}$ \\
Av. Brasil & 2 & 7.14 & 8.41 & 9.46 & 10.00 & $\mathbf{6 . 9 1}$ \\
Rod. Anhanguera & 1 & $\mathbf{3 . 0 0}$ & 4.15 & 3.43 & 3.00 & 3.09 \\
Rod. Anhanguera & 2 & 4.00 & 4.19 & 4.64 & $\mathbf{3 . 0 0}$ & 3.23 \\
Rod. Rio Teresópolis & 1 & 4.67 & 3.38 & 3.68 & 4.00 & $\mathbf{3 . 2 7}$ \\
Rod. Rio Teresópolis & 2 & 5.00 & 4.37 & 5.07 & 5.00 & $\mathbf{4 . 3 6}$ \\
Rod. Fernão Dias & 1 & 9.08 & 10.47 & 9.76 & 20.00 & $\mathbf{8 . 1 0}$ \\
Rod. Fernão Dias & 2 & 9.00 & 8.63 & 8.87 & 19.00 & $\mathbf{7 . 8 8}$ \\
\hline
\end{tabular}


Table 6.4: Running Times (seconds)

\begin{tabular}{cccccc}
\hline \hline \multirow{2}{*}{ Road } & \multirow{2}{*}{ Direction } & \multicolumn{2}{c}{ Method 4 } & \multicolumn{2}{c}{ Method 5 } \\
& & Training & Test & Training & Test \\
\hline Av. Brasil & 1 & 36.74 & 0.07 & 5.64 & 0 \\
Av. Brasil & 2 & 40.64 & 0.02 & 5.25 & 0 \\
Rod. Anhanguera & 1 & 35.80 & 0.01 & 4.78 & 0 \\
Rod. Anhanguera & 2 & 19.62 & 0 & 4.81 & 0 \\
Rod. Rio Teresópolis & 1 & 17.33 & 0 & 4.09 & 0 \\
Rod. Rio Teresópolis & 2 & 18.76 & 0 & 4.18 & 0 \\
Rod. Fernão Dias & 1 & 18.27 & 0 & 4.93 & 0 \\
Rod. Fernão Dias & 2 & 19.22 & 0 & 5.30 & 0 \\
\hline
\end{tabular}

Table 6.5: Mean Absolute Percentage Error (ETA)

\begin{tabular}{ccc}
\hline \hline Road & Direction & MAPE \\
\hline Av. Brasil & 1 & 0.30 \\
Av. Brasil & 2 & 0.35 \\
Rod. Anhanguera & 1 & 0.14 \\
Rod. Anhanguera & 2 & 0.15 \\
Rod. Rio Teresópolis & 1 & 0.15 \\
Rod. Rio Teresópolis & 2 & 0.14 \\
Rod. Fernão Dias & 1 & 0.22 \\
Rod. Fernão Dias & 2 & 0.31 \\
\hline
\end{tabular}




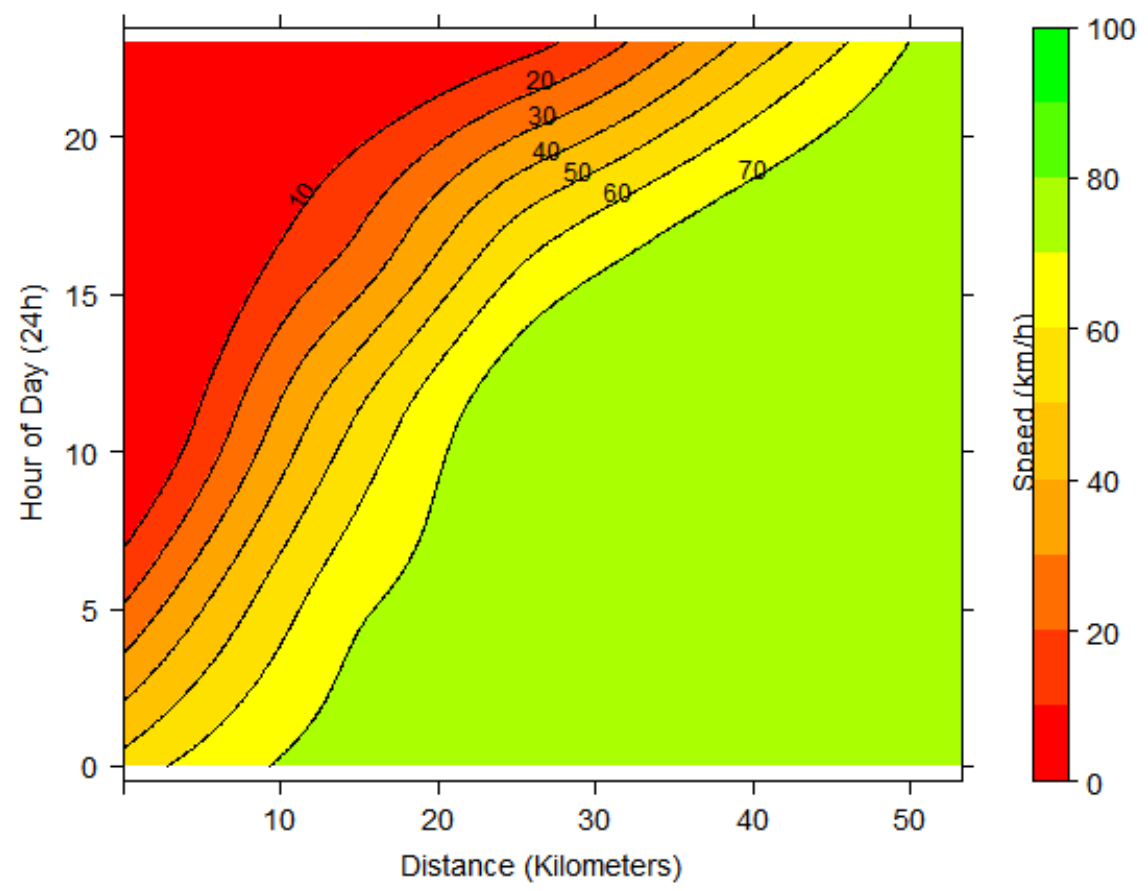

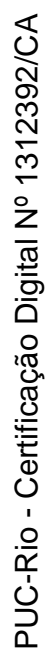

6.1(a): Method 4 on Av. Brasil, directed to Santa Cruz

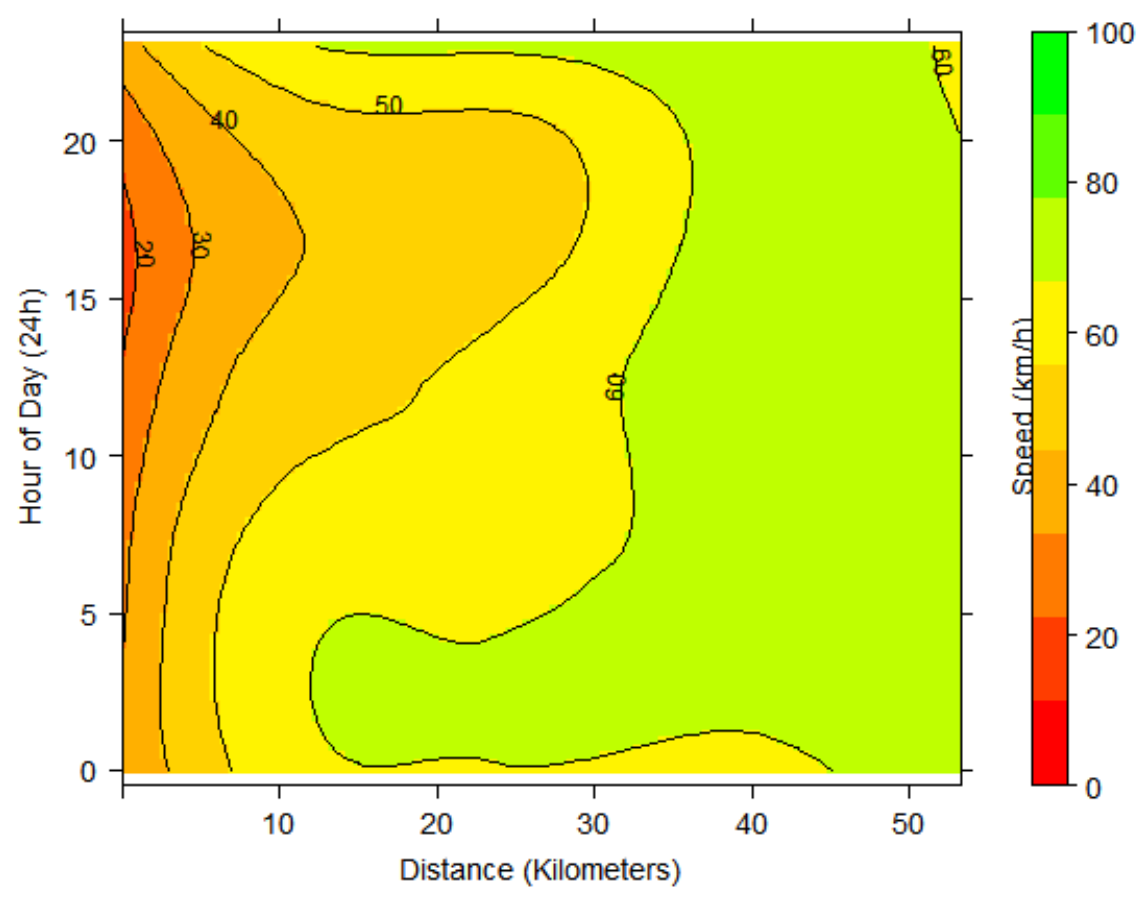

6.1(b): Method 5 on Av. Brasil, directed to Santa Cruz 


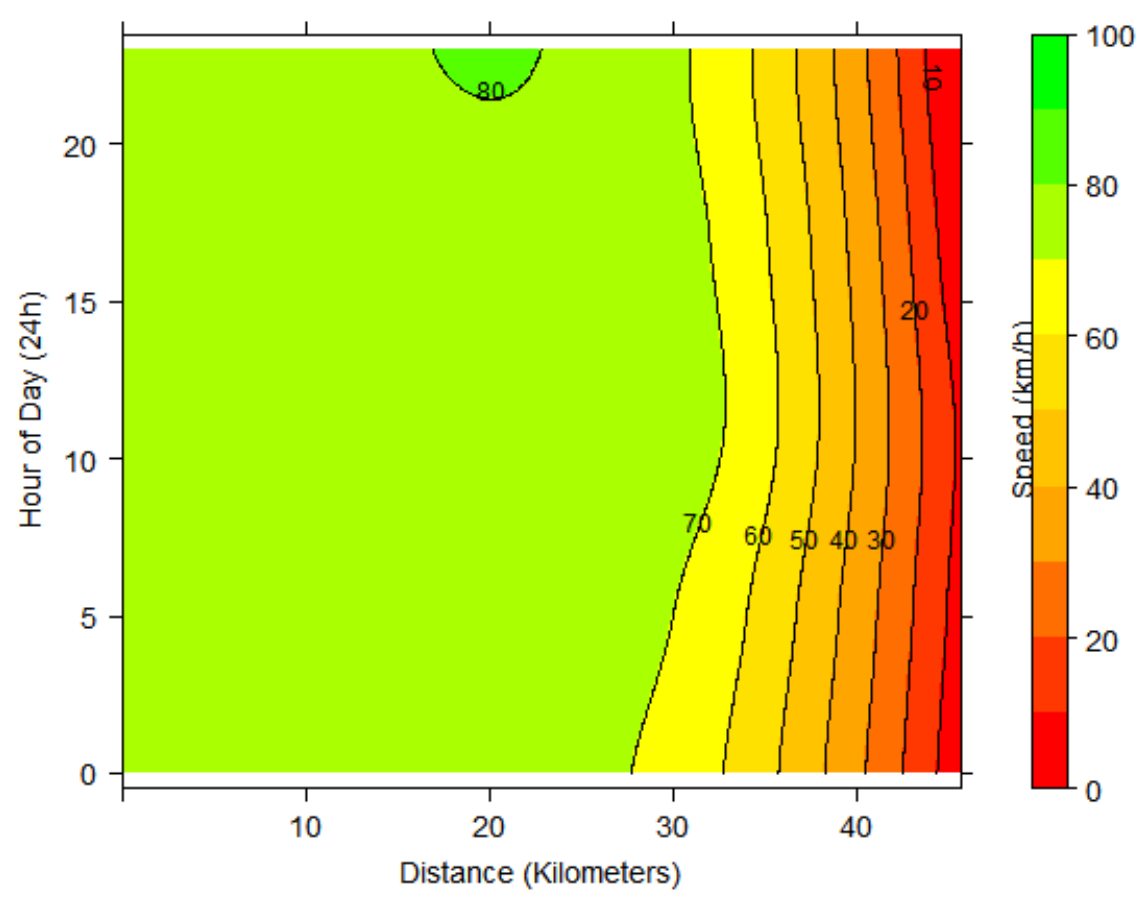

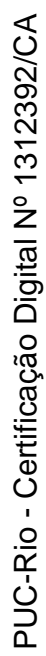

6.1(c): Method 4 on Rod. Rio Teresópolis, directed to Rio

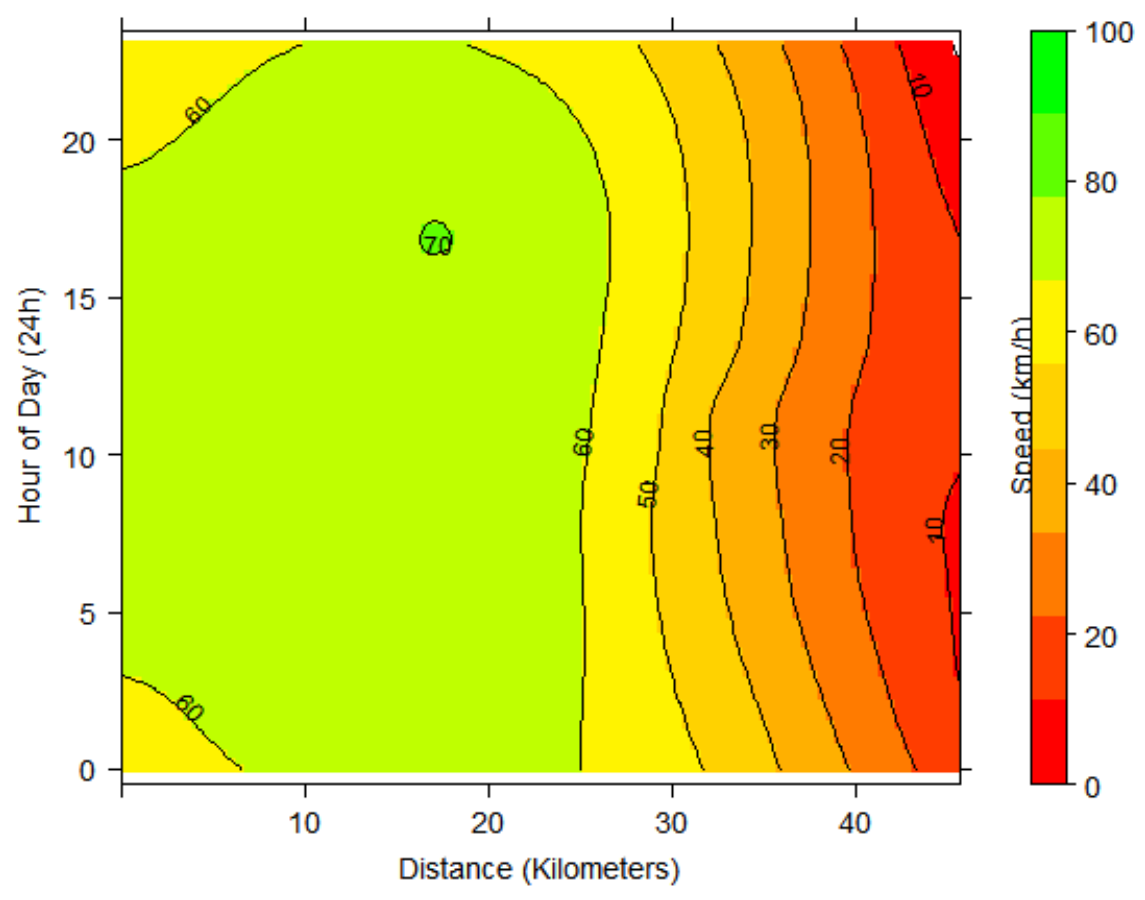

6.1(d): Method 5 on Rod. Rio Teresópolis, directed to Rio 


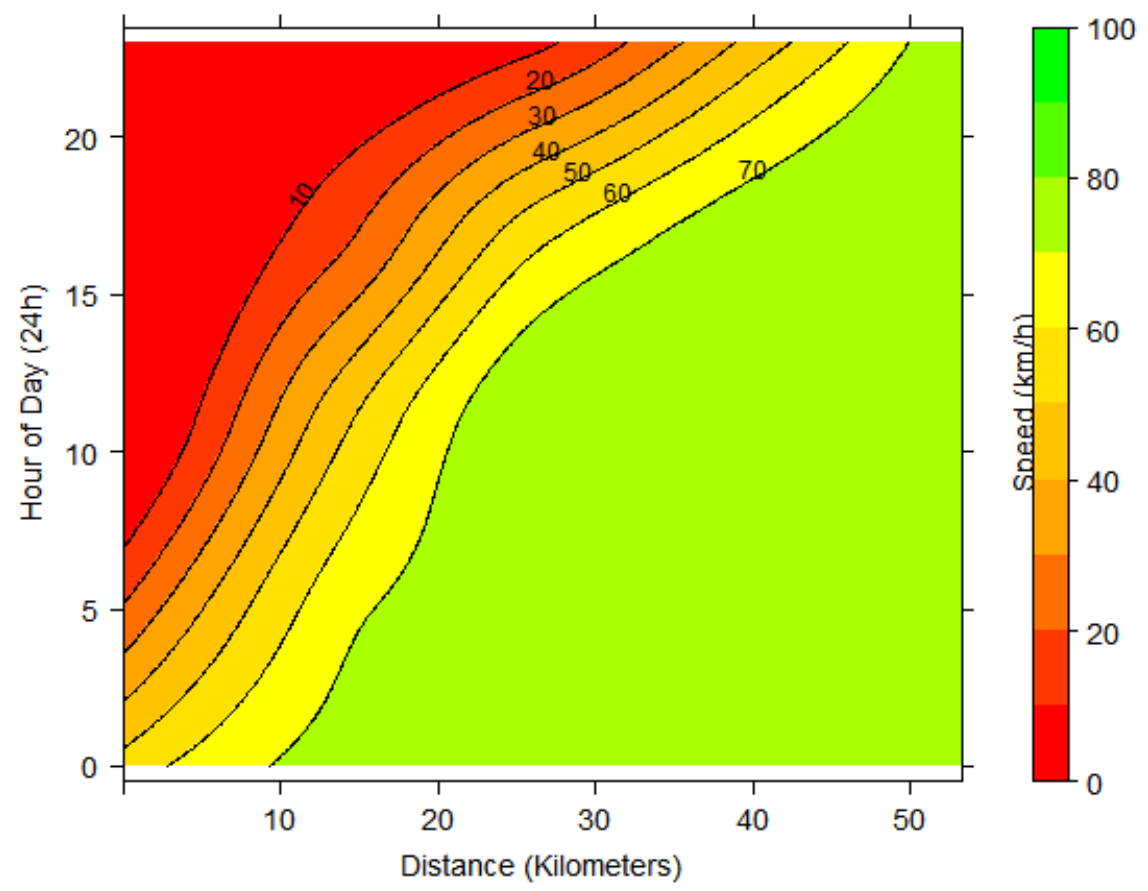

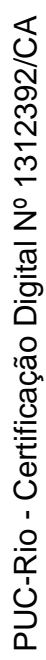

6.1(e): Method 4 on Rod. Anhanguera, directed to Limeira

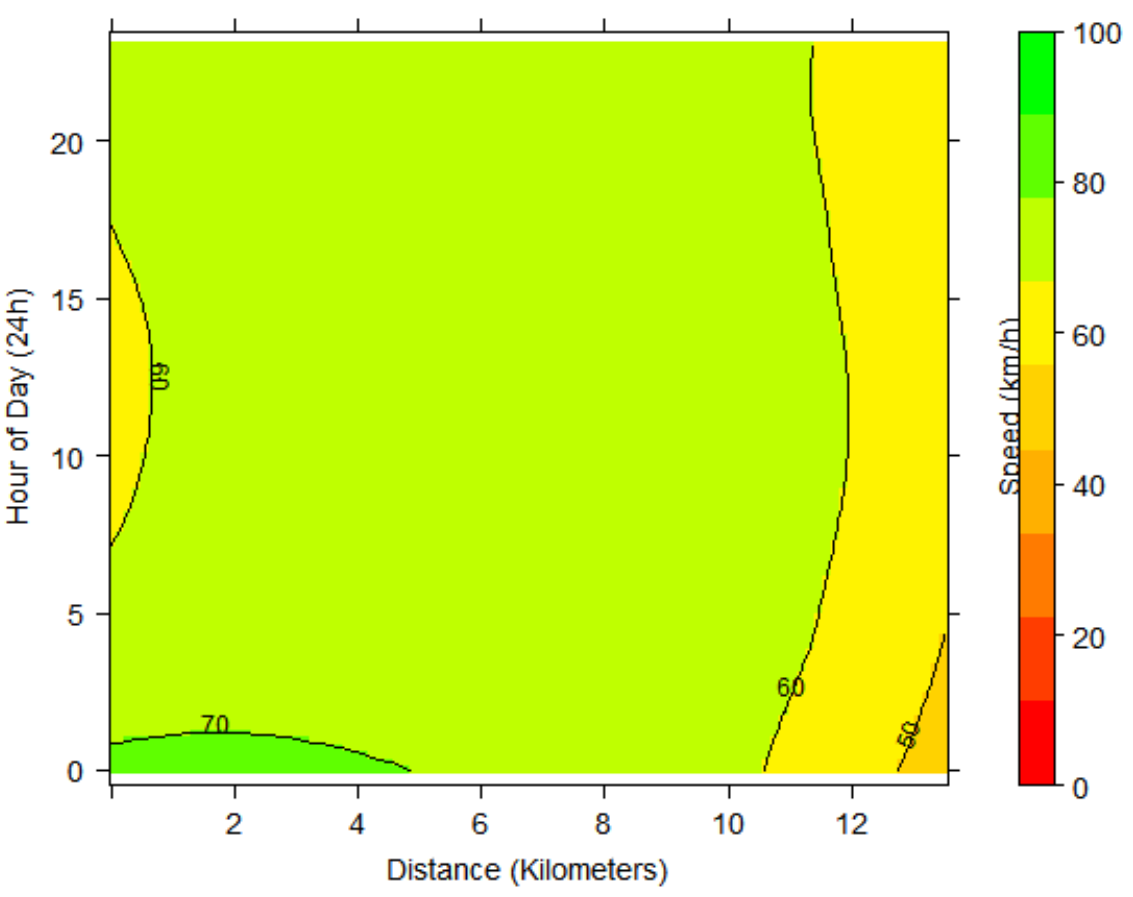

6.1(f): Method 5 on Rod. Anhanguera, directed to Limeira 


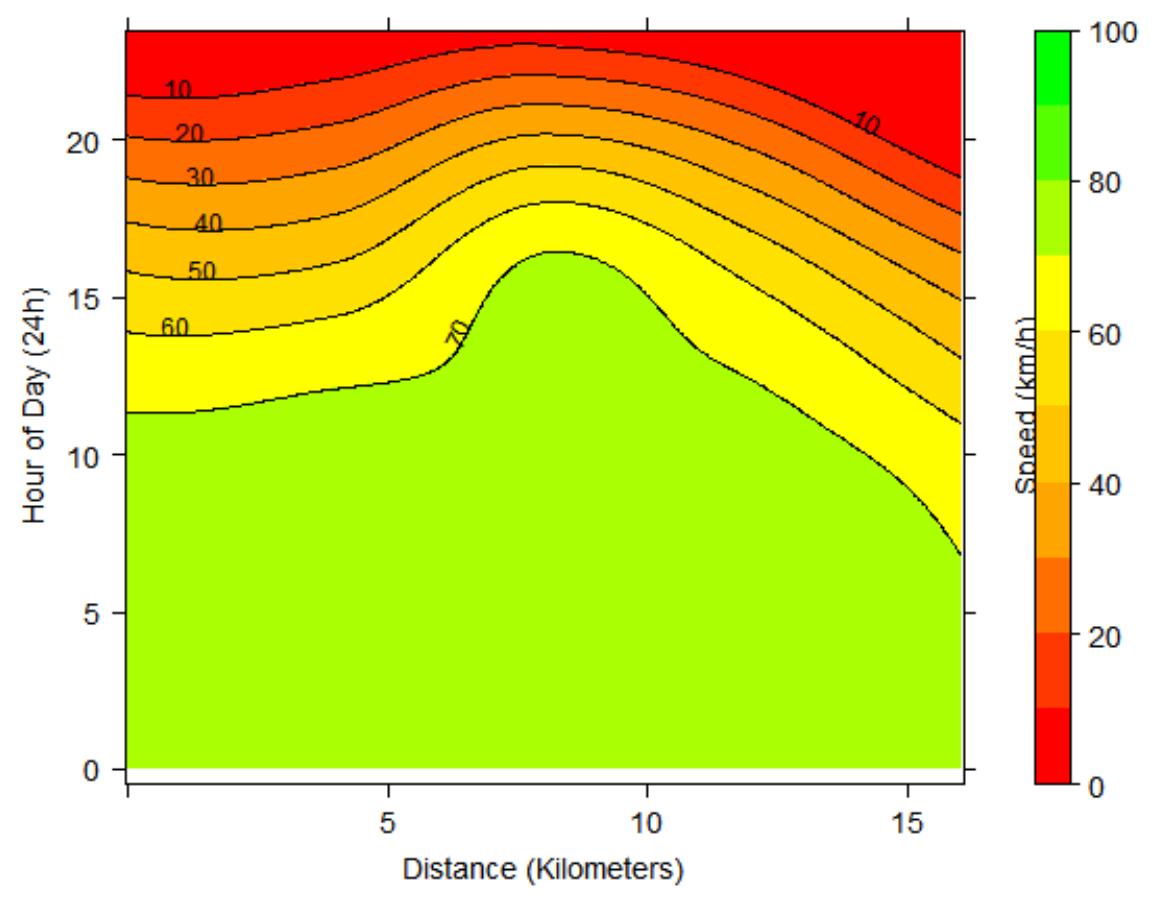

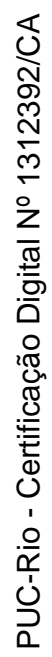

6.1(g): Method 4 on Rod. Fernão Dias, directed to Betim

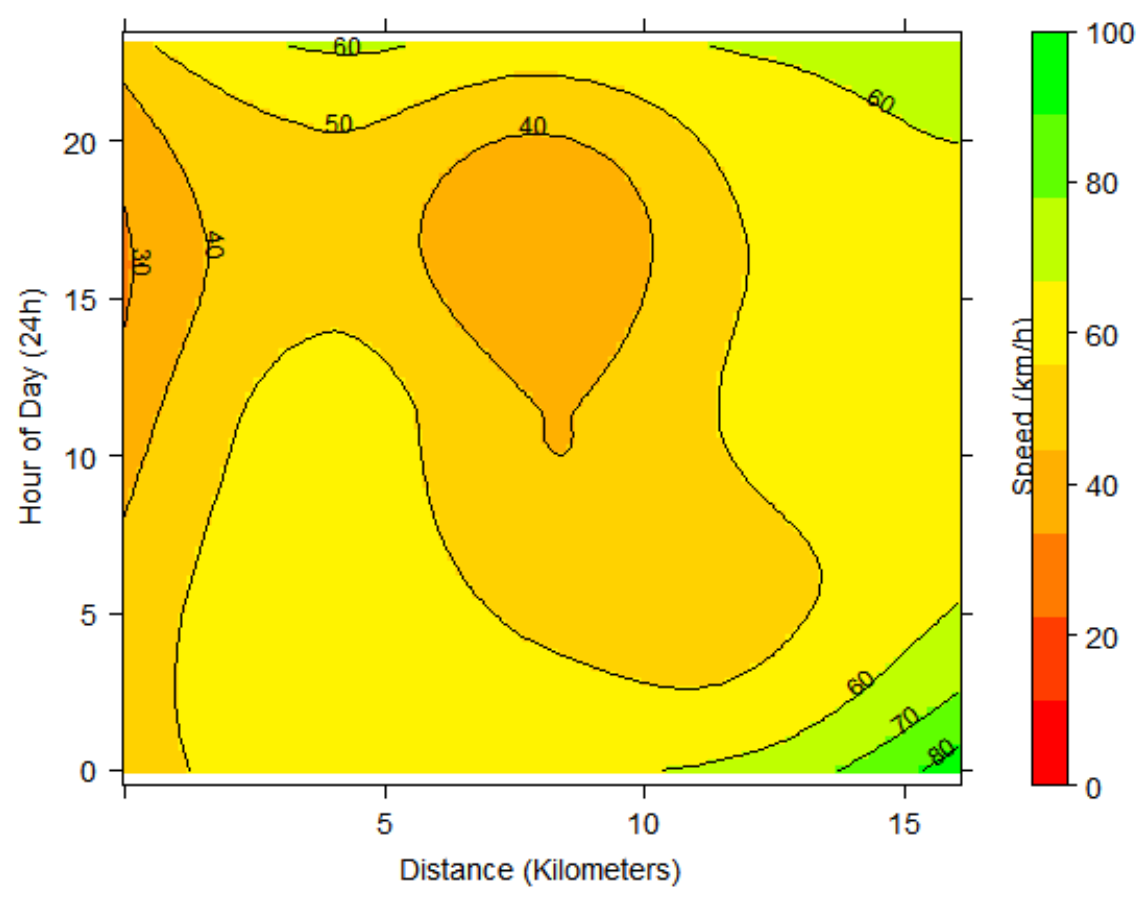

6.1(h): Method 5 on Rod. Fernão Dias, directed to Betim

Figure 6.1: Contour comparison of methods 4 and 5 on direction 1 


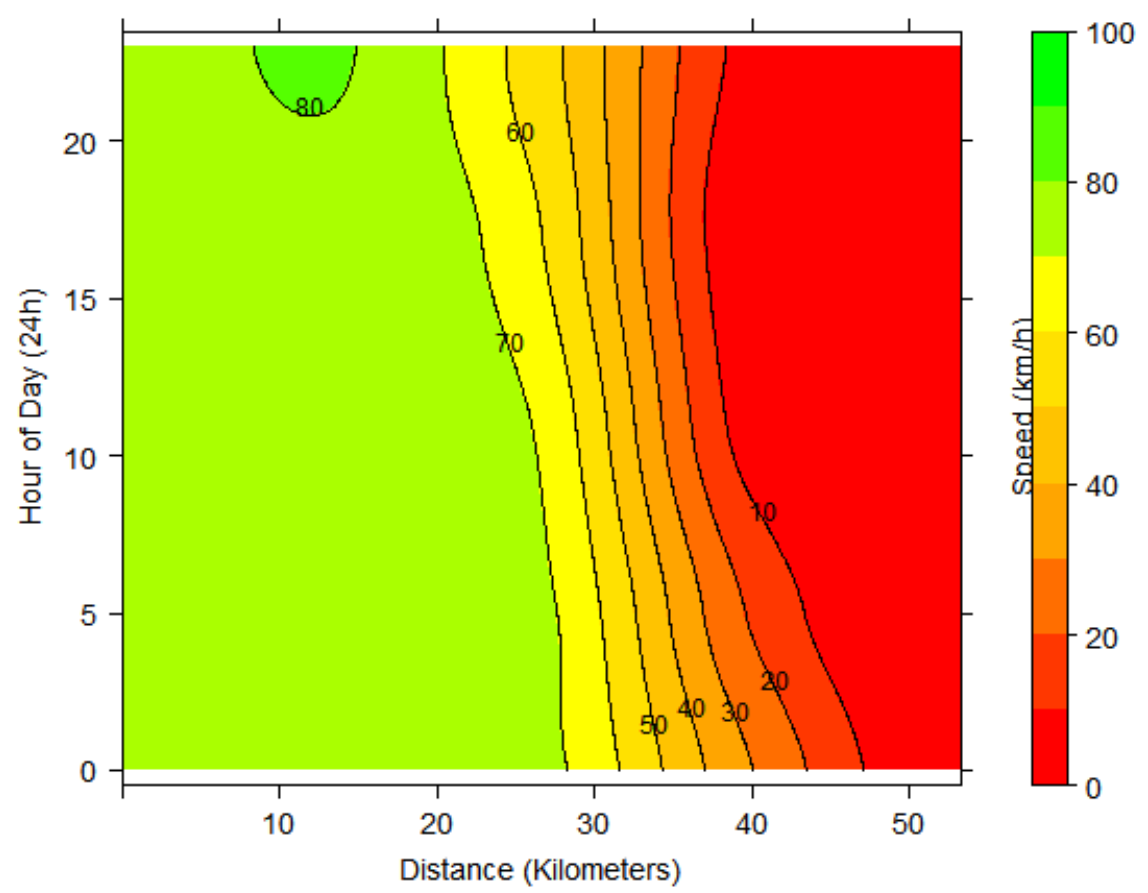

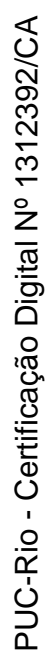

6.2(a): Method 4 on Av. Brasil, directed to Centro

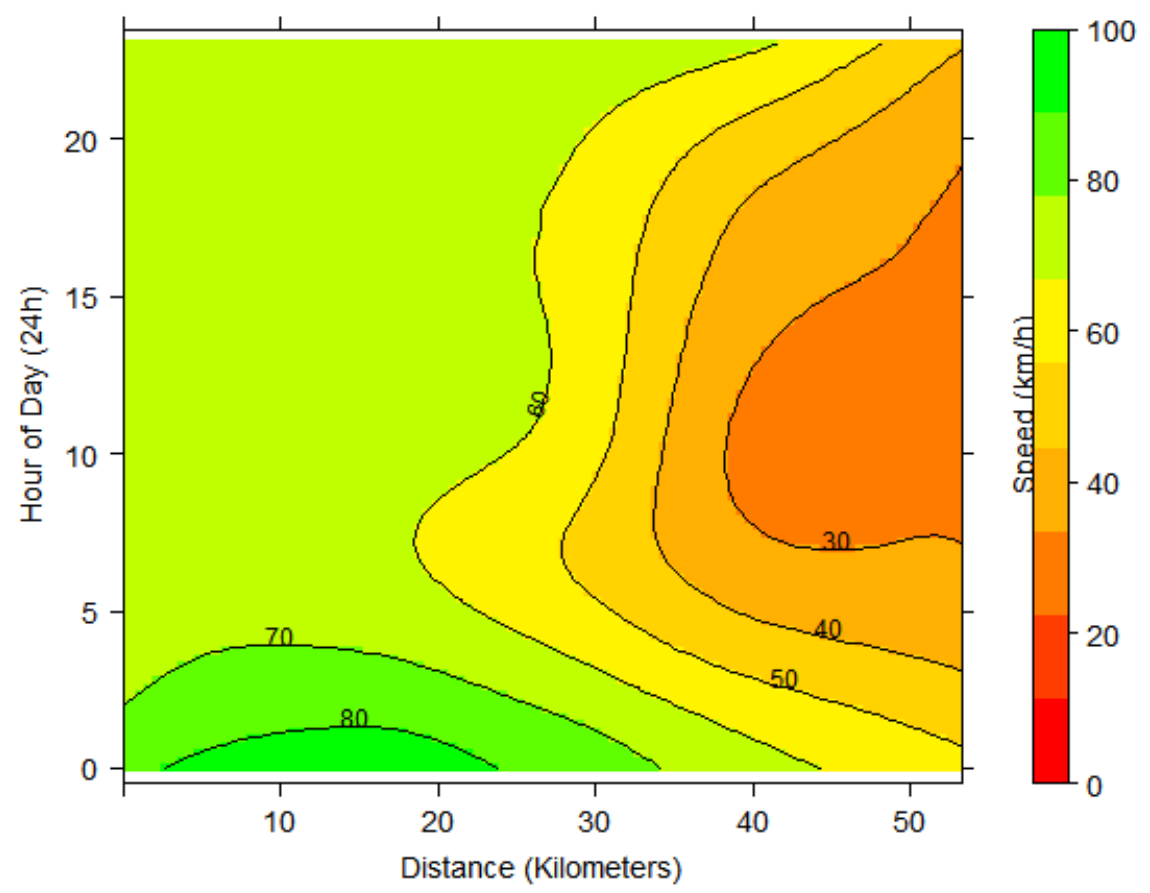

6.2(b): Method 5 on Av. Brasil, directed to Centro 


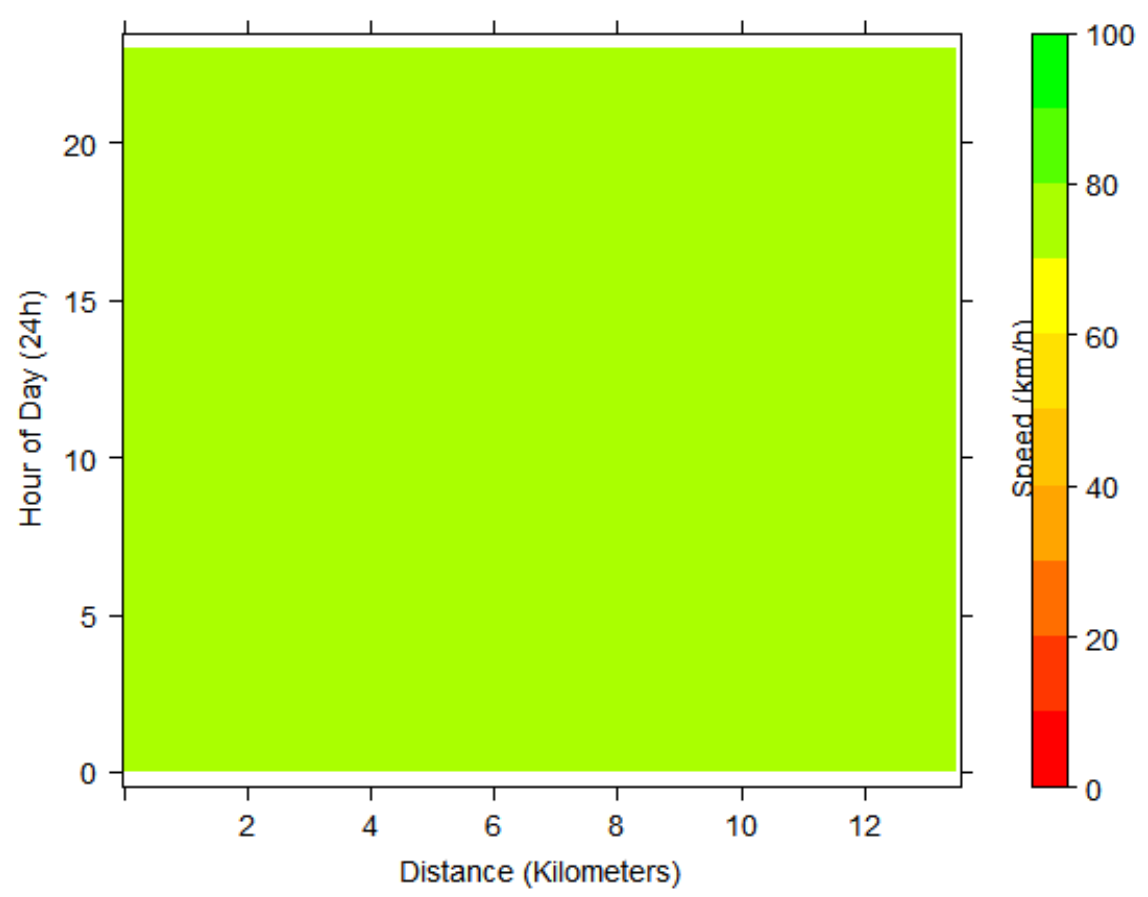

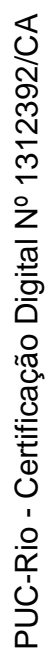

6.2(c): Method 4 on Rod. Rio Teresópolis, directed to Teresópolis

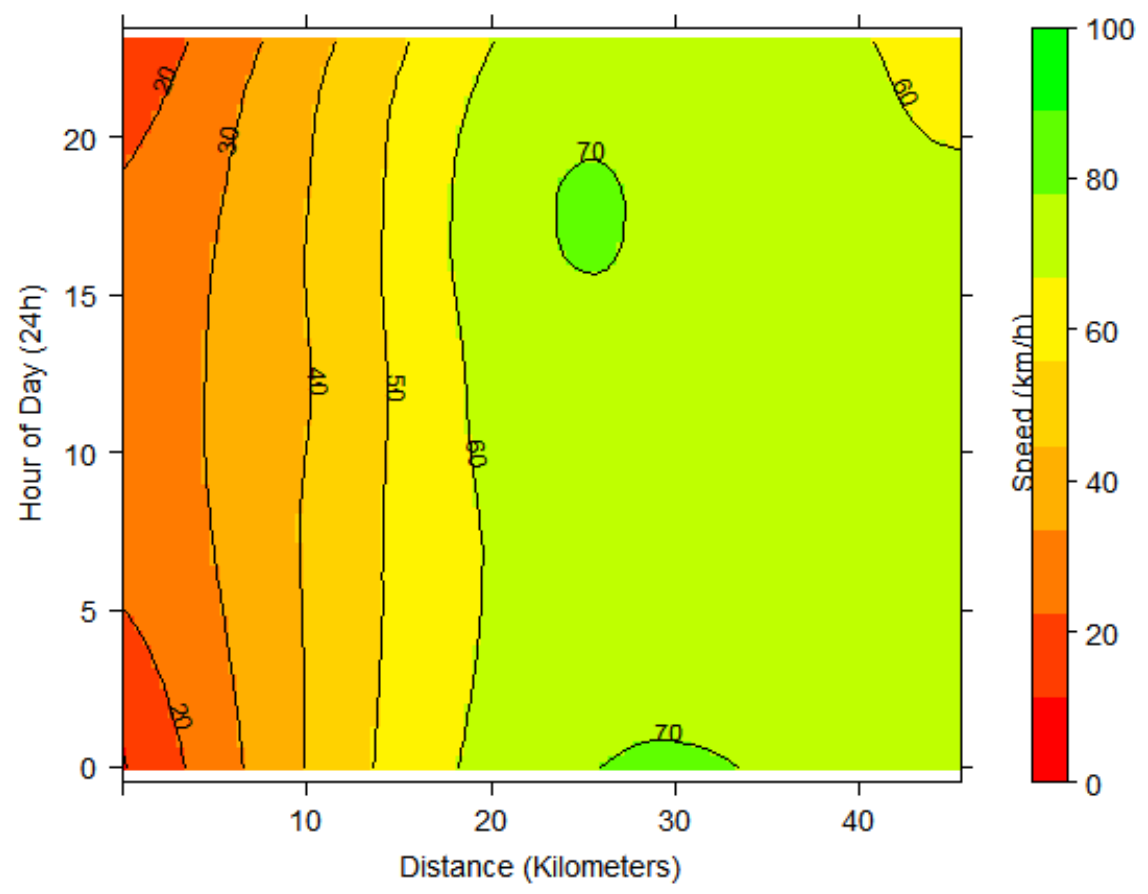

6.2(d): Method 5 on Rod. Rio Teresópolis, directed to Teresópolis 


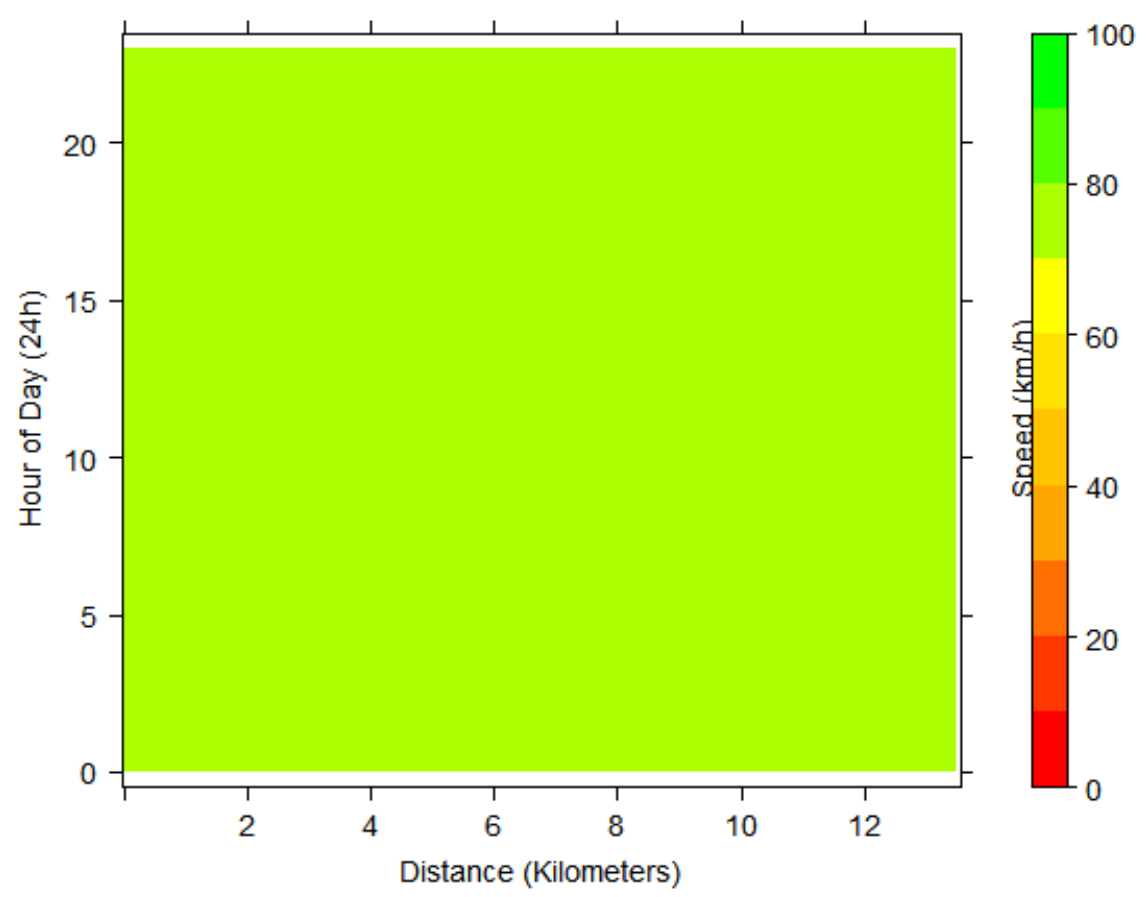

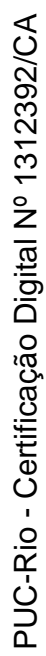

6.2(e): Method 4 on Rod. Anhanguera, directed to Americana

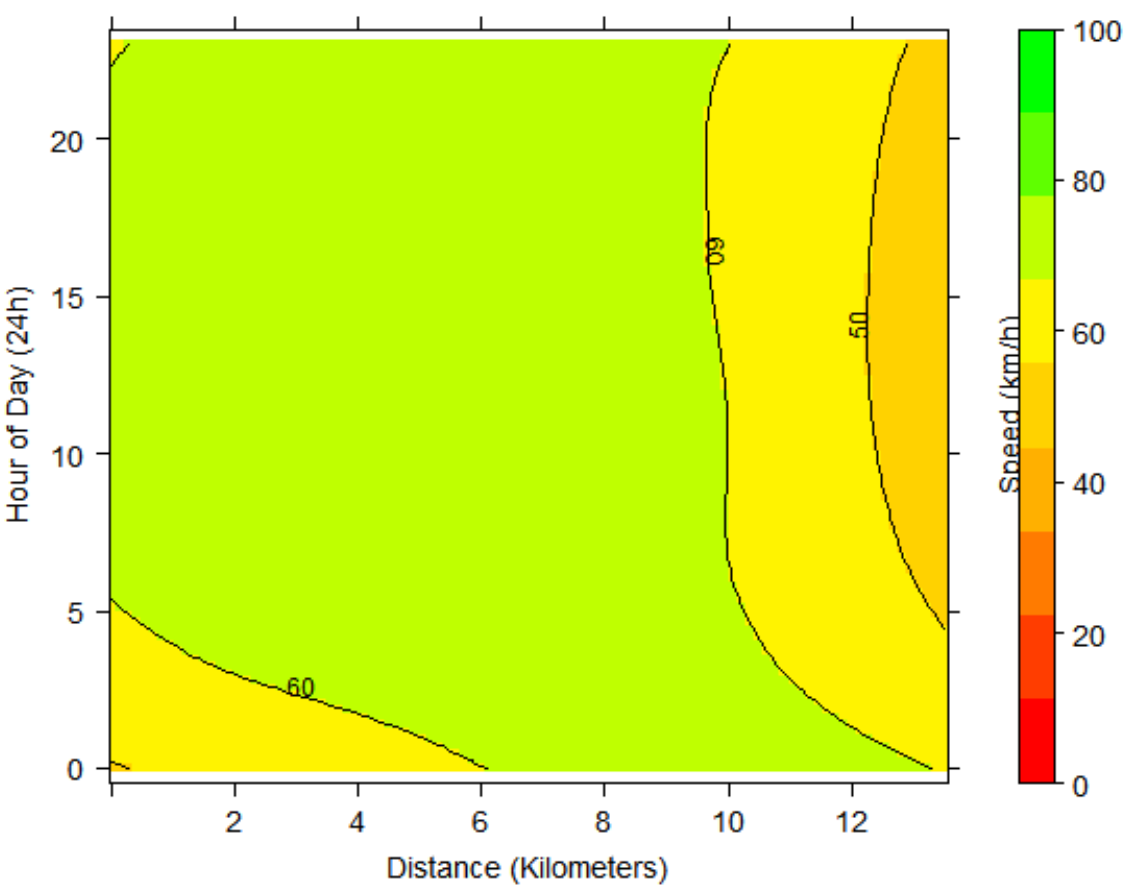

6.2(f): Method 5 on Rod. Anhanguera, directed to Americana 


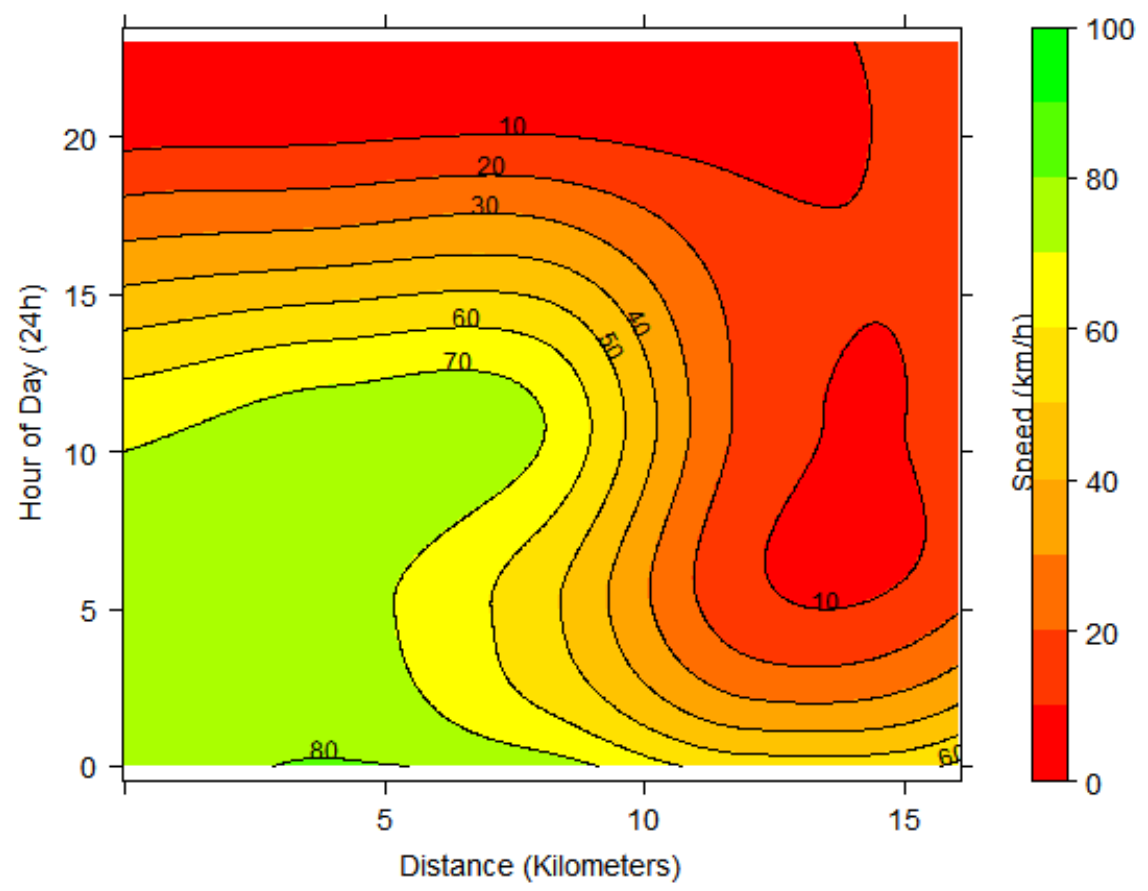

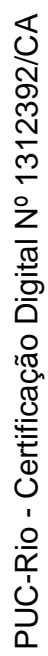

6.2(g): Method 4 on Rod. Fernão Dias, directed to Belo Horizonte

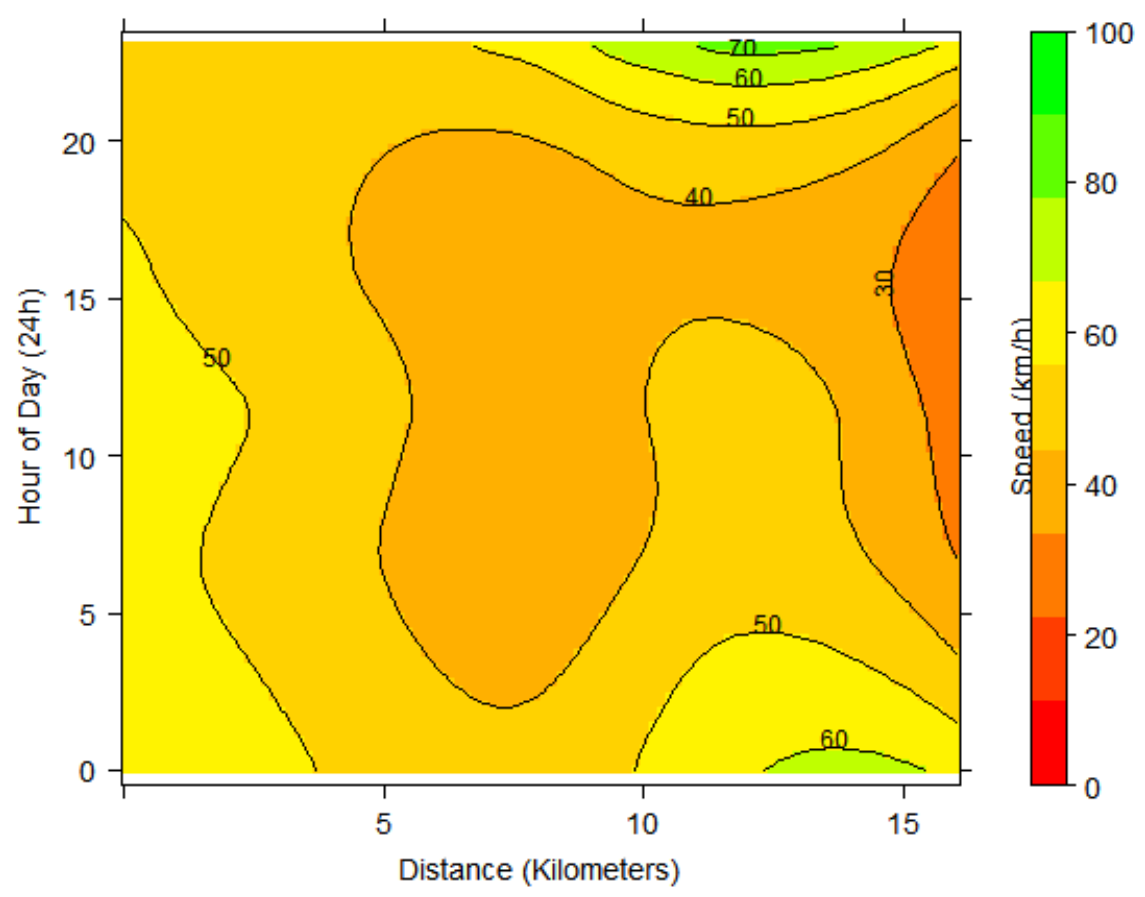

6.2(h): Method 5 on Rod. Fernão Dias, directed to Belo Horizonte

Figure 6.2: Contour comparison of methods 4 and 5 on direction 2 


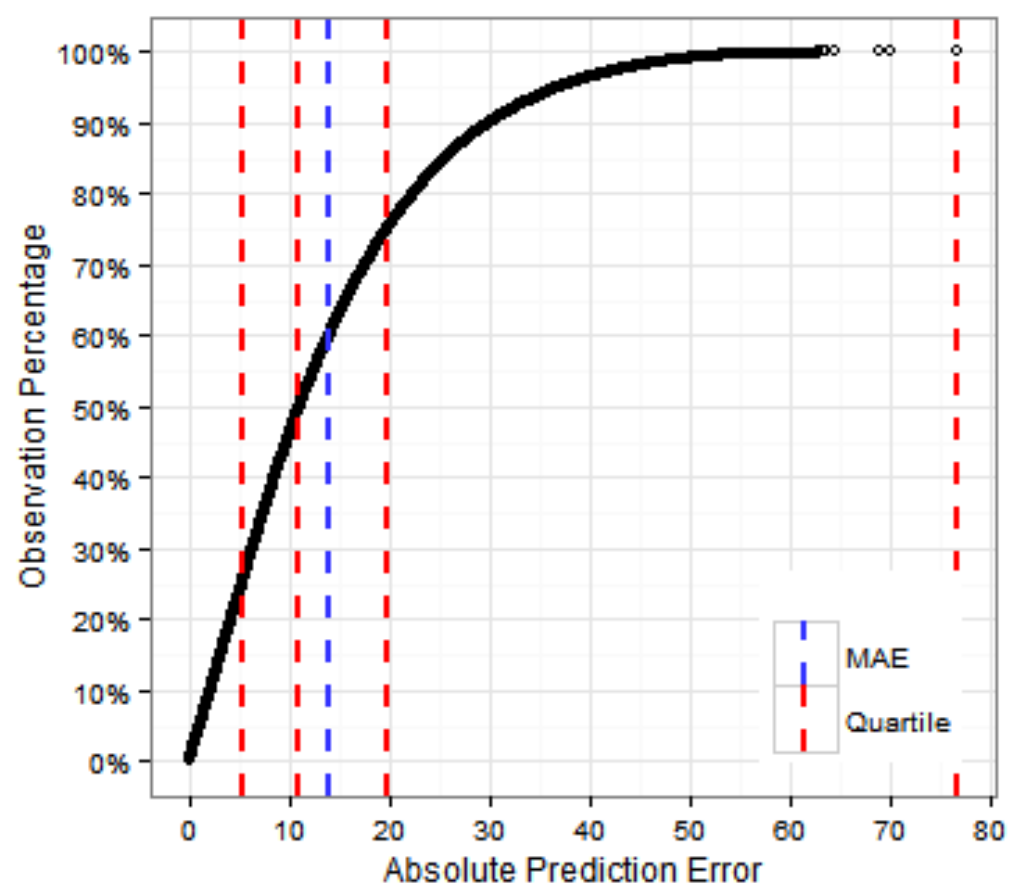

6.3(a): Method 4 on Av. Brasil, directed to Santa Cruz

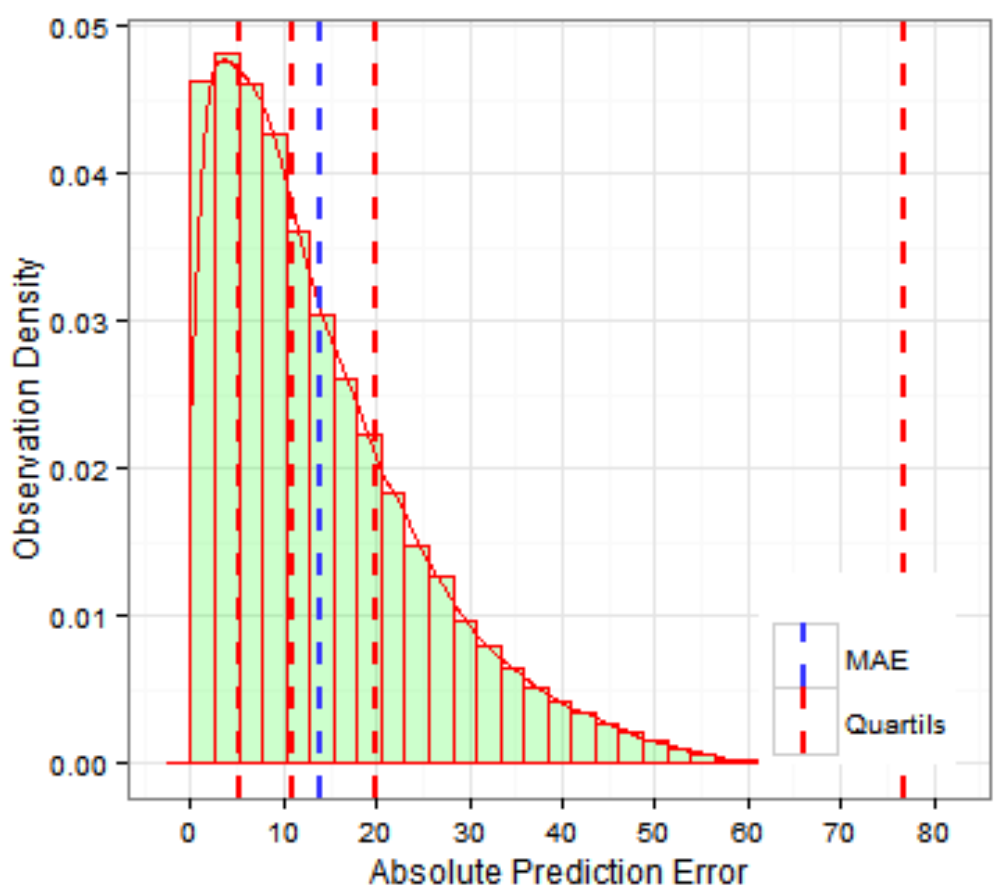

6.3(b): Method 5 on Av. Brasil, directed to Santa Cruz 


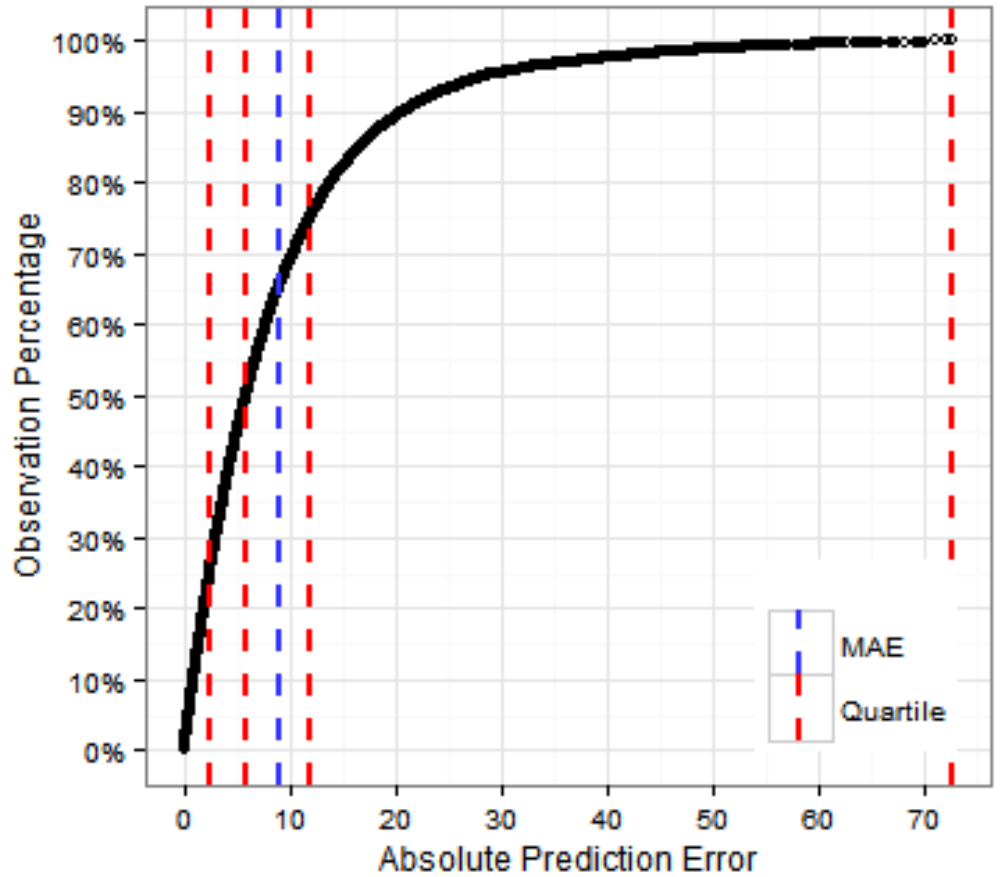

6.3(c): Method 4 on Rod. Rio Teresópolis, directed to Rio

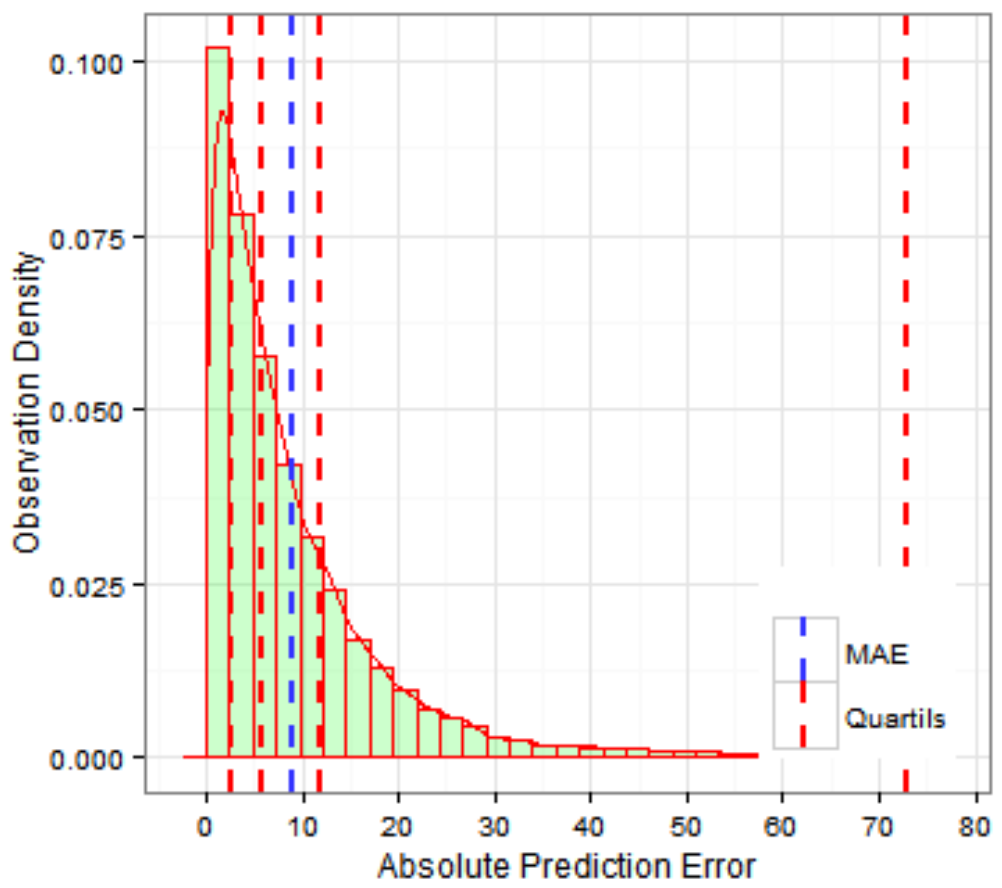

6.3(d): Method 5 on Rod. Rio Teresópolis, directed to Rio 


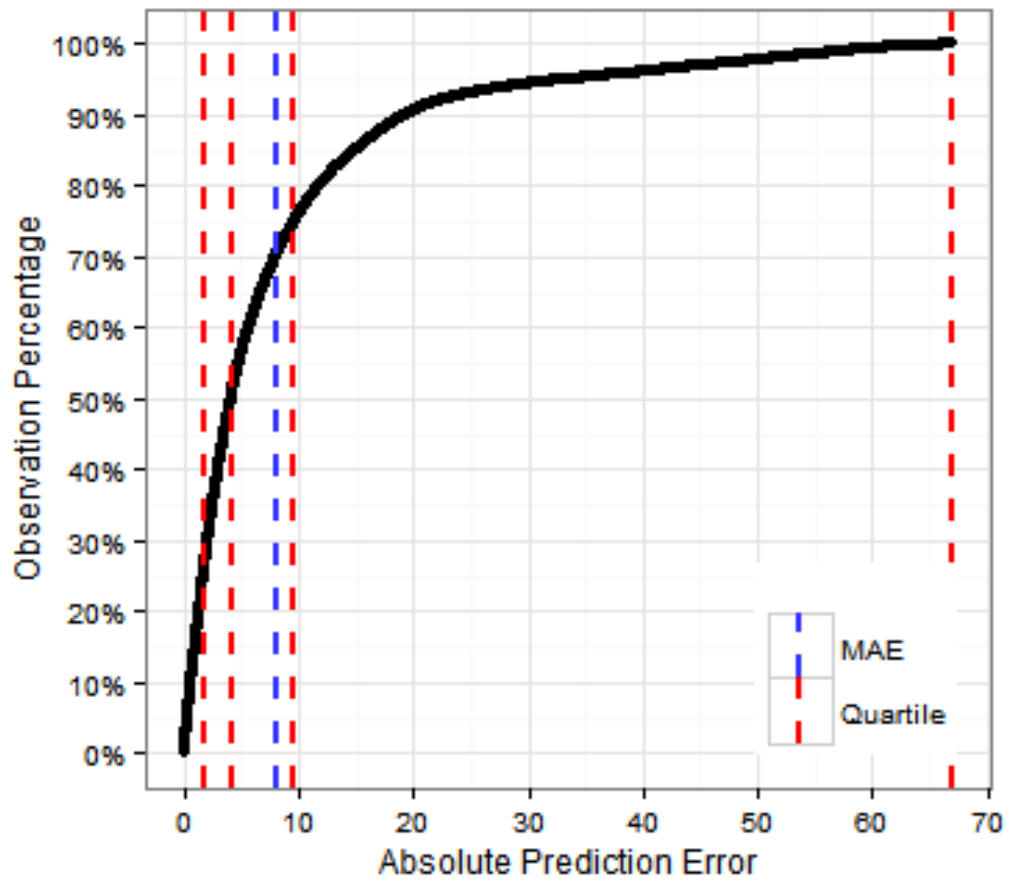

6.3(e): Method 4 on Rod. Anhanguera, directed to Limeira

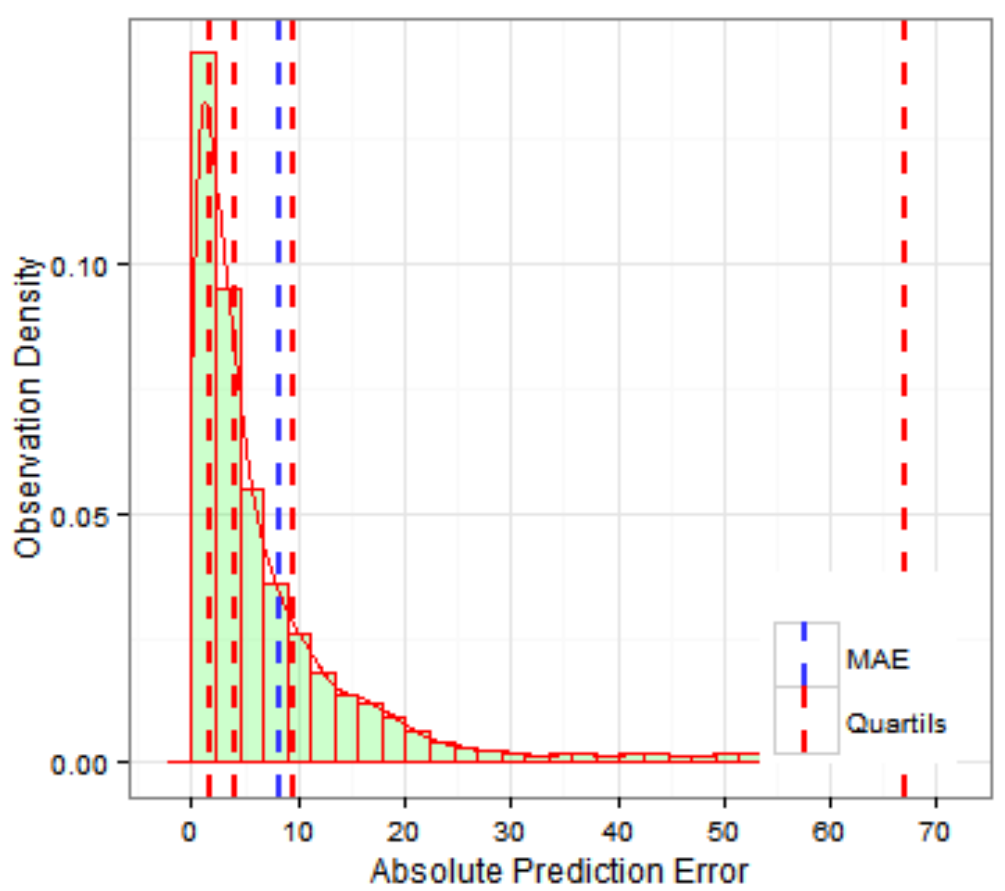

6.3(f): Method 5 on Rod. Anhanguera, directed to Limeira 


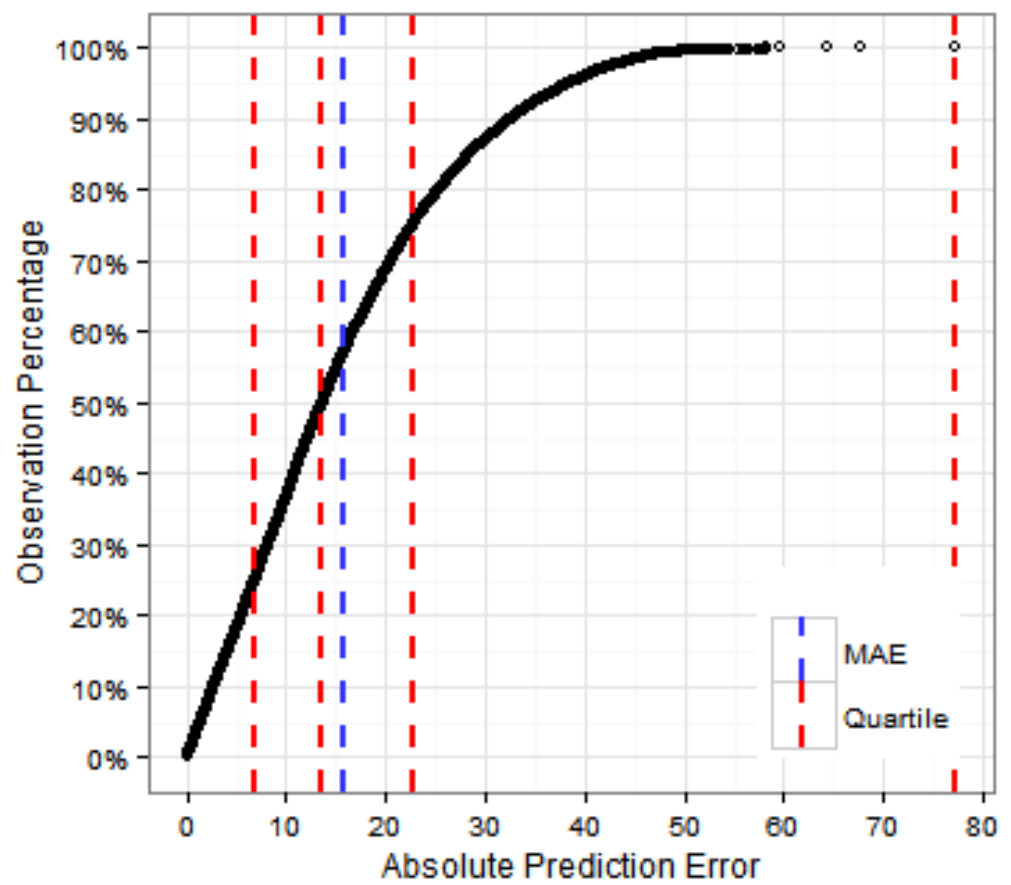

6.3(g): Method 4 on Rod. Fernão Dias, directed to Betim

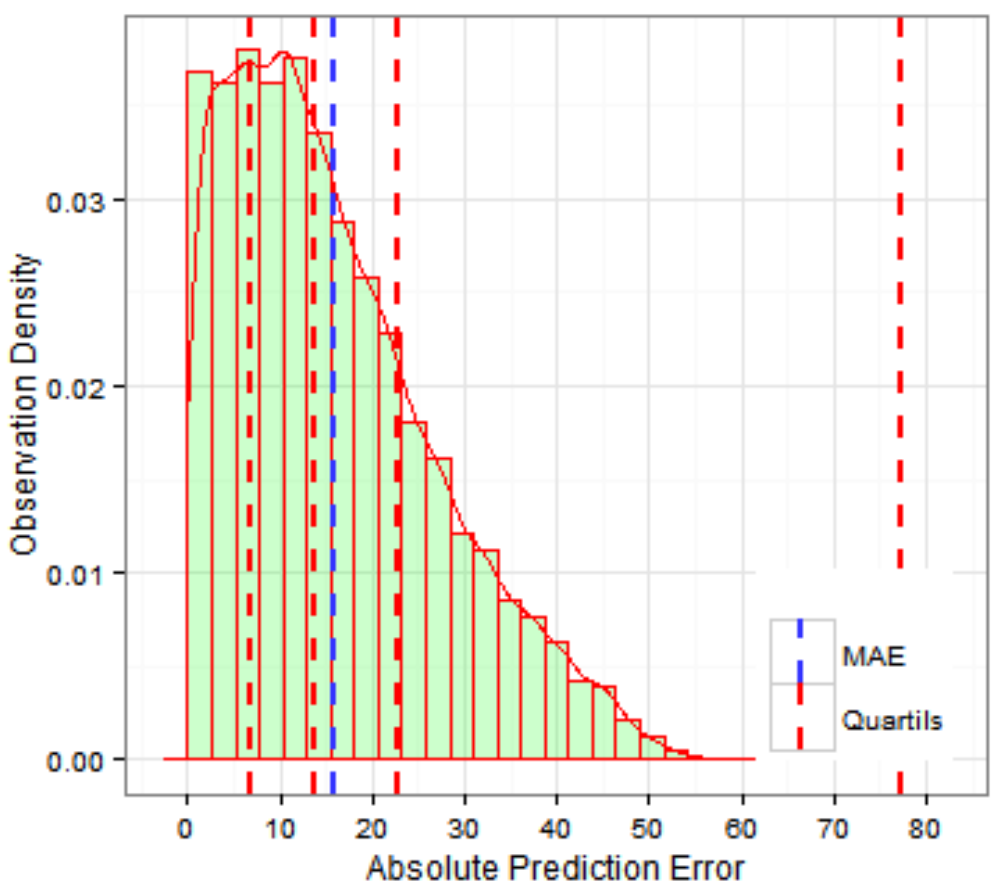

6.3(h): Method 5 on Rod. Fernão Dias, directed to Betim

Figure 6.3: Method 5 prediction error distribution analysis on direction 1 


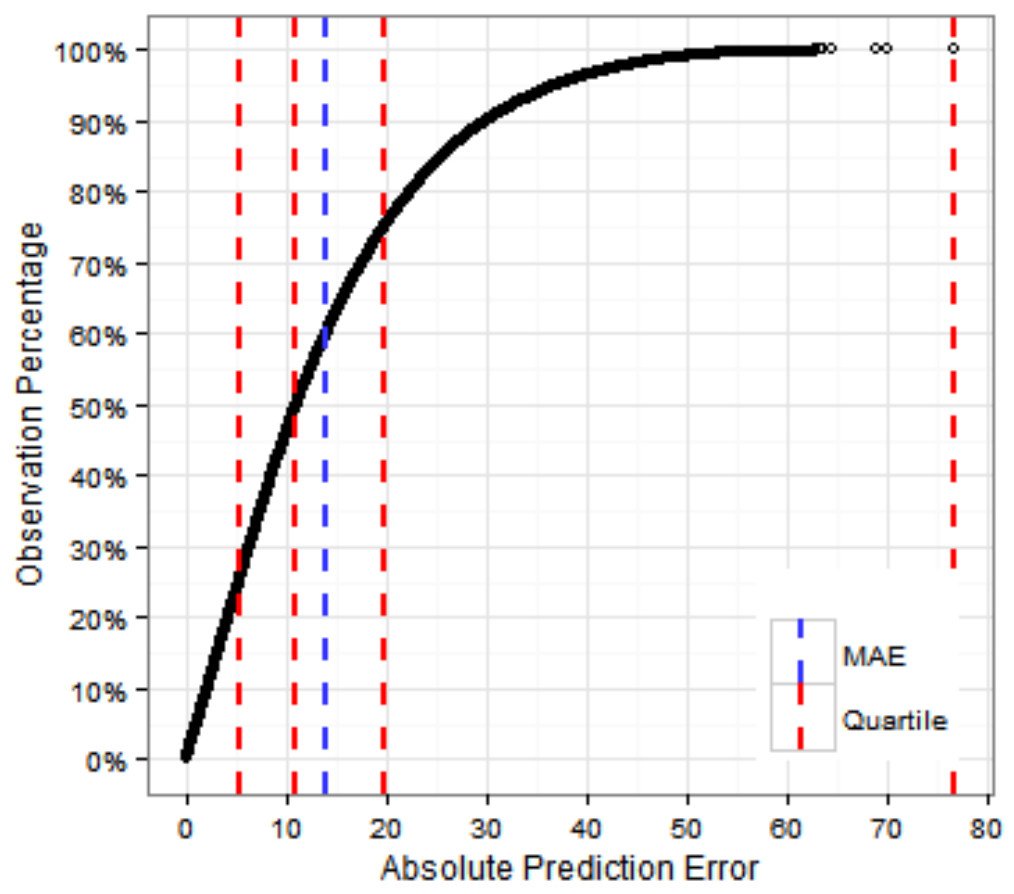

6.4(a): Method 4 on Av. Brasil, directed to Centro

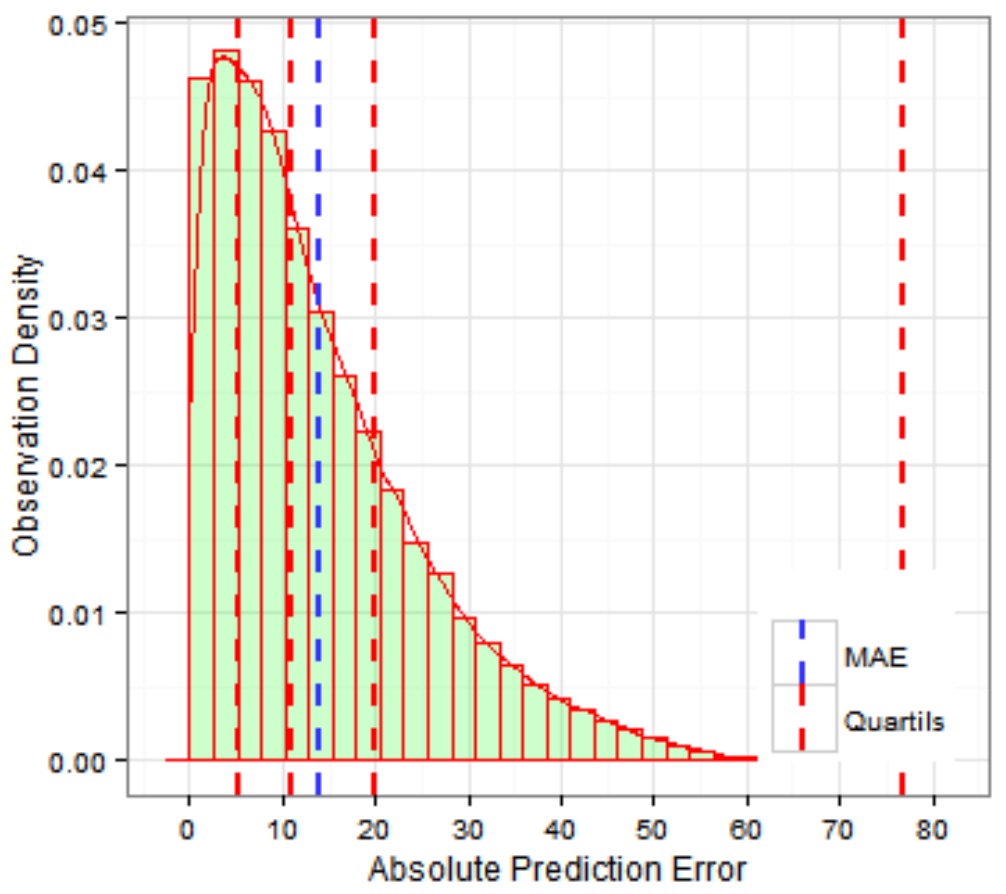

6.4(b): Method 5 on Av. Brasil, directed to Centro 


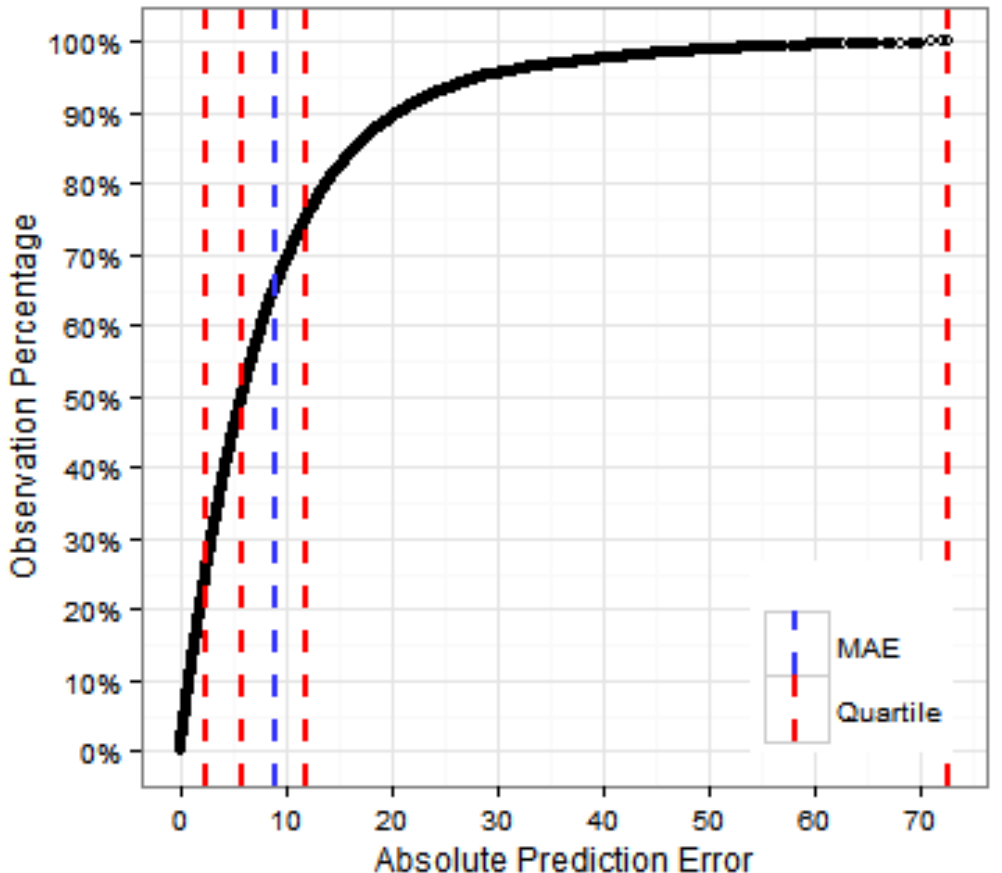

6.4(c): Method 4 on Rod. Rio Teresópolis, directed to Teresópolis

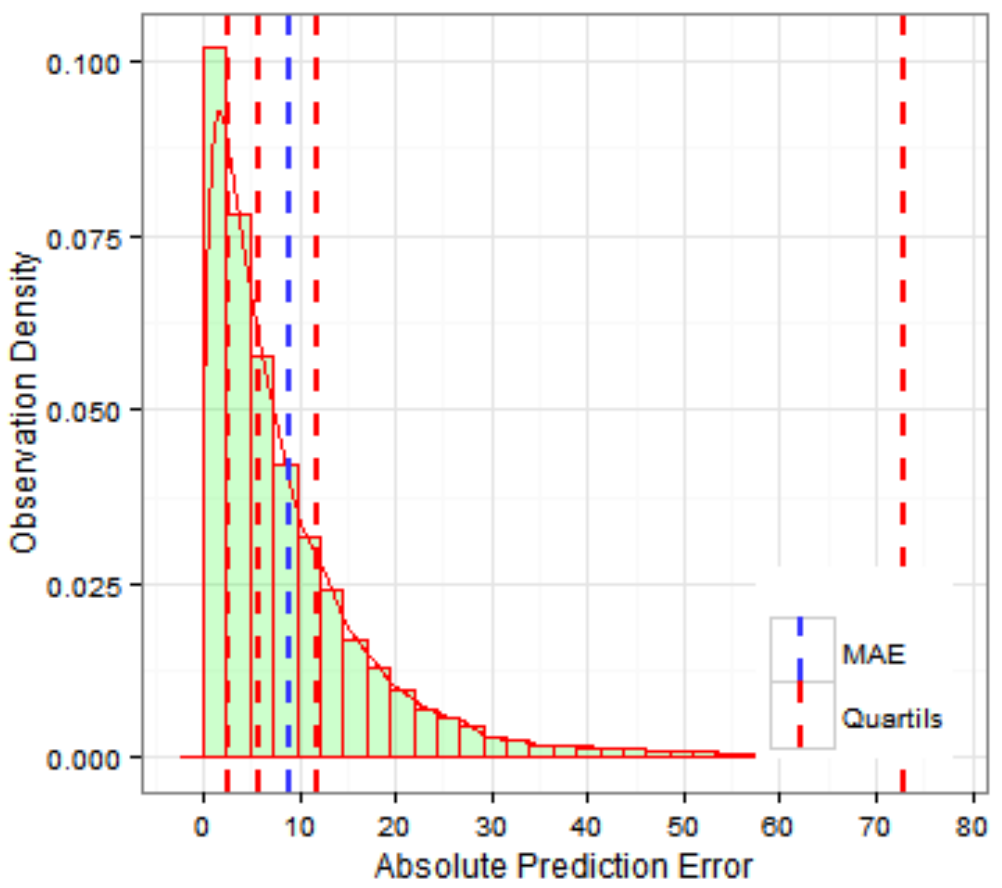

6.4(d): Method 5 on Rod. Rio Teresópolis, directed to Teresópolis 


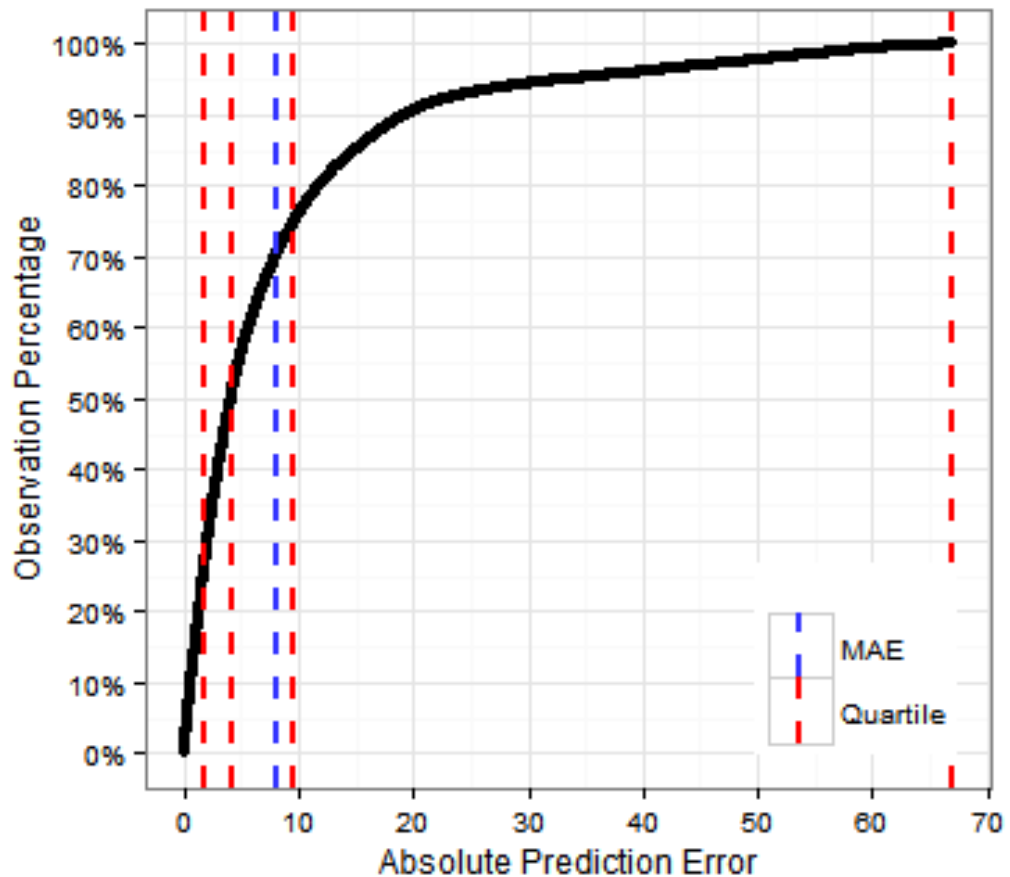

6.4(e): Method 4 on Rod. Anhanguera, directed to Americana

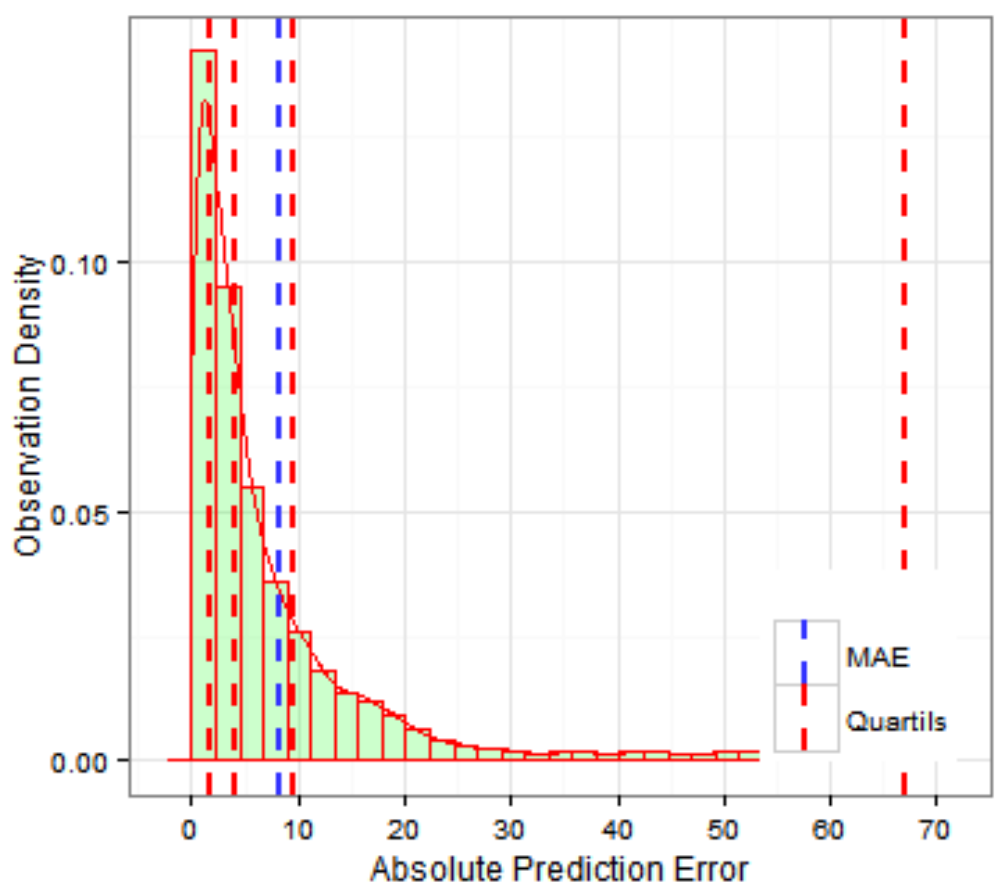

6.4(f): Method 5 on Rod. Anhanguera, directed to Americana 


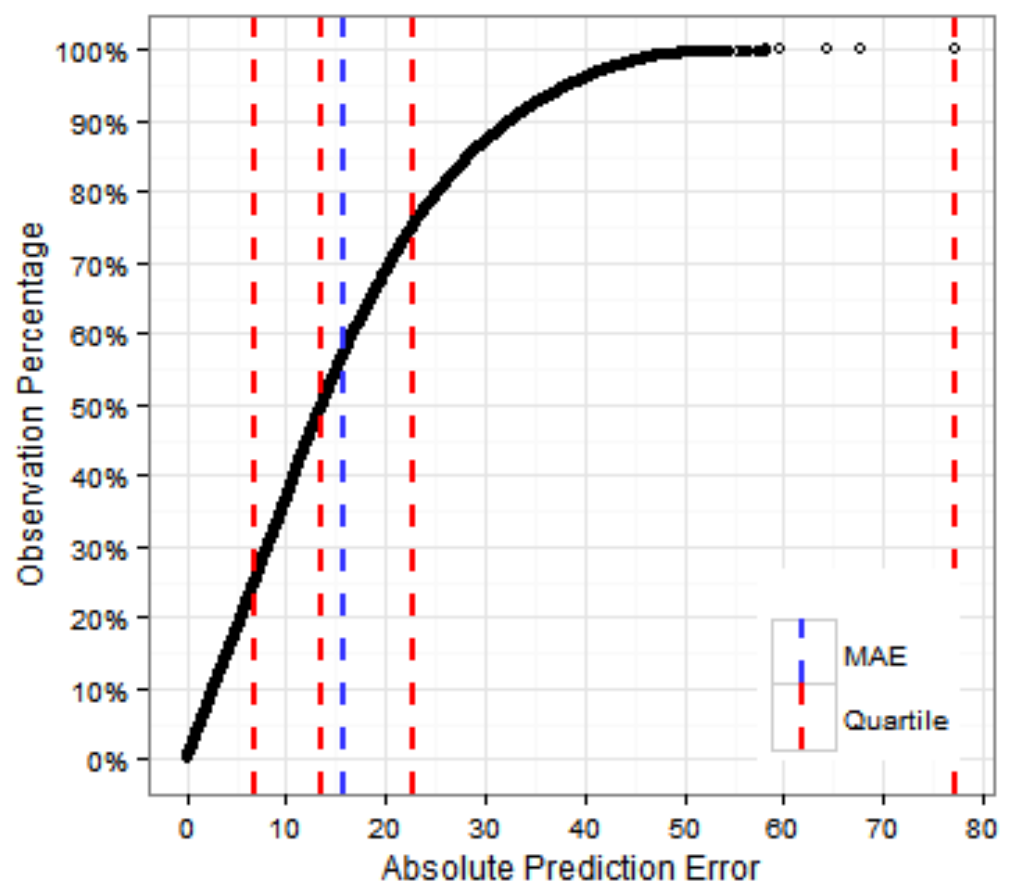

6.4(g): Method 4 on Rod. Fernão Dias, directed to Belo Horizonte

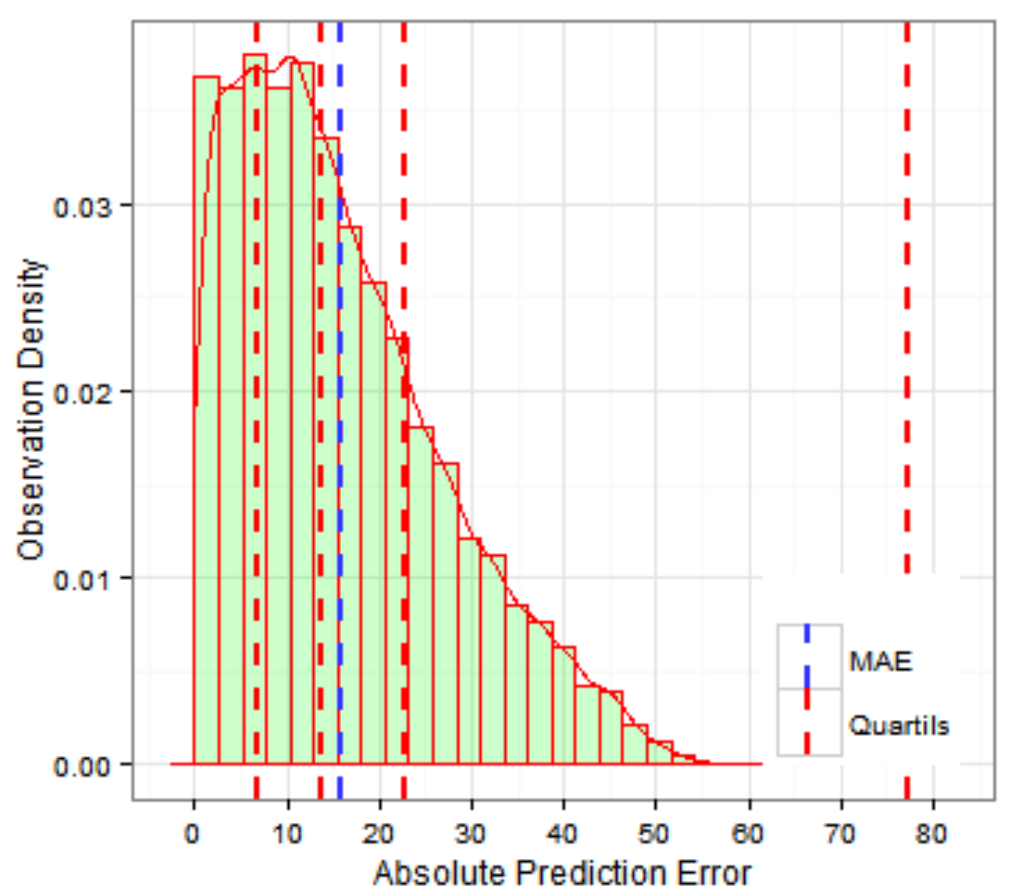

6.4(h): Method 5 on Rod. Fernão Dias, directed to Belo Horizonte

Figure 6.4: Method 5 prediction error distribution analysis on direction 2 


\section{7}

\section{Conclusions and Future Works}

In this study, the use of historic GPS data from fuel delivery trucks was analyzed in respect to time and space to create a mean speed predictor. Both temporal and spatial dimension influences were analyzed, and dimensional partitions were proposed to address their impact on the highway/speedway speed. The best partition strategy for the spatial dimension was below the second paired signal distance quartile, and hourly partitions for the temporal dimension were proposed based on the available samples. Having identified each partition, the STM model was created using the mean speed of each pair of consecutive GPS signals of the same device, along with the instantaneous speed provided within each GPS signal. To measure the STM performance, four other methods were implemented for comparison, in which the method based on Support Vector Regression was selected as baseline. Results indicated that STM was superior, rather than using each dimension individually, exceeding even the baseline and proving that the union of the two dimensions improves prediction, as expected. While other models are limited to real data or short-term predictions, it stands as a fast and simple solution that can be further evolved incorporating real time data and other road speed related factors.

As future work, the first natural evolution of STM is to investigate other factors such as months, weekdays, school breaks, rain, road visibility, and others. Besides investigating new factors, many modifications can be applied based on the final application. Another natural step is to incorporate real time data. ETA prediction, for instance, could benefit from real time observations by adjusting the current segment mean speed based on real time observations of it, or adjust it based on observations of previous segments 
as the travel occurs. Another possible improvement could be to adapt STM as an analogue model for SVR and ANN. Second-order Route Optimizations can be another direction of study, using STM to optimize routes based on predictions, instead of current observed data. Also, an accident detection framework can be implemented comparing the predicted mean speed to current mean speeds, if large deviations are identified they may implicate on a car crash or other random events.

There is a vast range of possible applications and evolutions for STM since, in general, STM can be used as a base model to be evolved accordingly, or as a final model to be queried by any highway or speedway traffic related application. Although room for improvement is always present, STM offers a satisfactory quality over speed factor. 
8

\section{Bibliography}

AMARAL, B. G. do. A visual analysis of bus GPS data in Rio. Dissertação (Mestrado) - PUC-Rio, June 2015.

BAJWA, S.; CHUNG, E.; KUWAHARA, M. An adaptive travel time prediction model based on pattern matching. In: Proc. of 11th Intelligent Transport Systems World Congress. [S.I.: s.n.], 2004.

BIN, Y.; ZHONGZHEN, Y.; BAOZHEN, Y. Bus arrival time prediction using support vector machines. Journal of Intelligent Transportation Systems, Taylor \& Francis, v. 10, n. 4, p. 151-158, 2006.

BRAKATSOULAS, S. et al. On map-matching vehicle tracking data. In: VLDB ENDOWMENT. Proceedings of the 31st international conference on Very large data bases. [S.I.], 2005. p. 853-864.

CHAKROBORTY, P.; KIKUCHI, S. Using bus travel time data to estimate travel times on urban corridors. Transportation Research Record: Journal of the Transportation Research Board, Transportation Research Board of the National Academies, n. 1870, p. 18-25, 2004.

CHIEN, S. I.-J.; DING, Y.; WEI, C. Dynamic bus arrival time prediction with artificial neural networks. Journal of Transportation Engineering, American Society of Civil Engineers, v. 128, n. 5, p. 429-438, 2002.

CHROBOK, R. et al. Different methods of traffic forecast based on real data. European Journal of Operational Research, Elsevier, v. 155, n. 3, p. 558-568, 2004. 
DEREKENARIS, G. et al. Integrating gis, gps and gsm technologies for the effective management of ambulances. Computers, Environment and Urban Systems, Elsevier, v. 25, n. 3, p. 267-278, 2001.

FABRITIIS, C. D.; RAGONA, R.; VALENTI, G. Traffic estimation and prediction based on real time floating car data. In: IEEE. Intelligent Transportation Systems, 2008. ITSC 2008. 11th International IEEE Conference on. [S.I.], 2008. p. 197-203.

FAN, R.-E. et al. Liblinear: A library for large linear classification. The Journal of Machine Learning Research, JMLR. org, v. 9, p. 1871-1874, 2008.

GEORGESCU, L.; ZEITLER, D.; STANDRIDGE, C. R. Intelligent transportation system real time traffic speed prediction with minimal data. Journal of Industrial Engineering and Management, v. 5, n. 2, p. 431-441, 2012.

GOPI, G. et al. Bayesian support vector regression for traffic speed prediction with error bars. In: IEEE. Intelligent Transportation Systems-(ITSC), 2013 16th International IEEE Conference on. [S.I.], 2013. p. 136-141.

HOFMANN-WELLENHOF, B.; LICHTENEGGER, H.; COLLINS, J. Global positioning system: theory and practice. [S.I.]: Springer Science \& Business Media, 2013.

HOLLANDS, R. G. Will the real smart city please stand up? intelligent, progressive or entrepreneurial? City, Taylor \& Francis, v. 12, n. 3, p. 303-320, 2008.

KAMRAN, S.; HAAS, O. A multilevel traffic incidents detection approach: Identifying traffic patterns and vehicle behaviours using real-time gps data. In: IEEE. Intelligent Vehicles Symposium, 2007 IEEE. [S.I.], 2007. p. 912-917.

KIRBY, H. R.; WATSON, S. M.; DOUGHERTY, M. S. Should we use neural networks or statistical models for short-term motorway traffic forecasting? International Journal of Forecasting, Elsevier, v. 13, n. 1, p. 43-50, 1997. 
KORMAKSSON, M. et al. Bus travel time predictions using additive models. In: IEEE. Data Mining (ICDM), 2014 IEEE International Conference on. [S.I.], 2014. p. 875-880.

LEE, W.-H.; TSENG, S.-S.; TSAI, S.-H. A knowledge based real-time travel time prediction system for urban network. Expert Systems with Applications, Elsevier, v. 36, n. 3, p. 4239-4247, 2009.

MARK, C. D.; SADEK, A. W.; RIZZO, D. Predicting experienced travel time with neural networks: a paramics simulation study. In: IEEE. Intelligent Transportation Systems, 2004. Proceedings. The 7th International IEEE Conference on. [S.I.], 2004. p. 906-911.

NANTHAWICHIT, C.; NAKATSUJI, T.; SUZUKI, H. Application of probe-vehicle data for real-time traffic-state estimation and short-term travel-time prediction on a freeway. Transportation Research Record: Journal of the Transportation Research Board, Transportation Research Board of the National Academies, n. 1855, p. 49-59, 2003.

SHALABY, A.; FARHAN, A. Bus travel time prediction model for dynamic operations control and passenger information systems. Transportation Research Board, 2003.

STEVEN, I.; CHIEN, J.; KUCHIPUDI, C. M. Dynamic travel time prediction with real-time and historic data. Journal of transportation engineering, American Society of Civil Engineers, 2003.

THOMAS, T.; WEIJERMARS, W.; BERKUM, E. V. Predictions of urban volumes in single time series. Intelligent Transportation Systems, IEEE Transactions on, IEEE, v. 11, n. 1, p. 71-80, 2010.

TOWNSHEND, A. D.; WORRINGHAM, C. J.; STEWART, I. B. Assessment of speed and position during human locomotion using nondifferential gps. Medicine and science in sports and exercise, Citeseer, v. 40, n. 1, p. 124, 2008.

VANAJAKSHI, L.; SUBRAMANIAN, S. C.; SIVANANDAN, R. Travel time prediction under heterogeneous traffic conditions using global positioning system 
data from buses. IET intelligent transport systems, IET, v. 3, n. 1, p. 1-9, 2009.

WU, C.-H.; HO, J.-M.; LEE, D.-T. Travel-time prediction with support vector regression. Intelligent Transportation Systems, IEEE Transactions on, IEEE, v. 5, n. 4, p. 276-281, 2004.

YANG, J.-S. Travel time prediction using the gps test vehicle and kalman filtering techniques. In: IEEE. American Control Conference, 2005. Proceedings of the 2005. [S.I.], 2005. p. 2128-2133.

YASDI, R. Prediction of road traffic using a neural network approach. Neural computing \& applications, Springer, v. 8, n. 2, p. 135-142, 1999.

YUSUF, A. Advanced machine learning models for online travel-time prediction on freeways. Georgia Institute of Technology, 2013.

ZHANG, G.; PATUWO, B. E.; HU, M. Y. Forecasting with artificial neural networks:: The state of the art. International journal of forecasting, Elsevier, v. 14, n. 1, p. $35-62,1998$.

ZHENG, Y. Trajectory data mining: an overview. ACM Transactions on Intelligent Systems and Technology (TIST), ACM, v. 6, n. 3, p. 29, 2015. 